\title{
Synthesis of Medium-Sized Carbocycles by Gallium-Catalyzed Tandem Carbonyl-Olefin Metathesis/Transfer Hydrogenation.
}

\author{
Supporting Information
}

Alexandre Djurovic, ${ }^{[a]}$ Marie Vayer, ${ }^{[a]}$ Zhilong Li, ${ }^{[a]}$ Régis Guillot,,${ }^{[a]}$ Jean-Pierre Baltaze, Vincent Gandon*[a,b] and Christophe Bour*[a]

${ }^{[a]}$ Institut de Chimie Moléculaire et des Matériaux d'Orsay, CNRS UMR 8182, Université Paris-Sud, Université Paris-Saclay, Bâtiment 420, 91405 Orsay cedex, France.

${ }^{[b]}$ Laboratoire de Chimie Moléculaire, CNRS UMR 9168, Ecole Polytechnique, Institut Polytechnique de Paris, route de Saclay, 91128 Palaiseau cedex, France. 
NMR Spectra

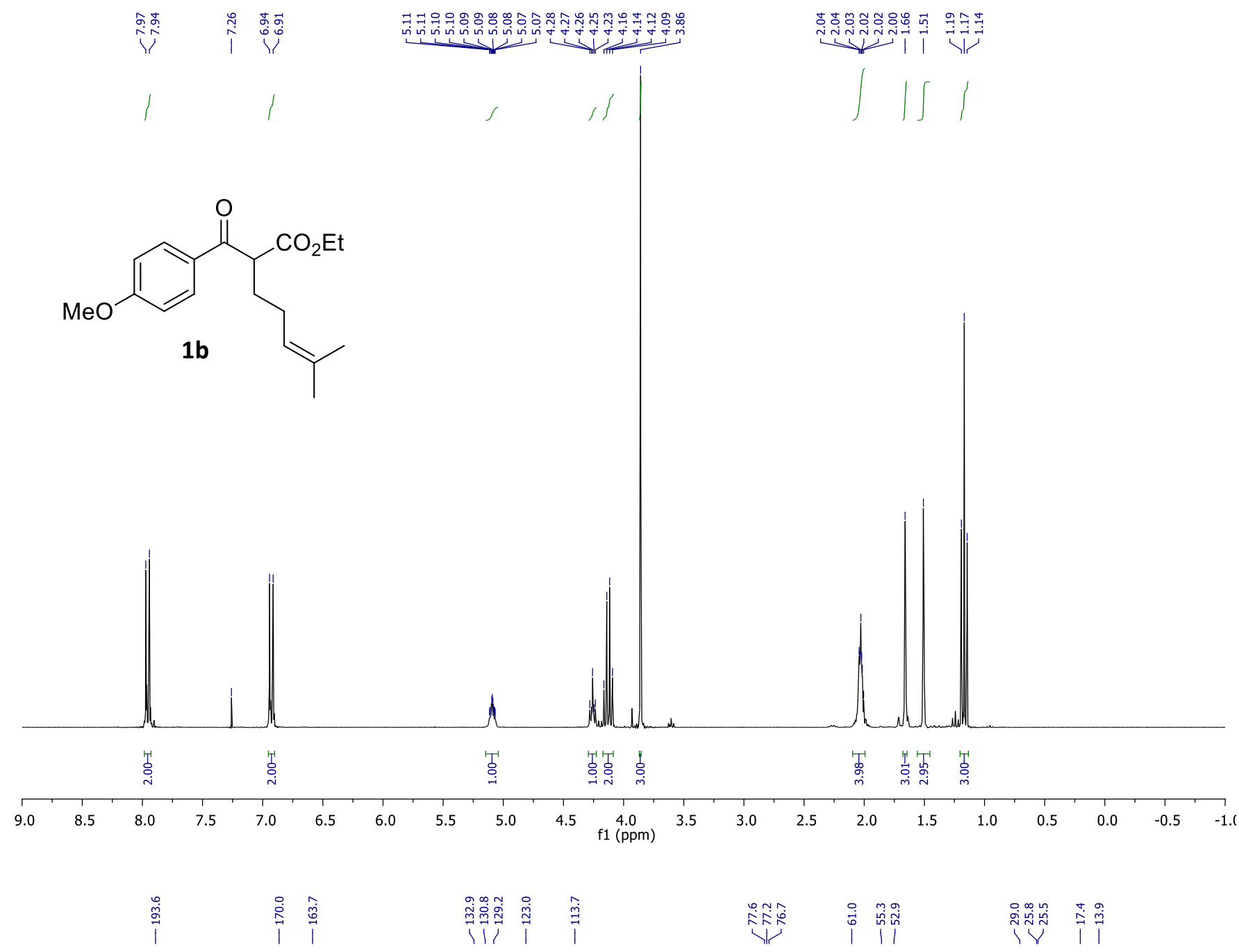<smiles>CCOC(=O)C(CCC=C(C)C)C(=O)c1ccc(OC)cc1</smiles>

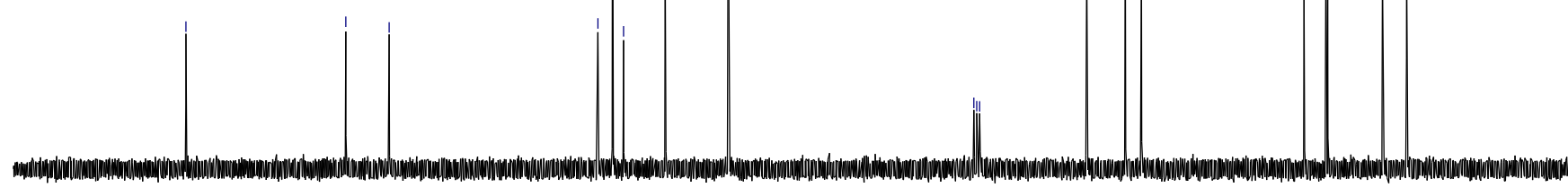

$\begin{array}{lllllllllllllllllllllll}210 & 200 & 190 & 180 & 170 & 160 & 150 & 140 & 130 & 120 & 110 & 100 & 90 & 80 & 70 & 60 & 50 & 40 & 30 & 20 & 10 & 0 & -10\end{array}$ 


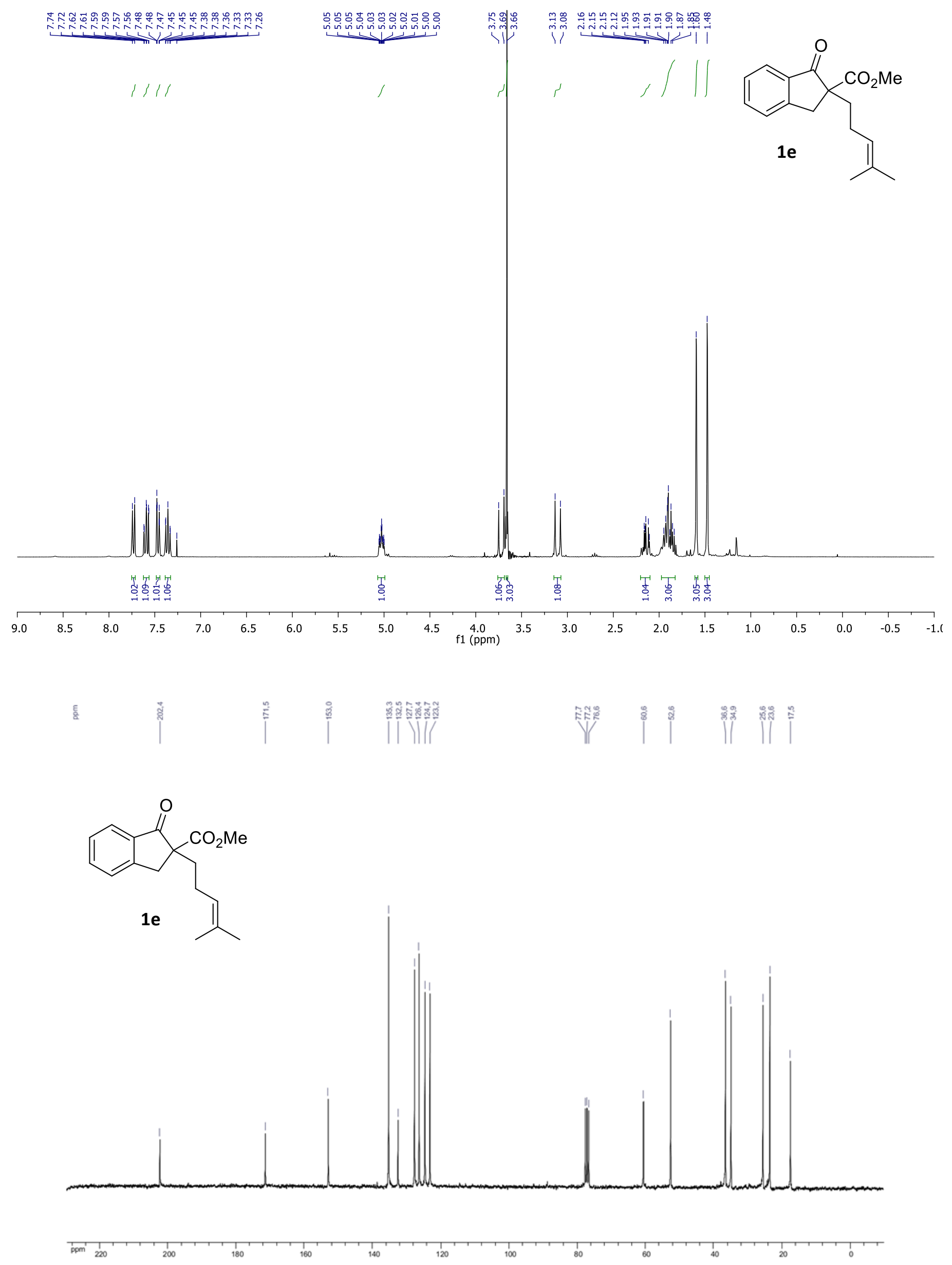



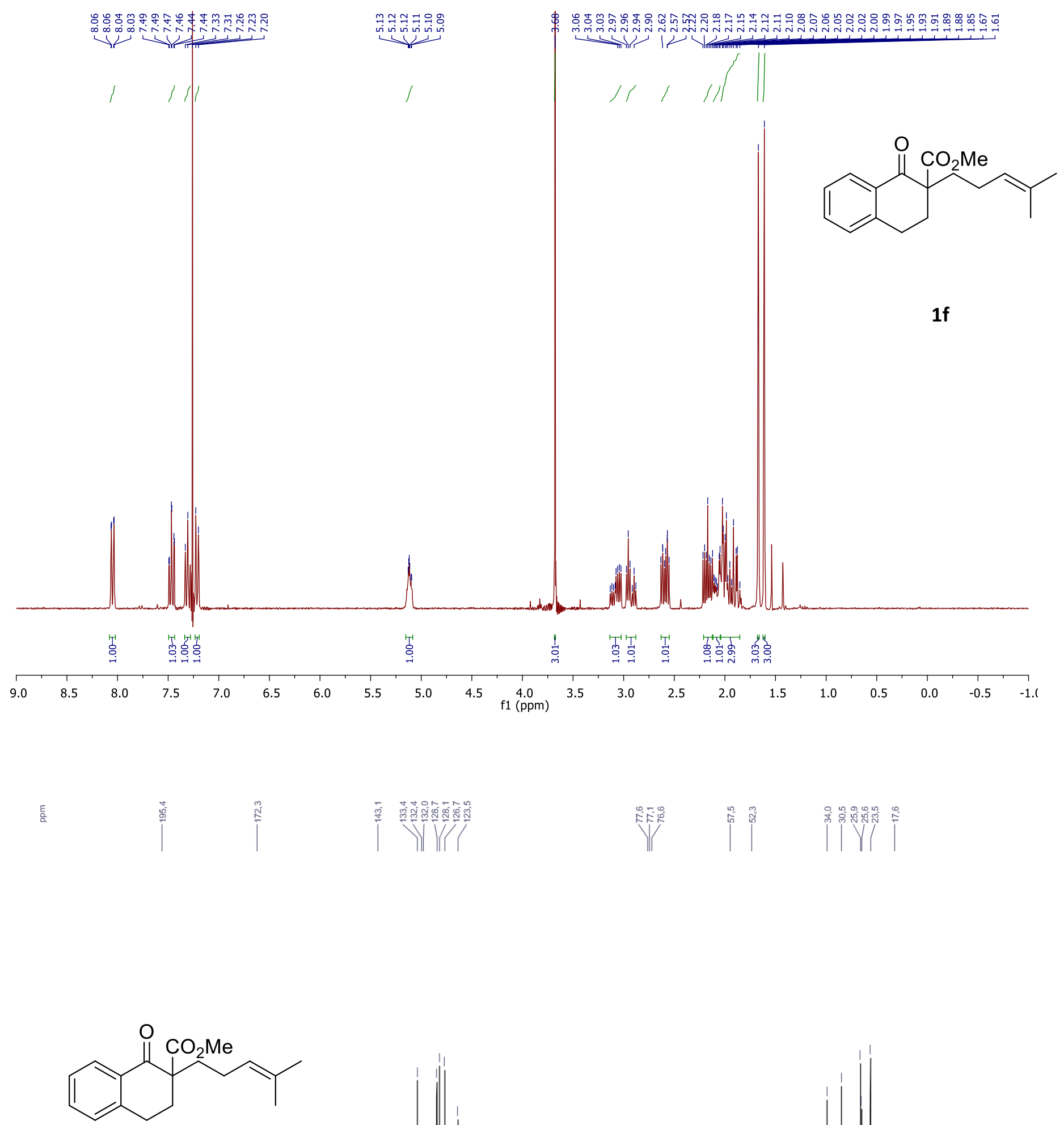

If
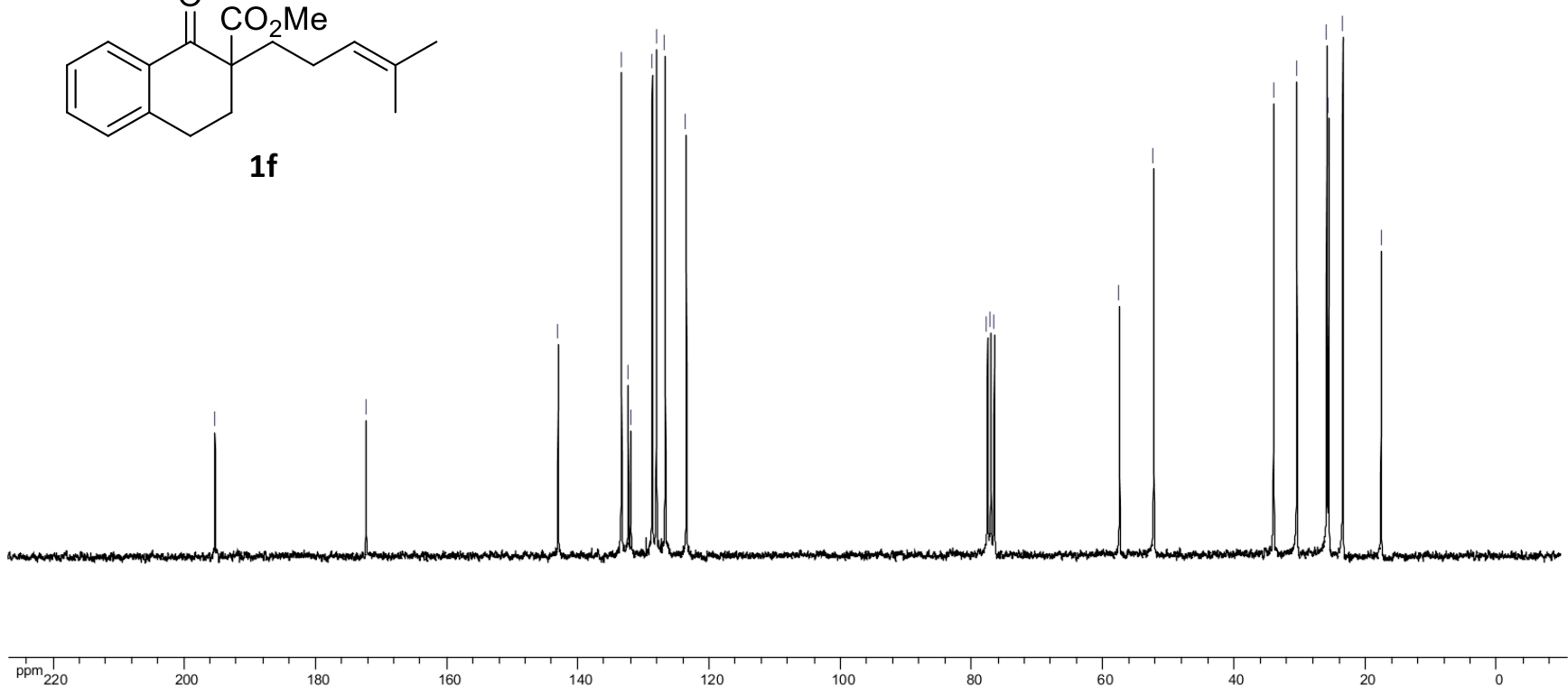


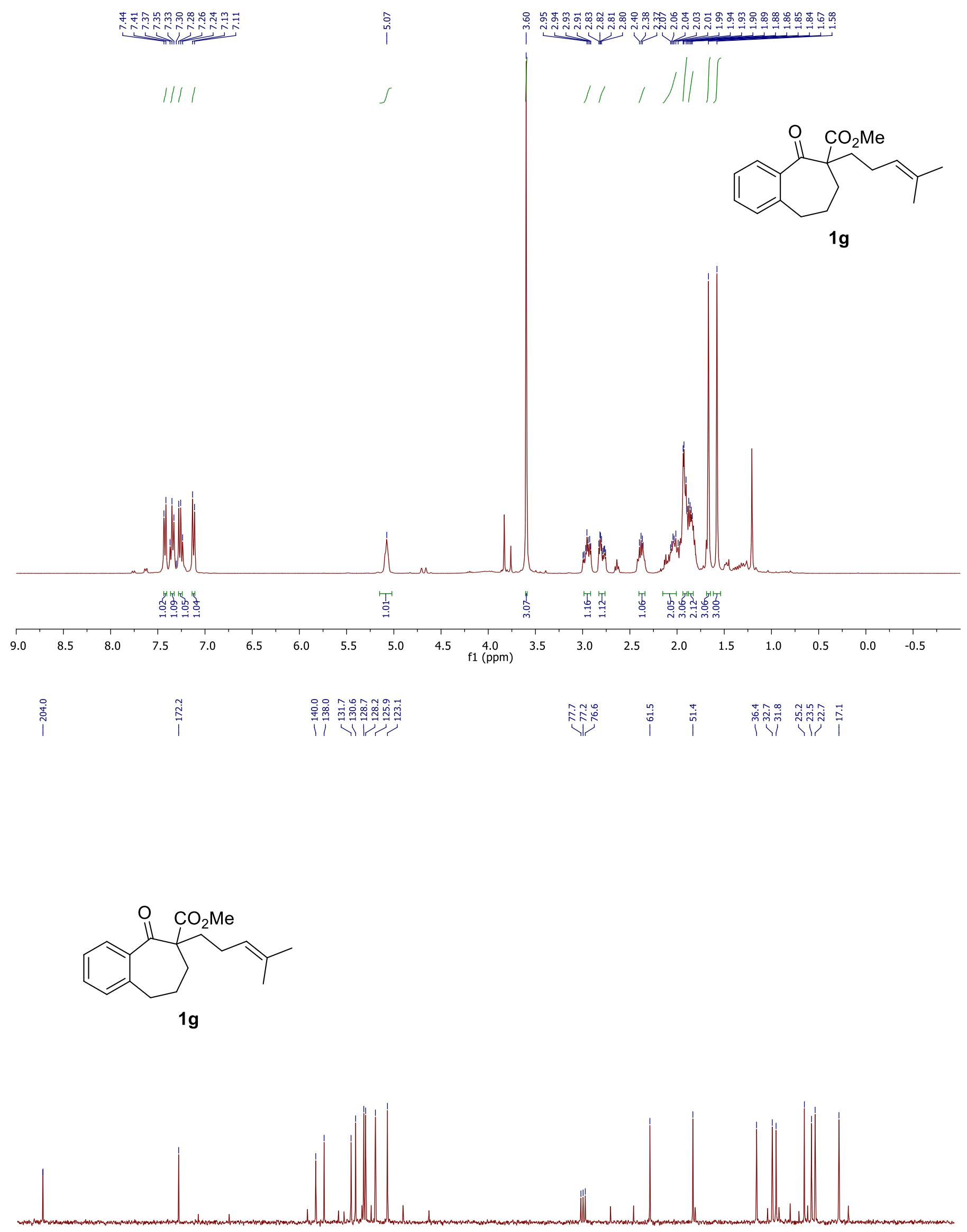

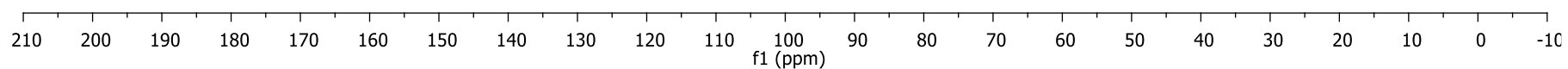




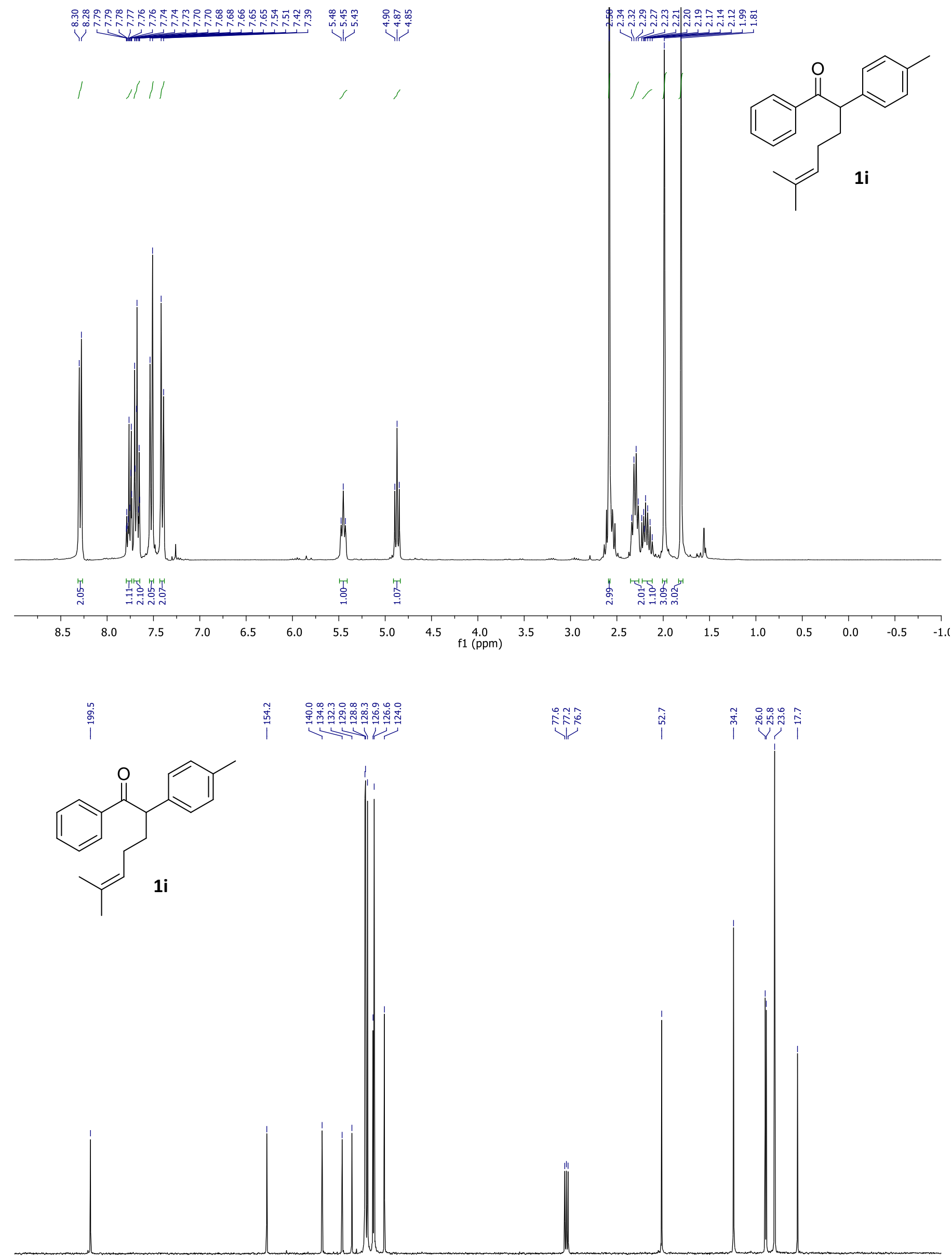

$\begin{array}{llllllllllllllllllllllllll}210 & 200 & 190 & 180 & 170 & 160 & 150 & 140 & 130 & 120 & 110 & \begin{array}{l}100 \\ \mathrm{f} 1(\mathrm{ppm})\end{array} & 80 & 70 & 60 & 50 & 40 & 30 & 20 & 10 & 0 & -10 & \end{array}$ 


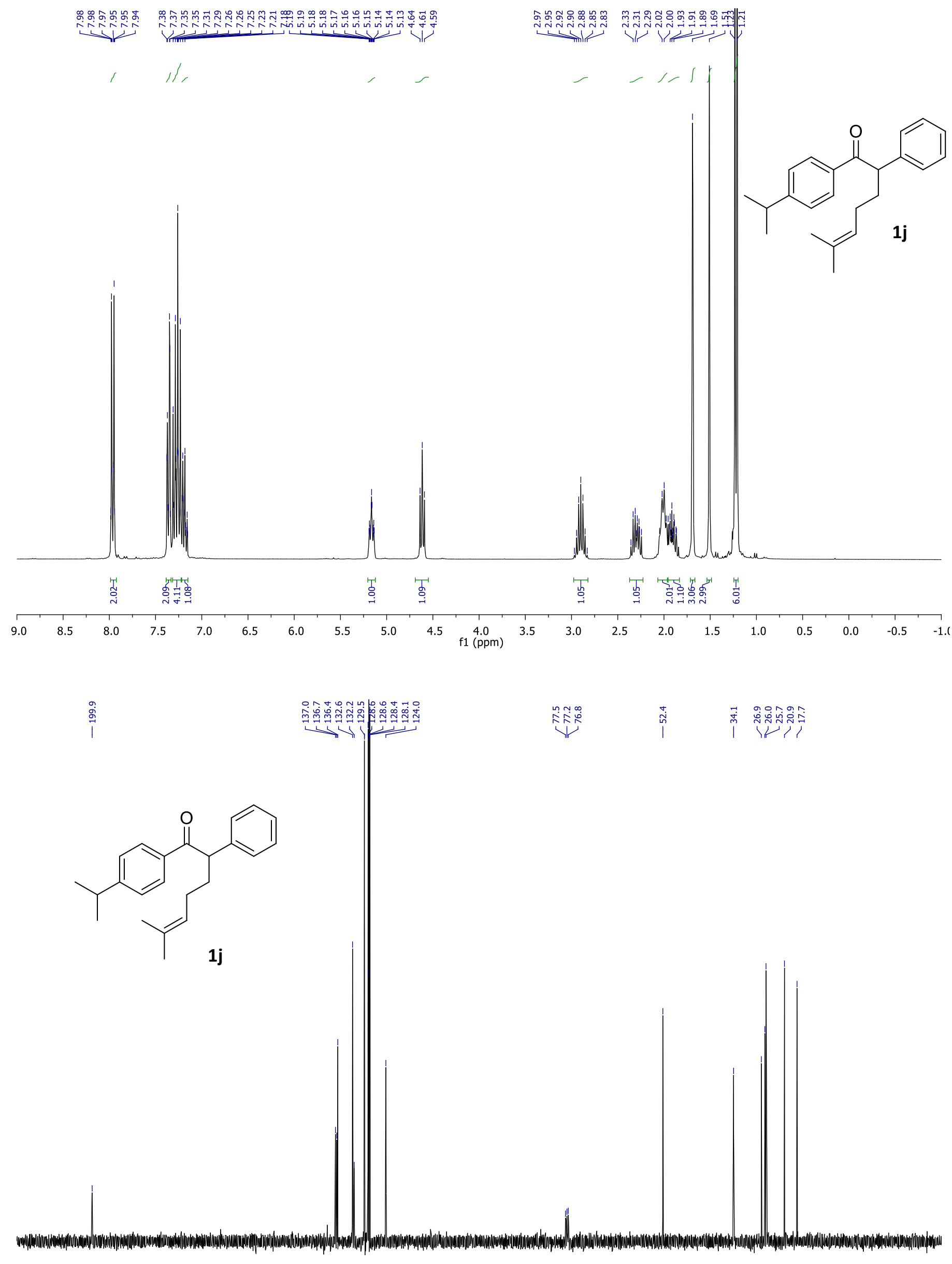

$\begin{array}{llllllllllllllllllllllllllll}210 & 200 & 190 & 180 & 170 & 160 & 150 & 140 & 130 & 120 & 110 & 100 & 90 & 80 & 70 & 60 & 50 & 40 & 30 & 20 & 10 & 0 & -10 & \end{array}$ 

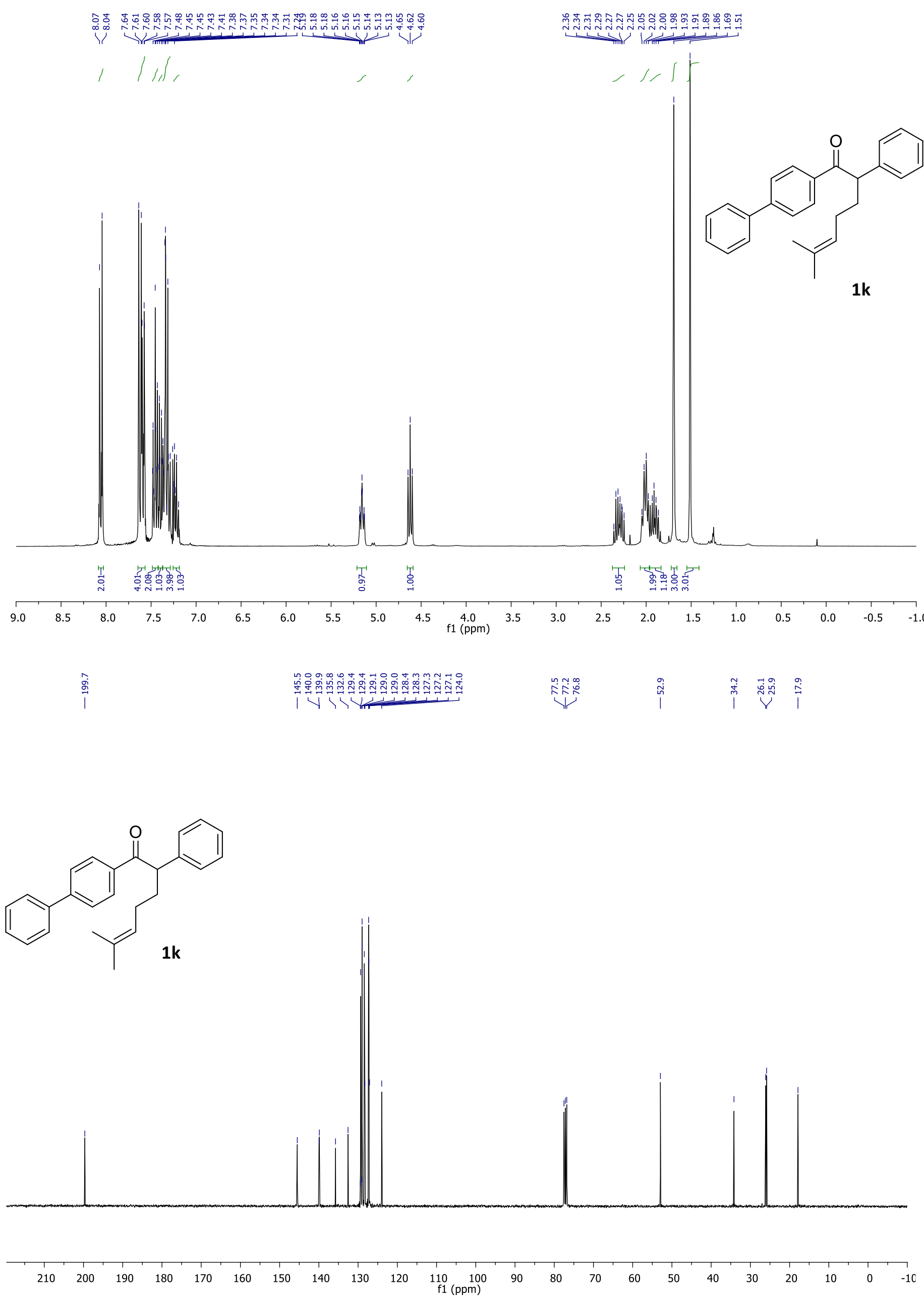


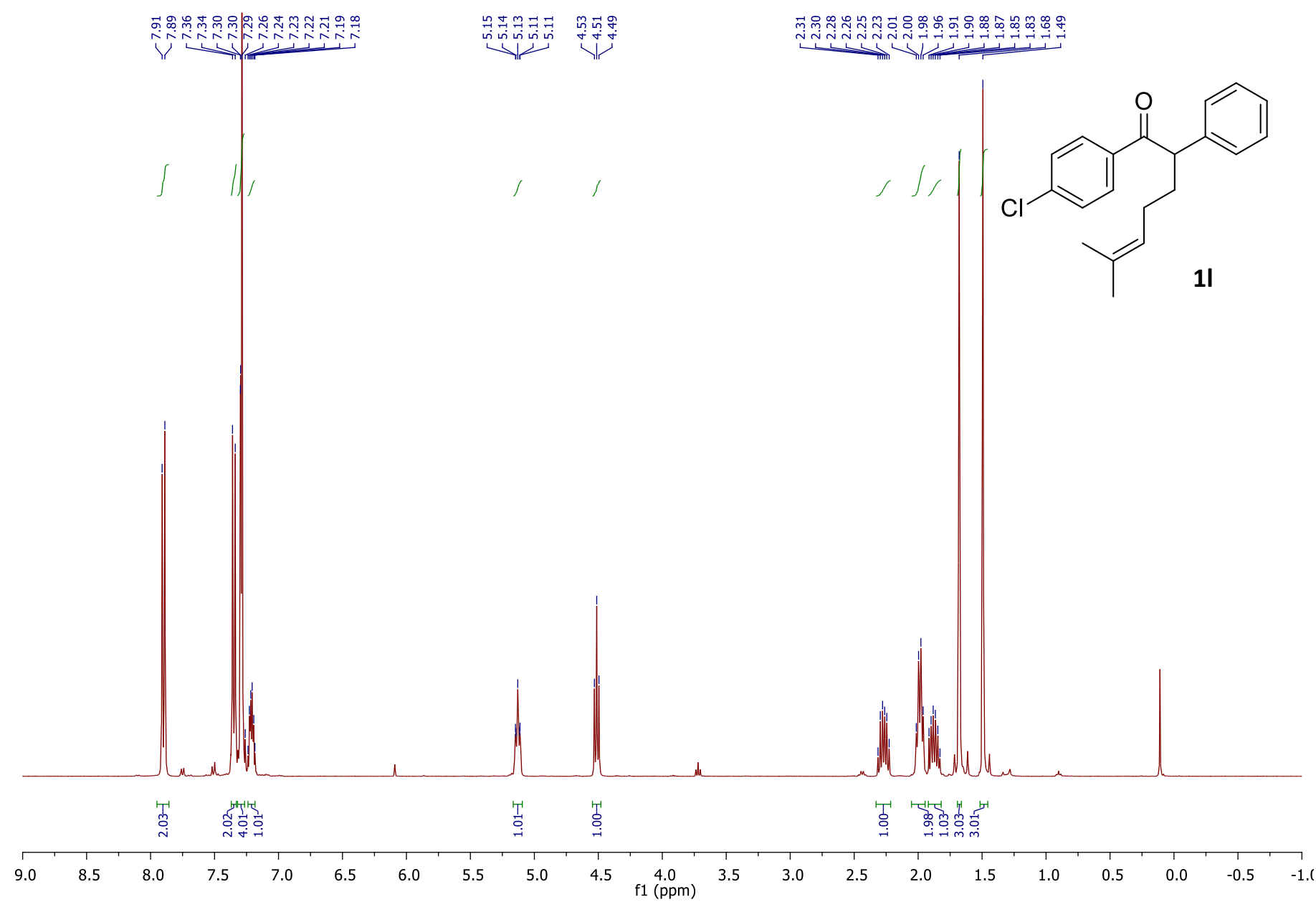

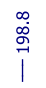

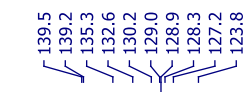

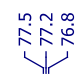

în<smiles>CC(C)=CCCC(C(=O)c1ccc(Cl)cc1)c1ccccc1</smiles>

11

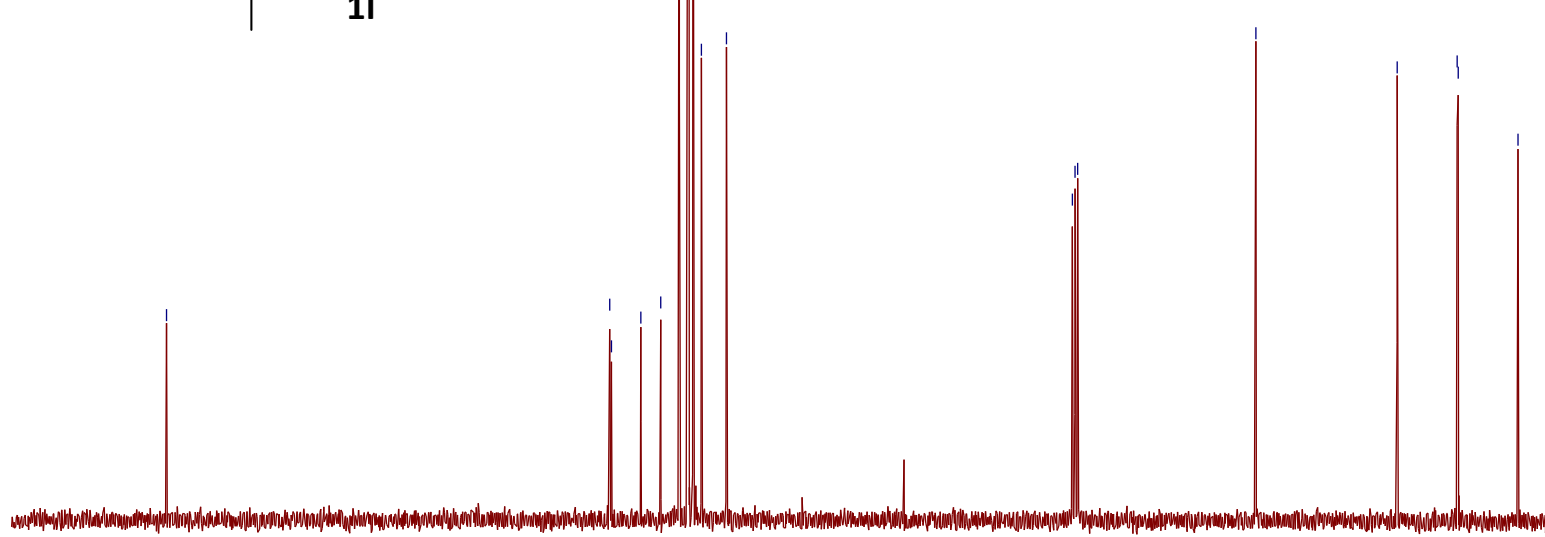



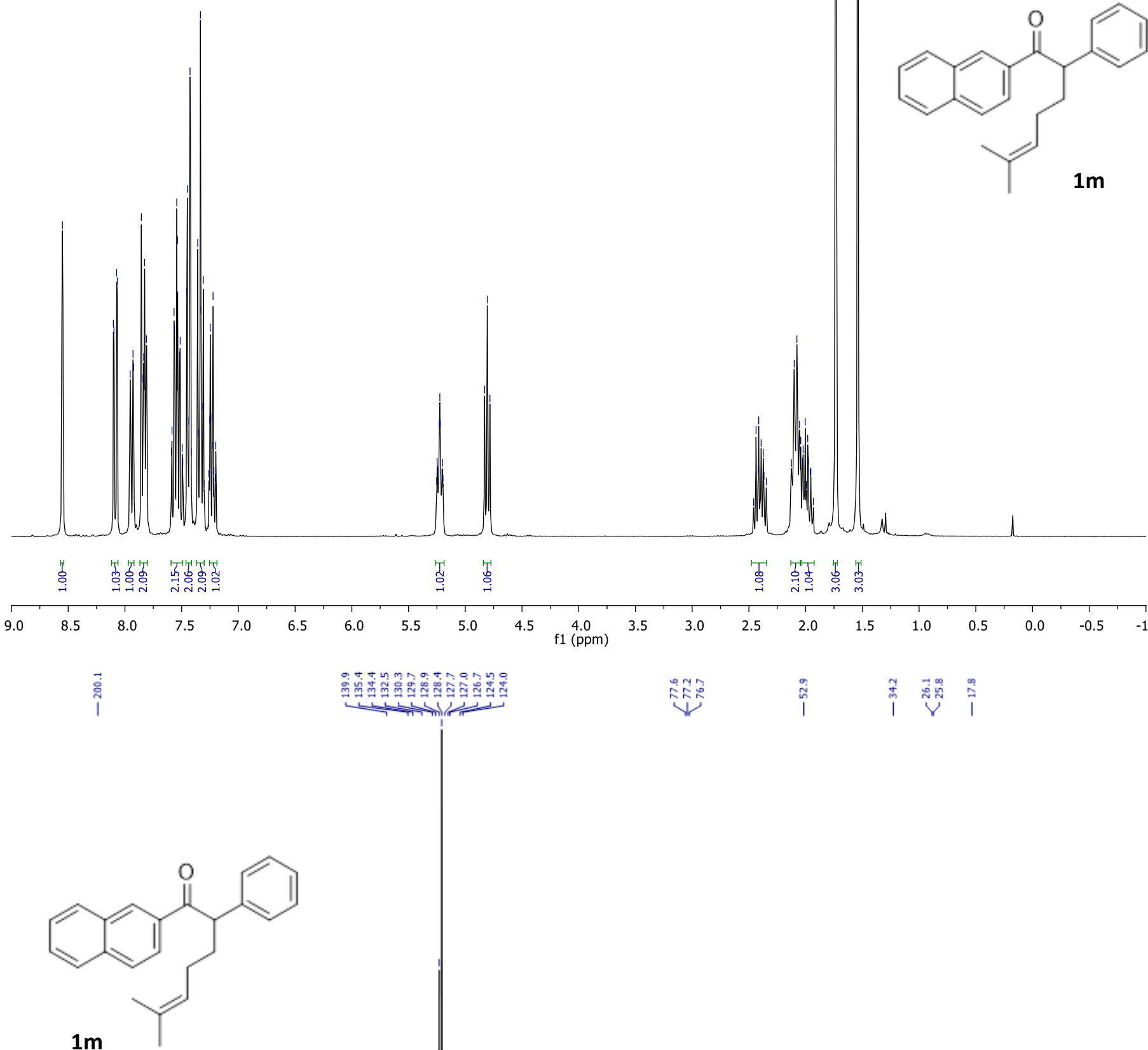

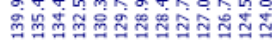

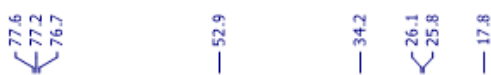

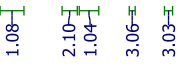

(ppm)
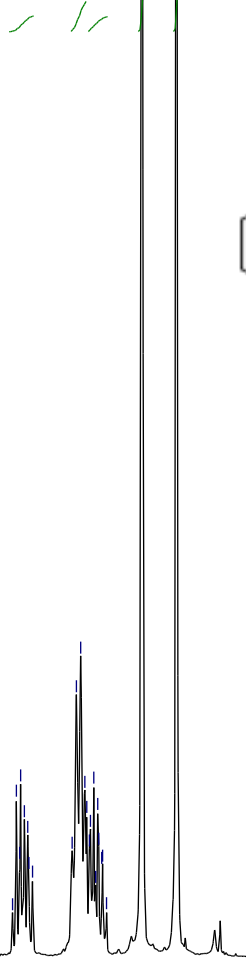

\section{1} +
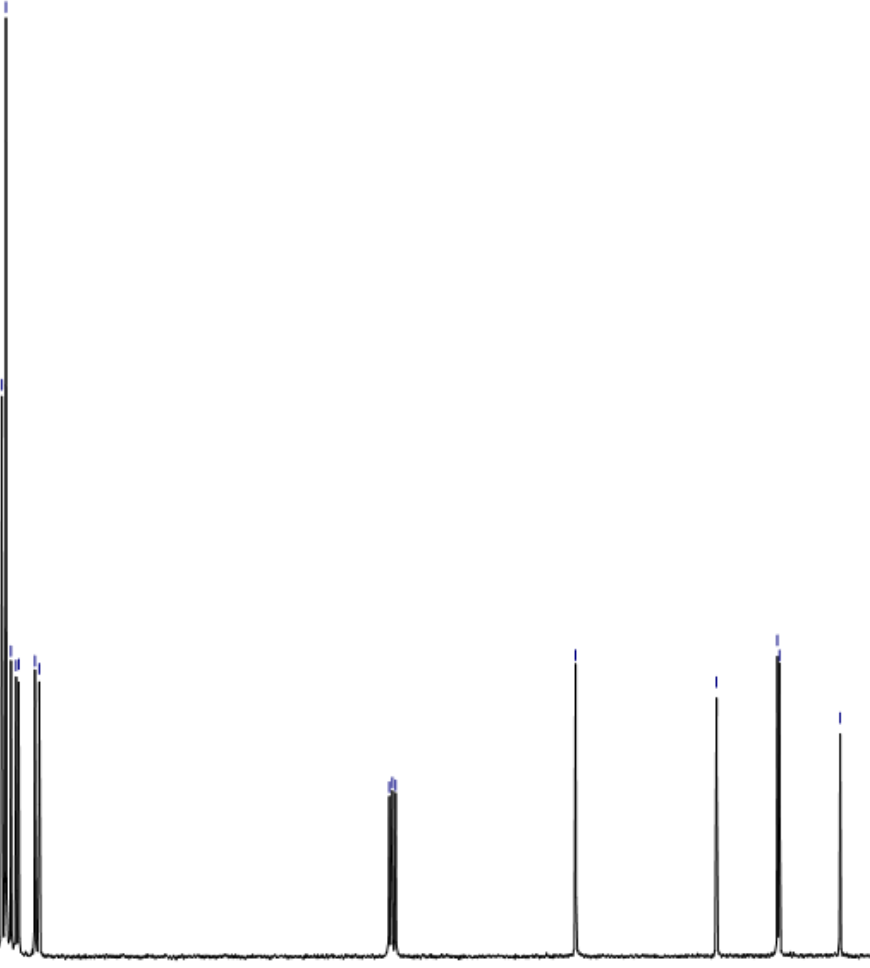

$\begin{array}{lllllllllll}210 & 200 & 190 & 180 & 170 & 160 & 150 & 140 & 130 & 120 & 110 \\ \mathrm{f} 1(\mathrm{ppm}) & 100\end{array}$ 
<smiles>CCOC(=O)C(CCCC(C)C)C(=O)c1ccccc1</smiles>
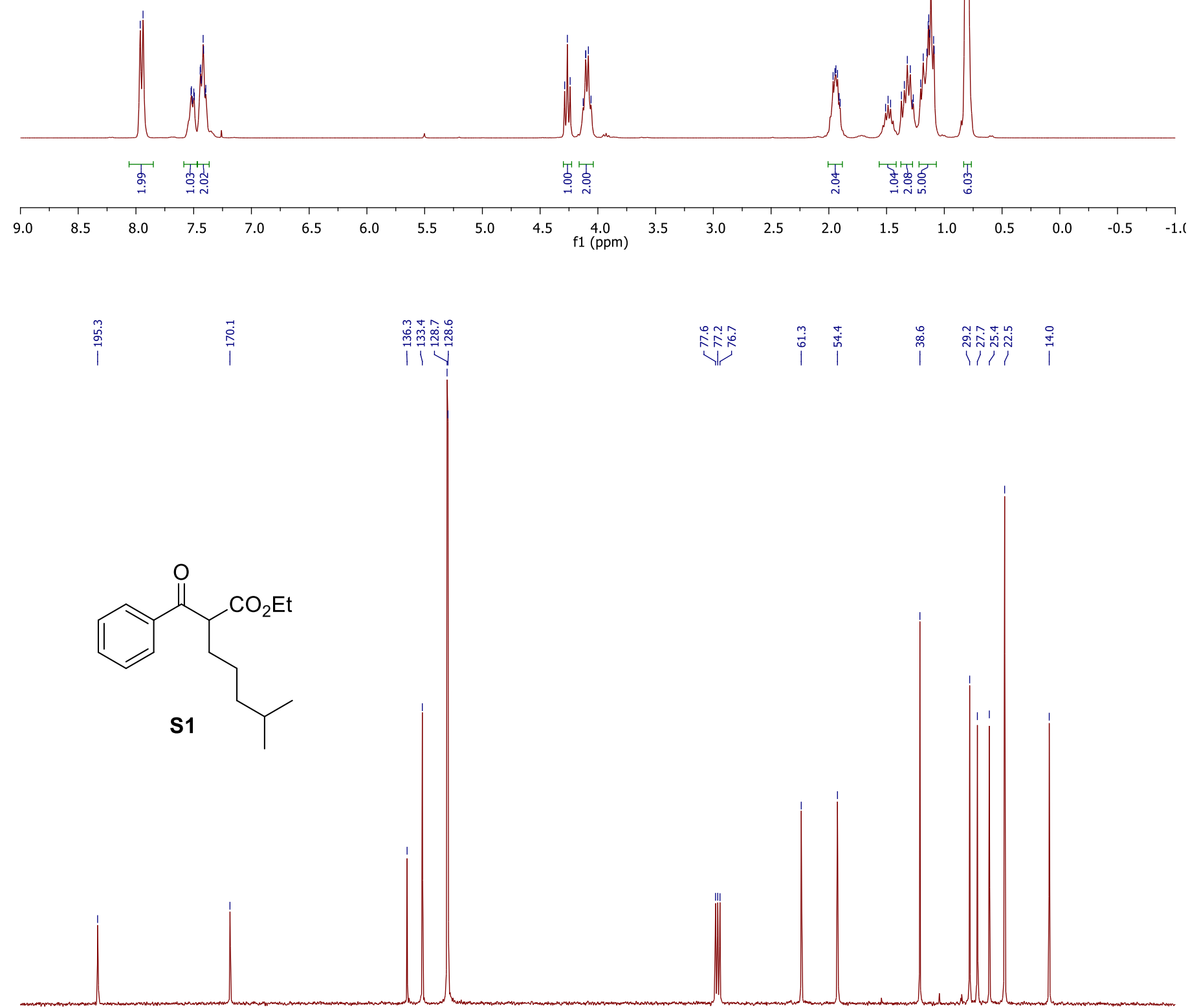

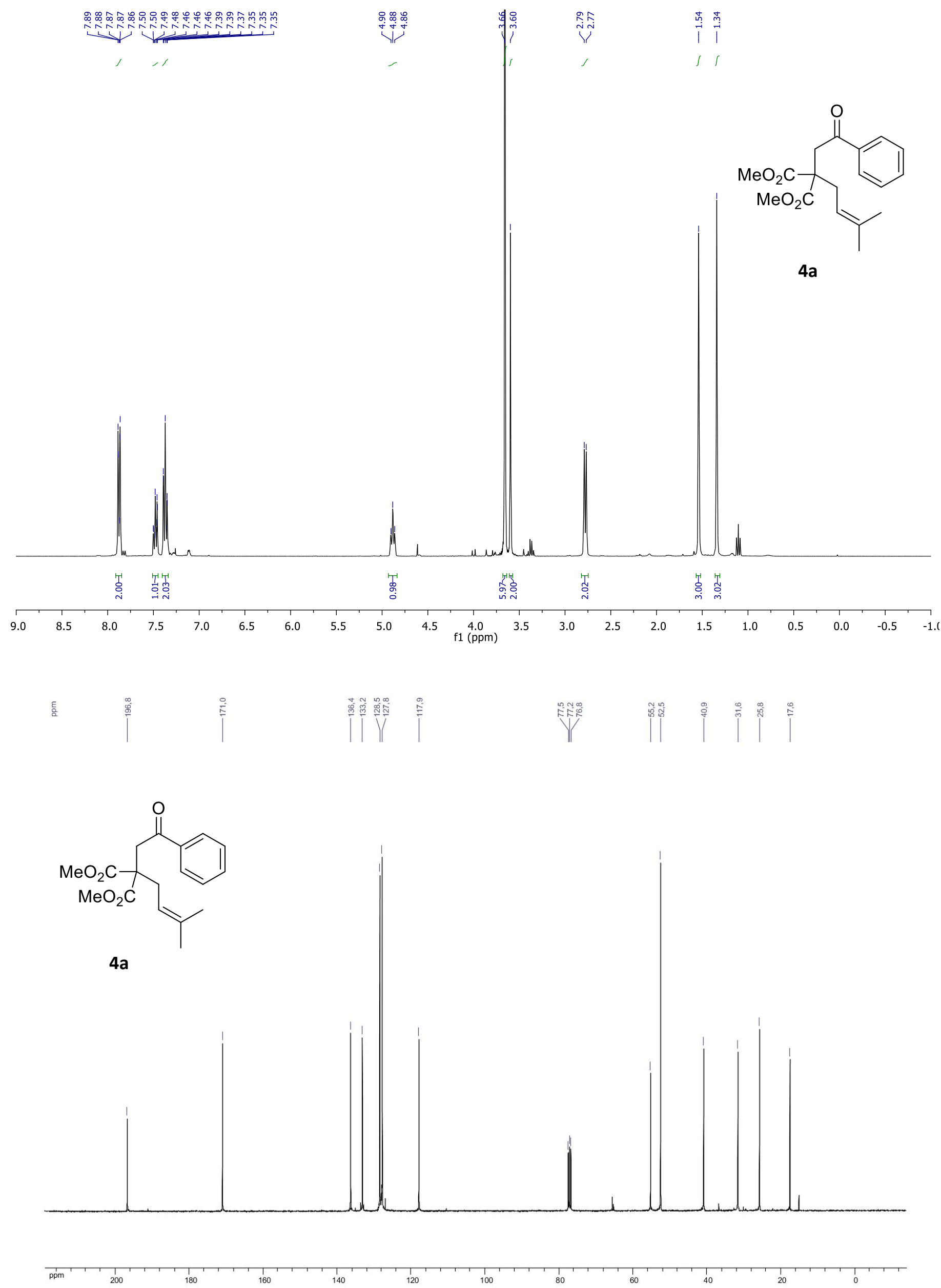

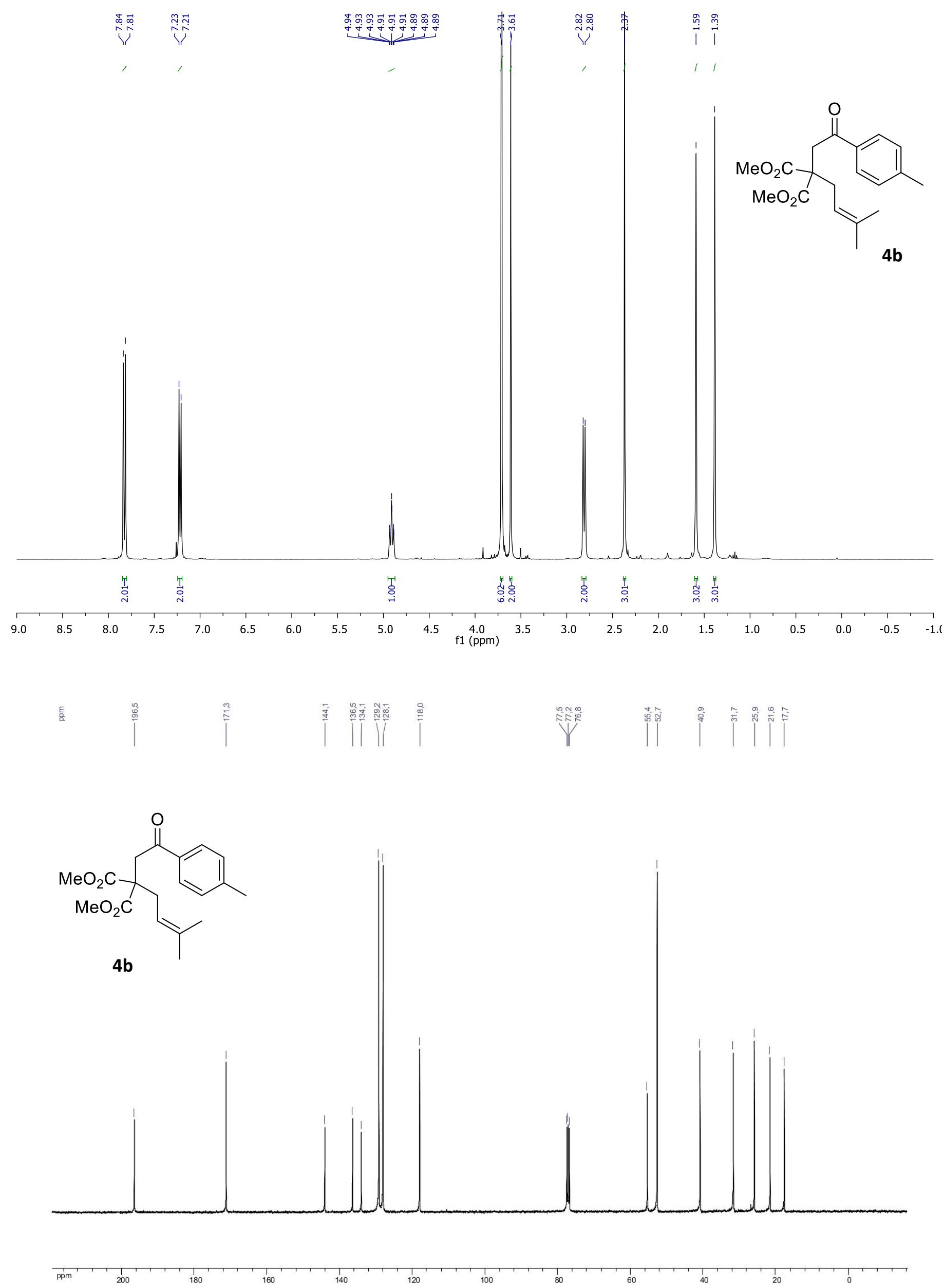
ํㅗㅇ

ֻู

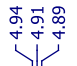

$\stackrel{\sim}{\sim}$

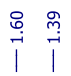

s
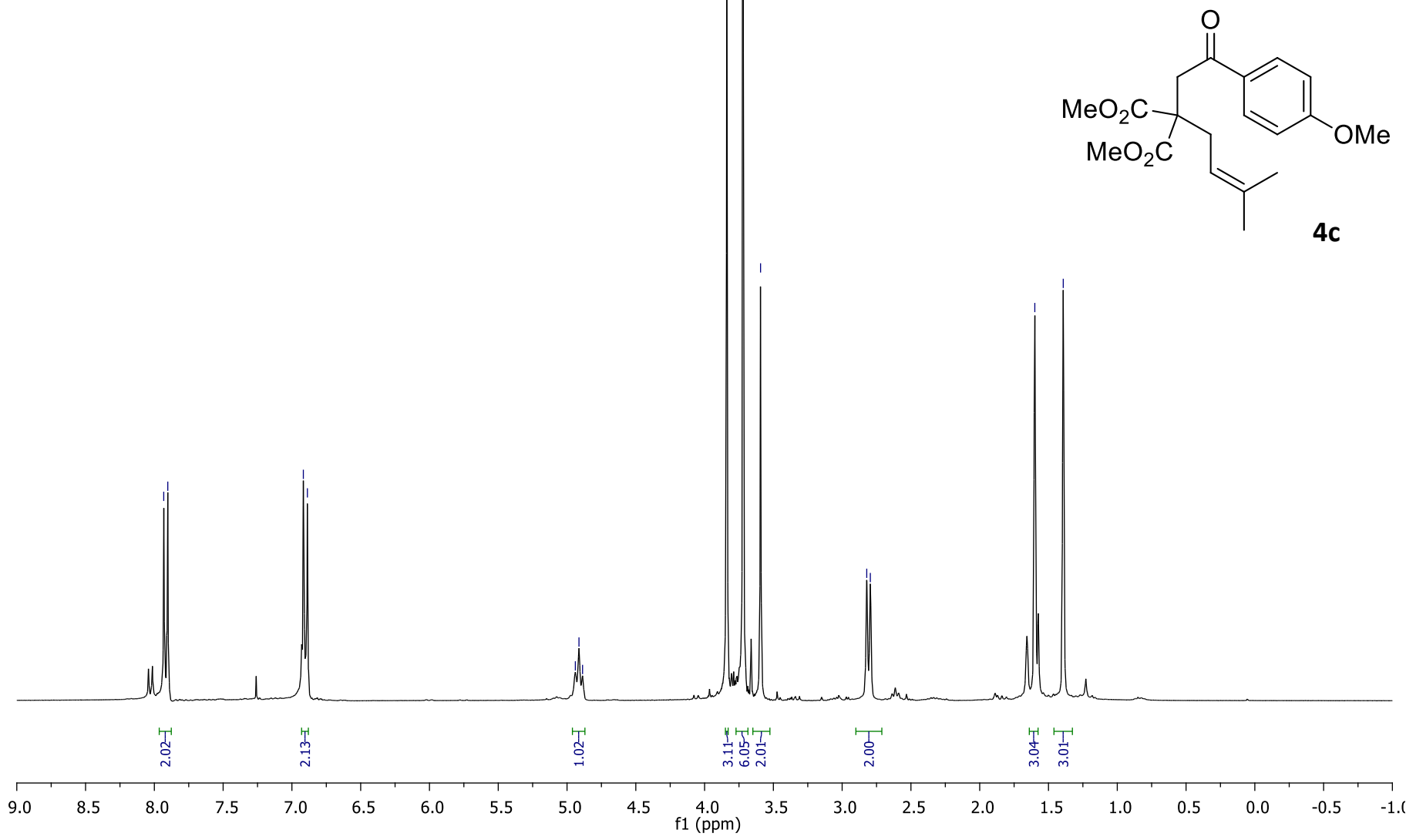

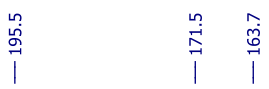

।

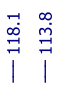

$\sqrt{\sqrt[4]{5}}$

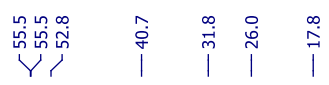
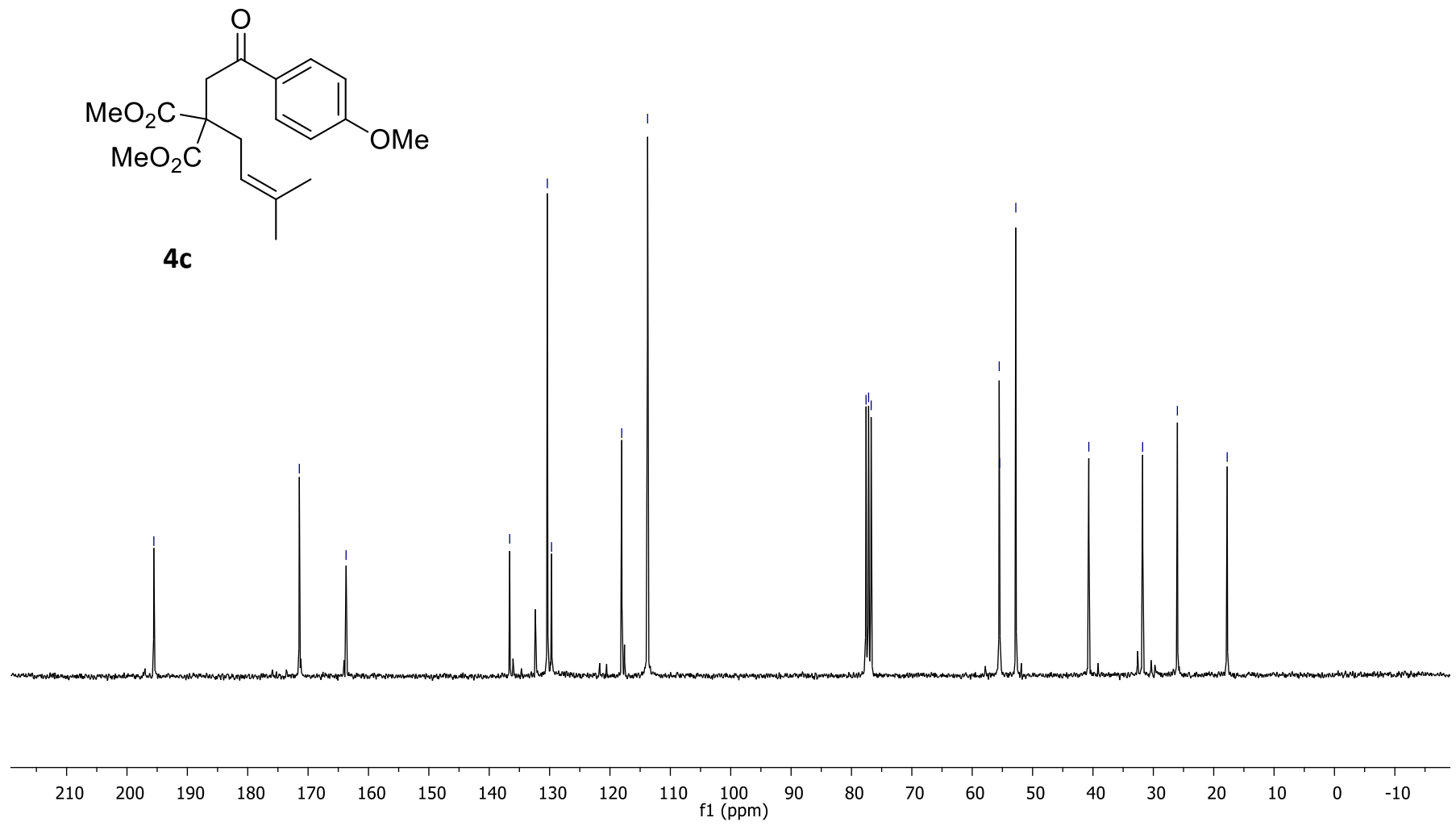


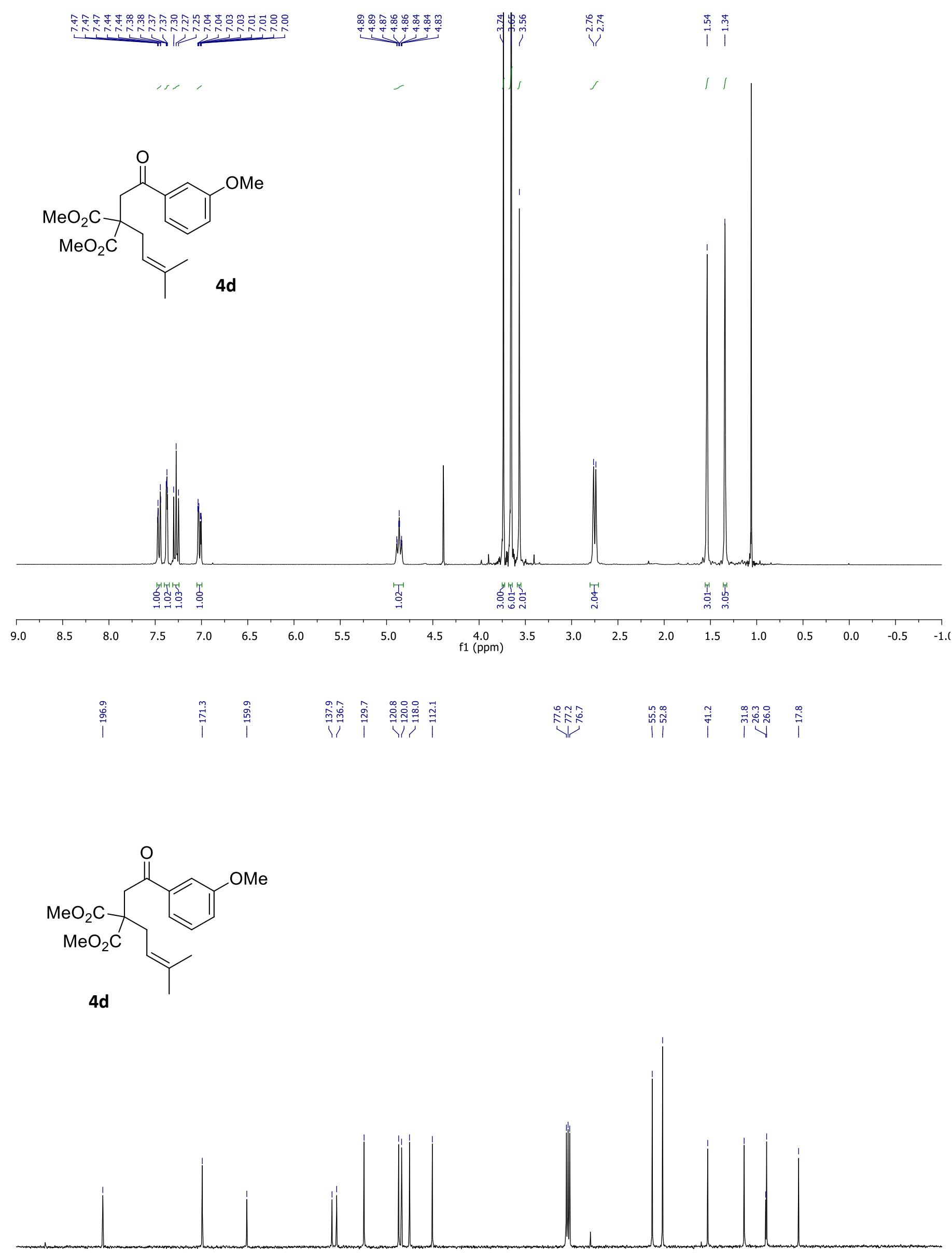

$\begin{array}{llllllllllllllllllllllllll}210 & 200 & 190 & 180 & 170 & 160 & 150 & 140 & 130 & 120 & 110 & 100 & 90 & 80 & 70 & 60 & 50 & 40 & 30 & 20 & 10 & 0 & -10 & \end{array}$ 

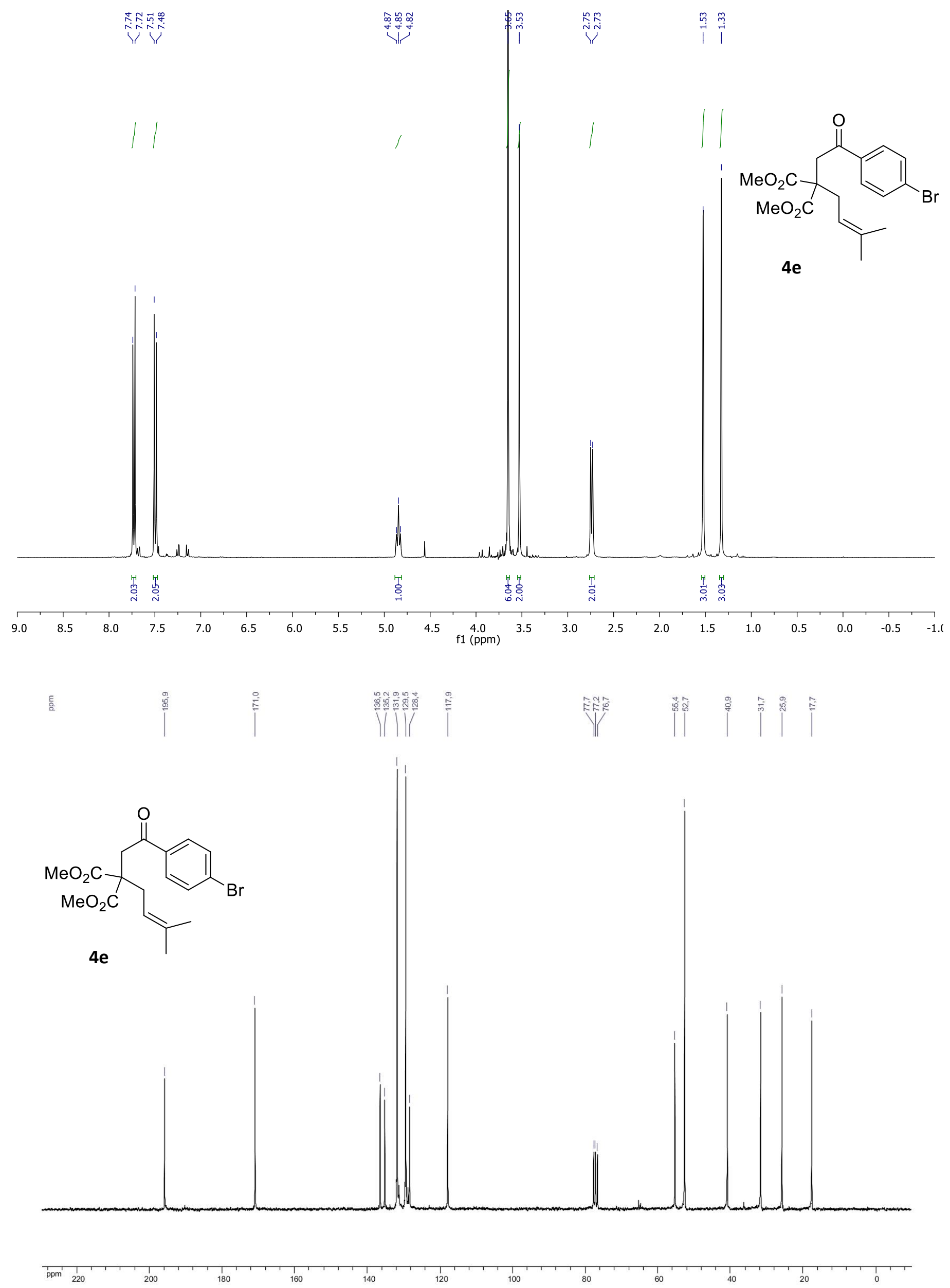

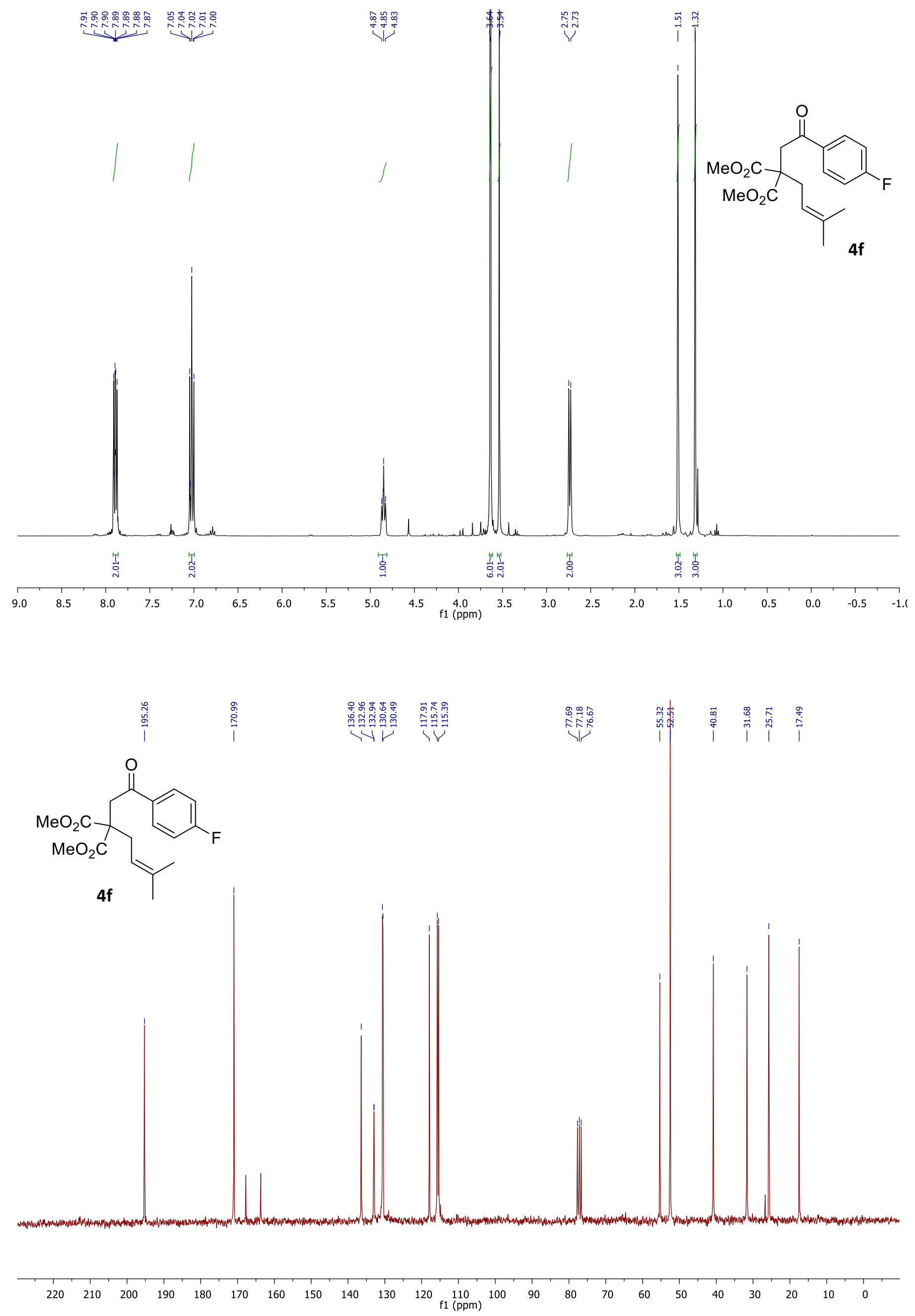
<smiles>COC(=O)C(CC=C(C)C)(CC(=O)c1ccc(F)cc1)C(=O)OC</smiles>

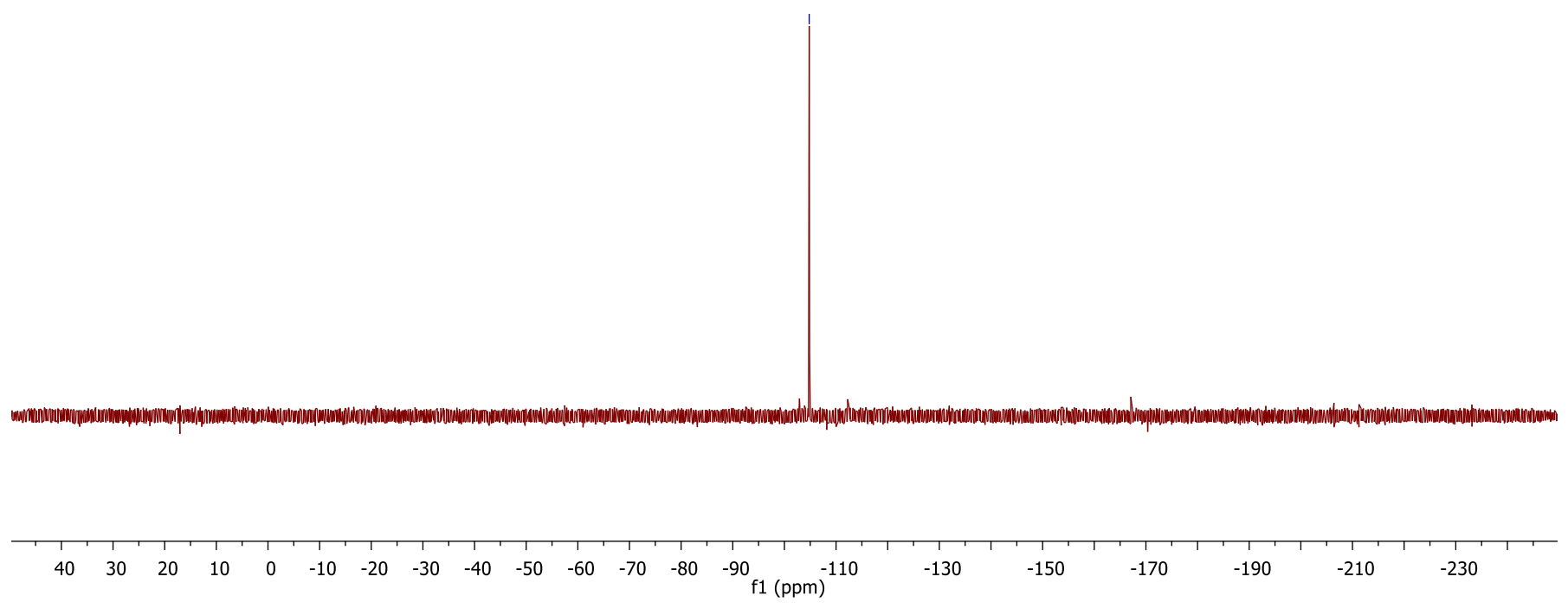



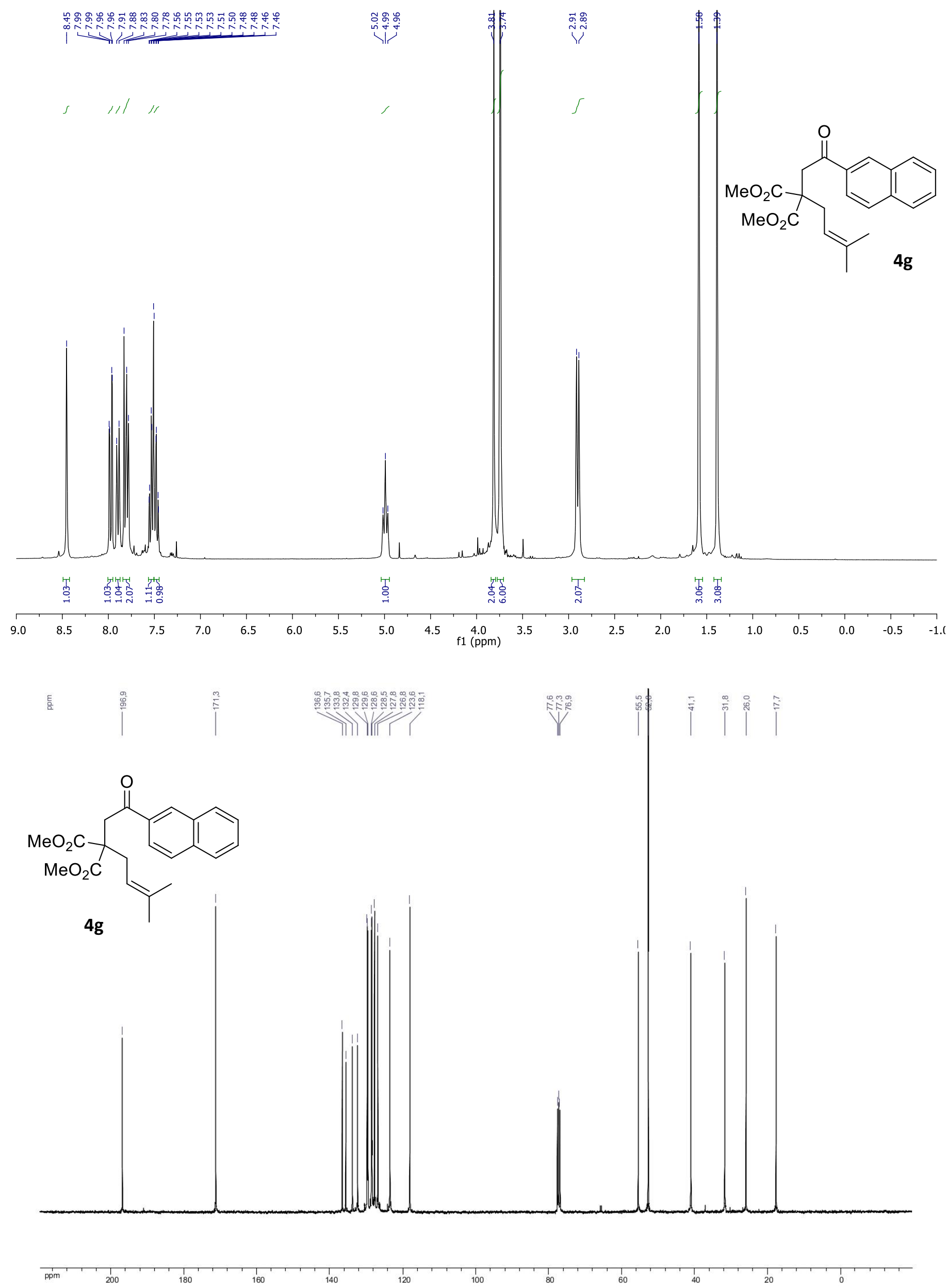

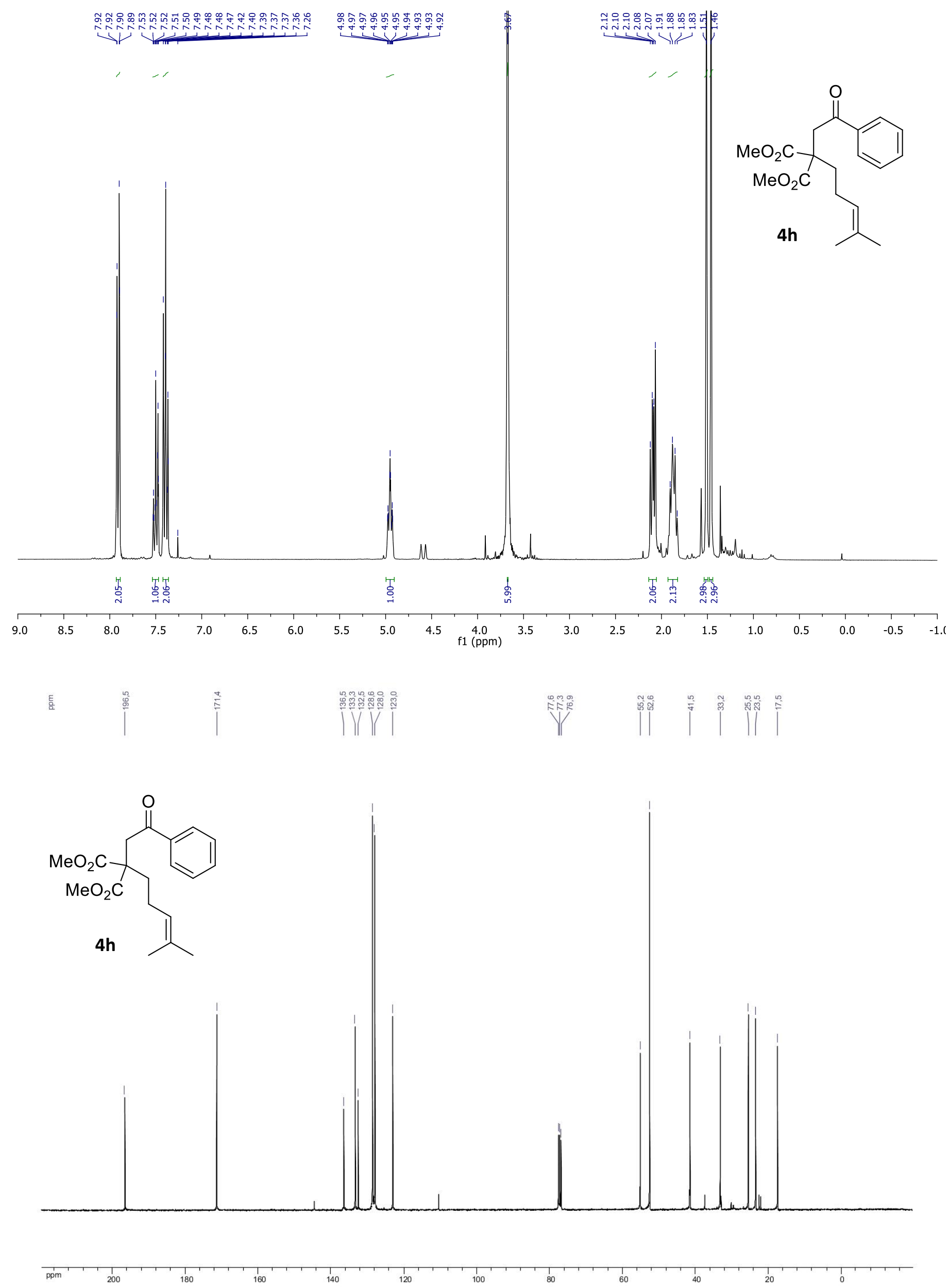

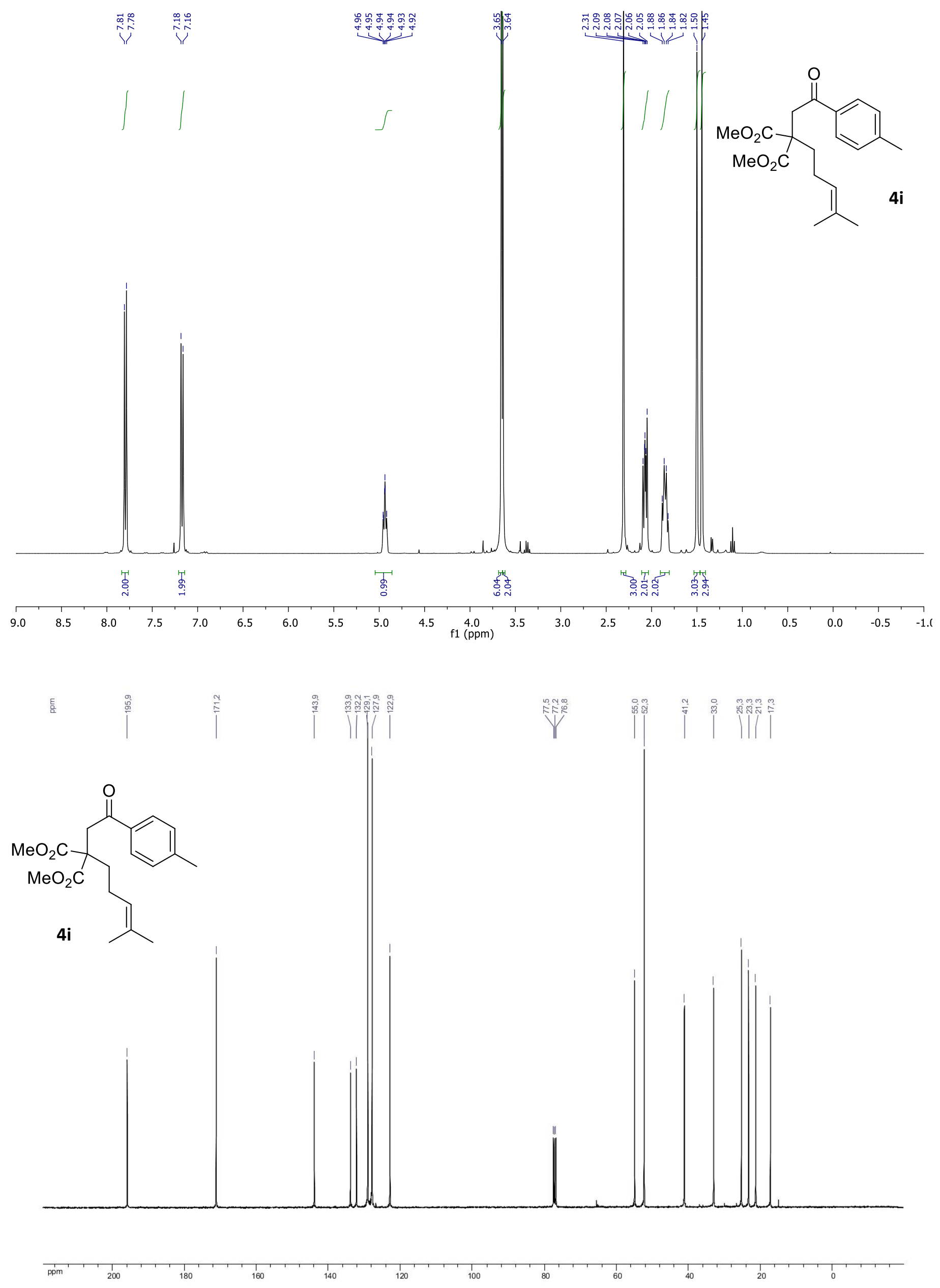


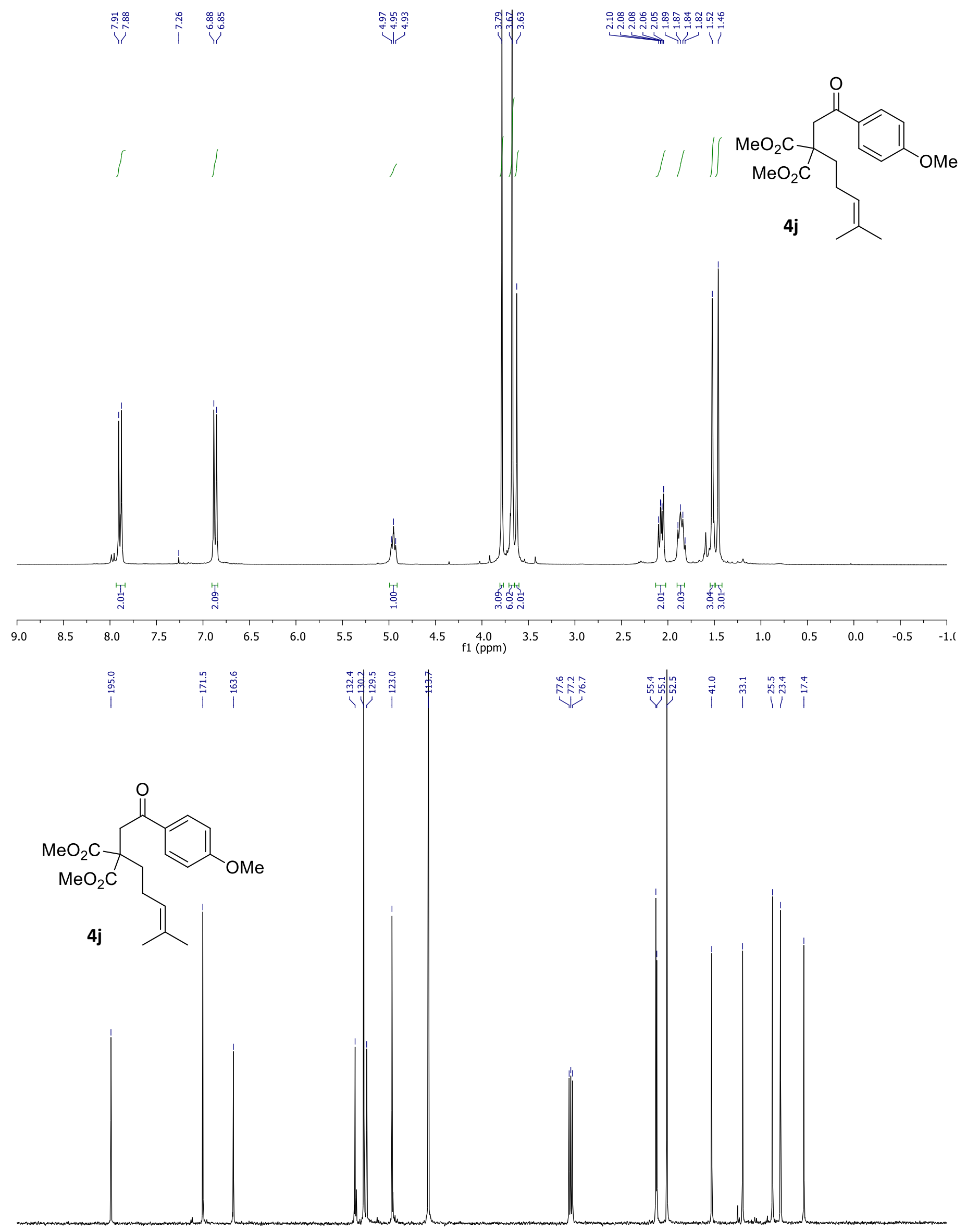

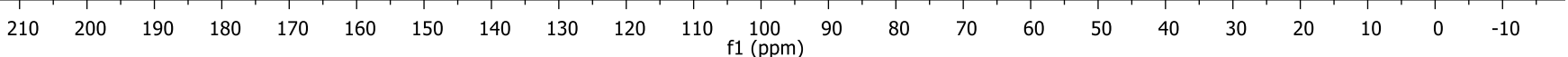



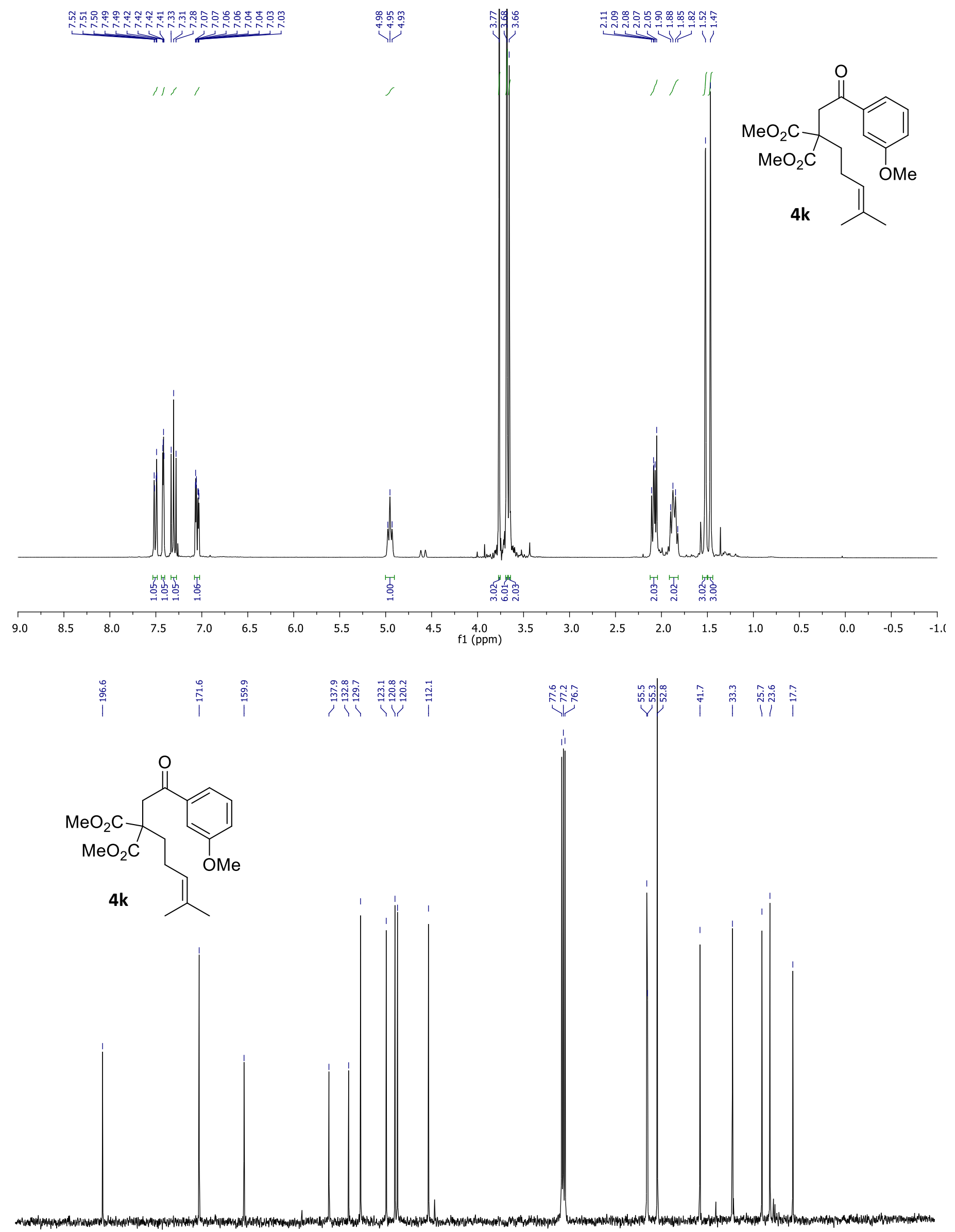

$\begin{array}{lllllllllllllllllllllll}210 & 200 & 190 & 180 & 170 & 160 & 150 & 140 & 130 & 120 & 110 & \begin{array}{c}100 \\ \mathrm{f} 1(\mathrm{ppm})\end{array} & 90 & 80 & 70 & 60 & 50 & 40 & 30 & 20 & 10 & 0 & -10\end{array}$ 

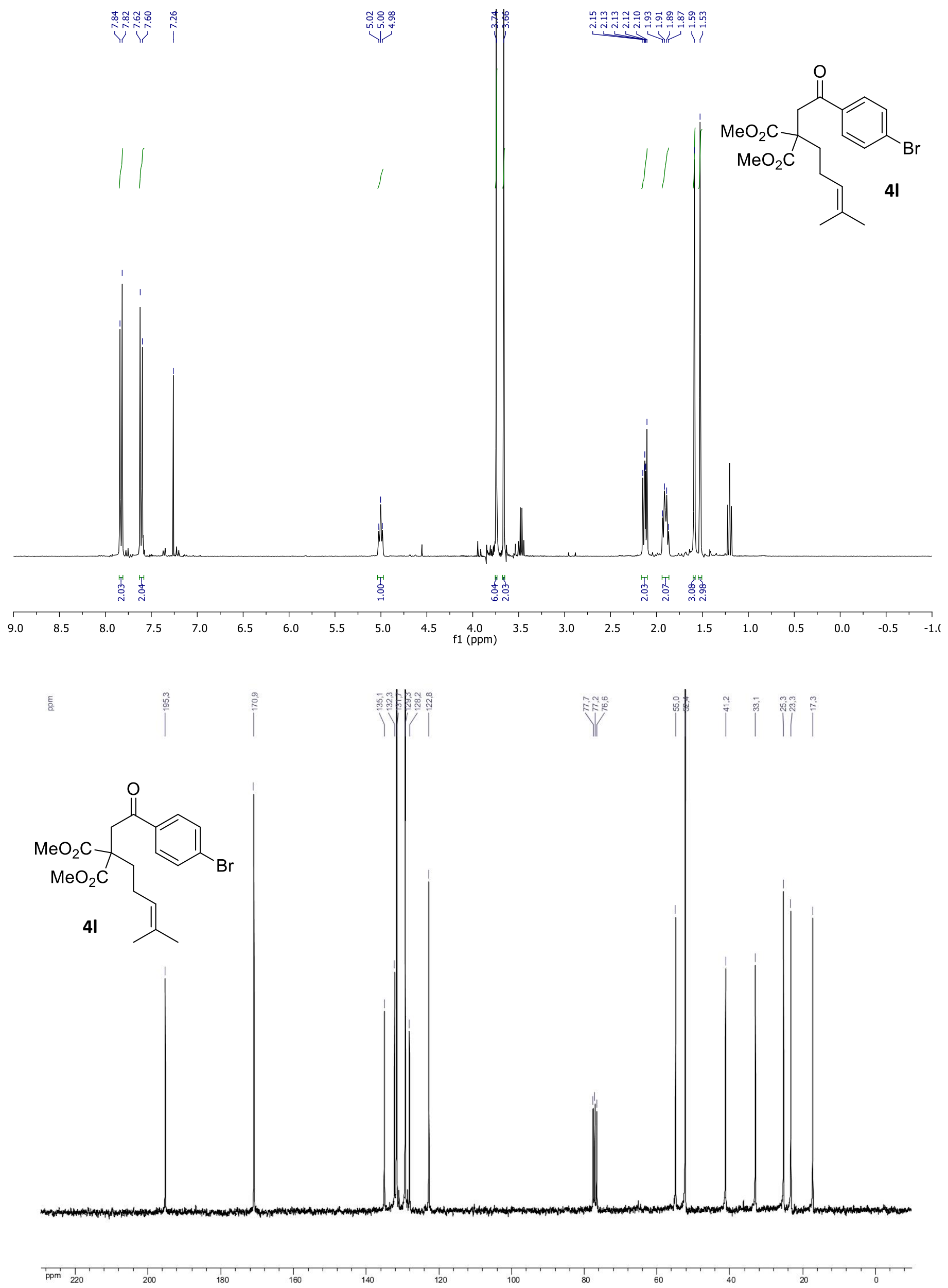

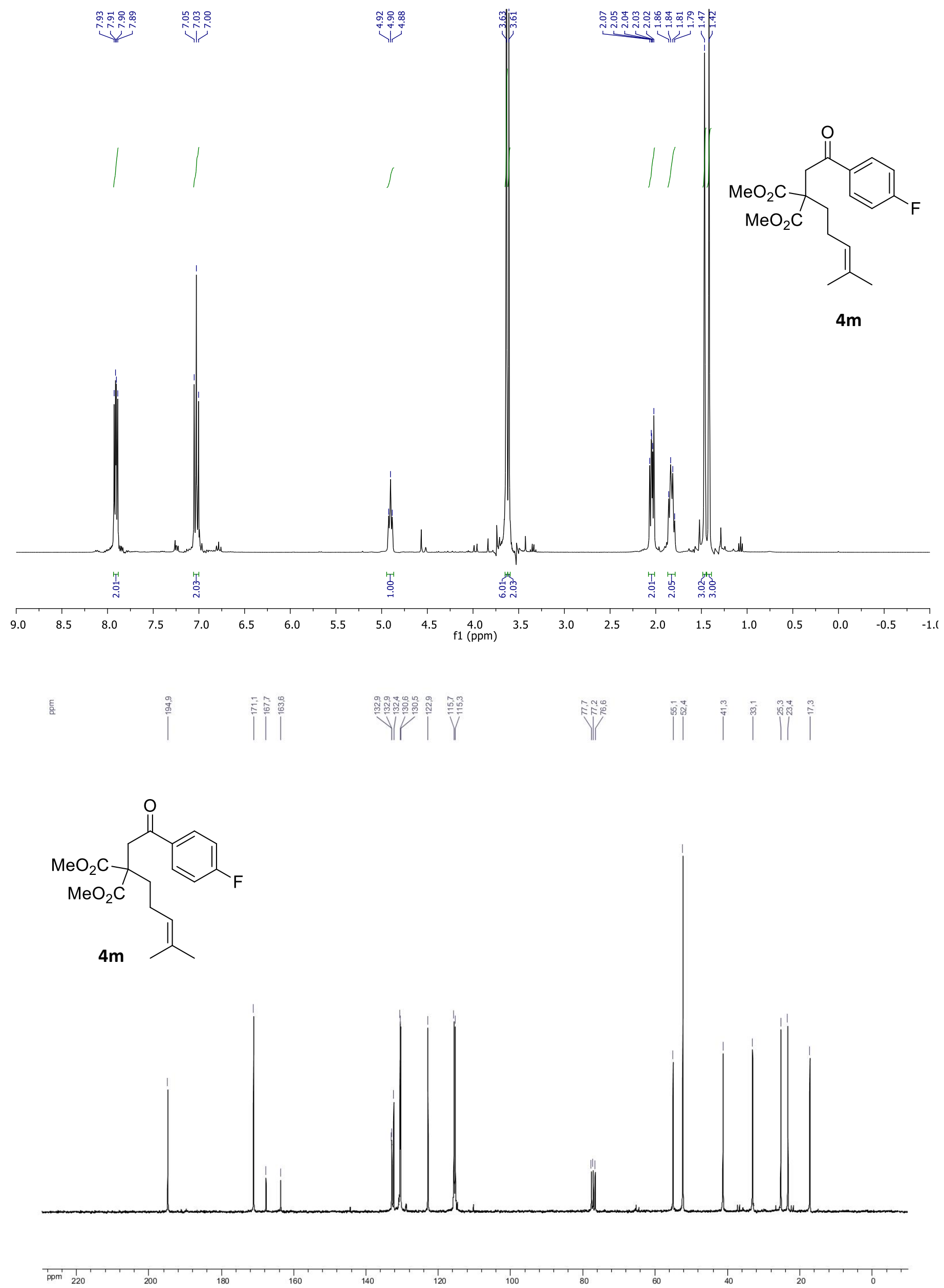
<smiles>COC(=O)C(CCC=C(C)C)(CCC(=O)c1ccc(F)cc1)C(C)=O</smiles>

$4 m$

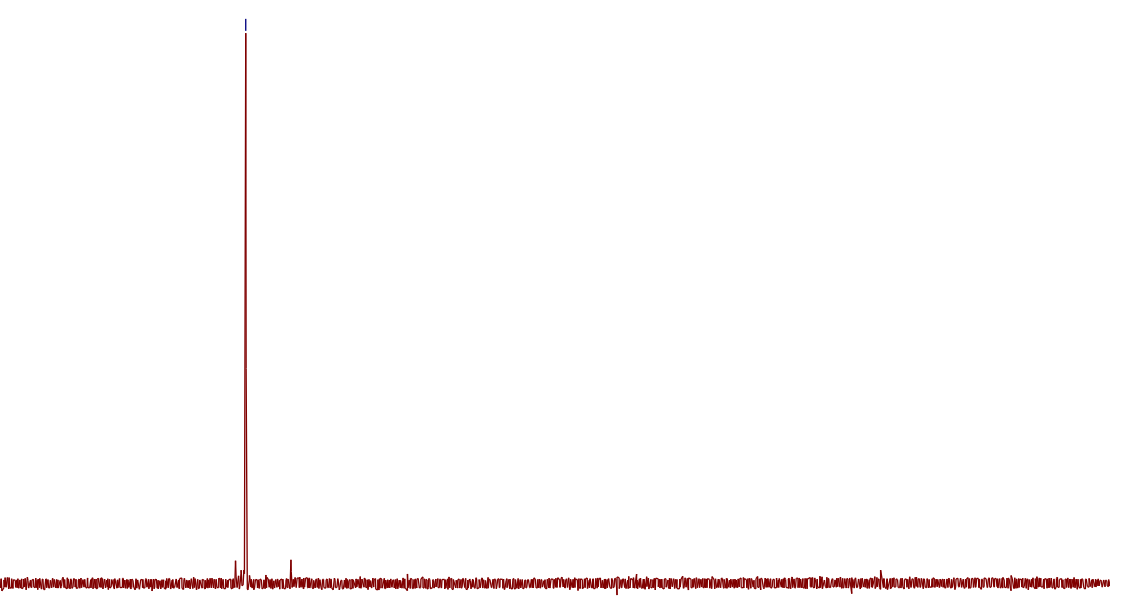

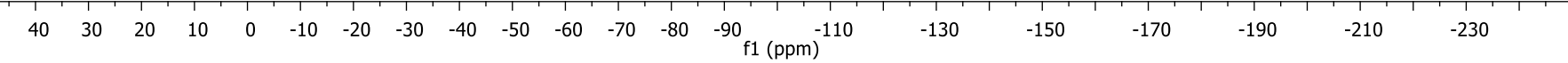




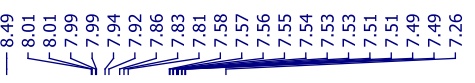

, 11/

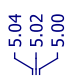

$s$

$\underbrace{2}$
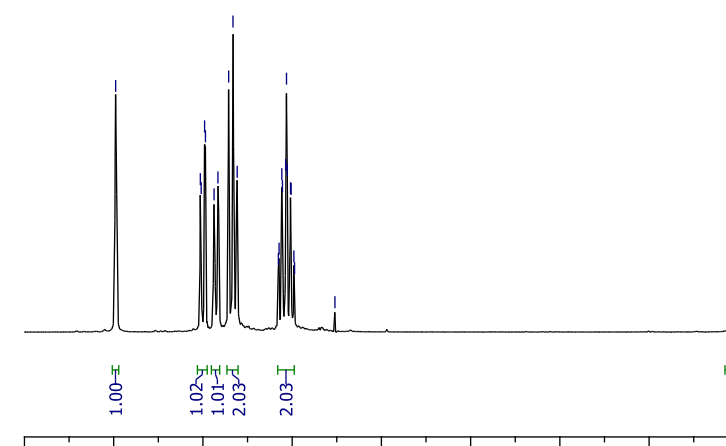

等

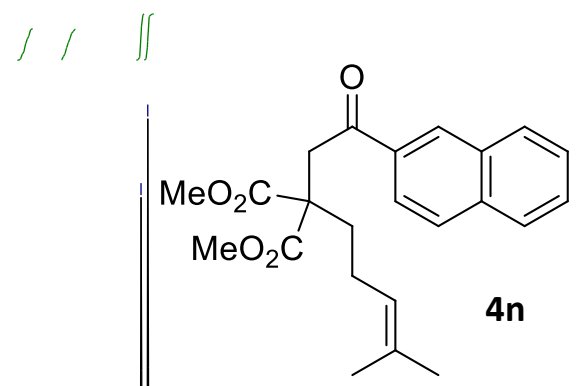

$\begin{array}{cccccc}9.0 & 8.5 & 8.0 & 7.5 & 7.0 \\ & & & & \\ & & & & \\ & & & & & \\ & & & & & \end{array}$

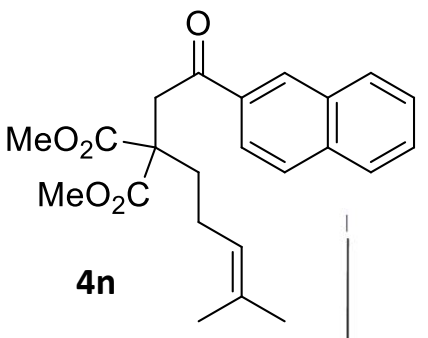

$\underbrace{1}$
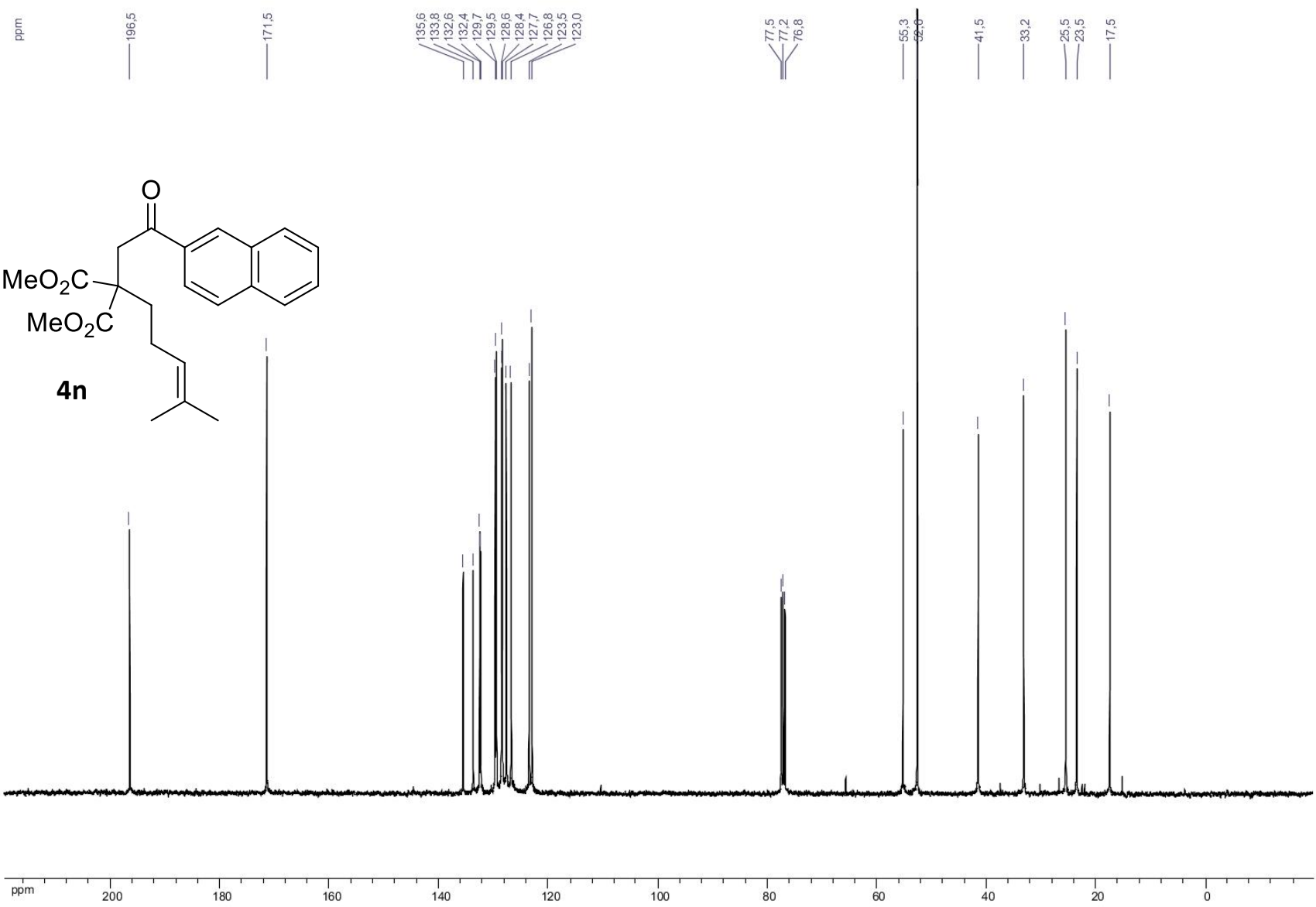

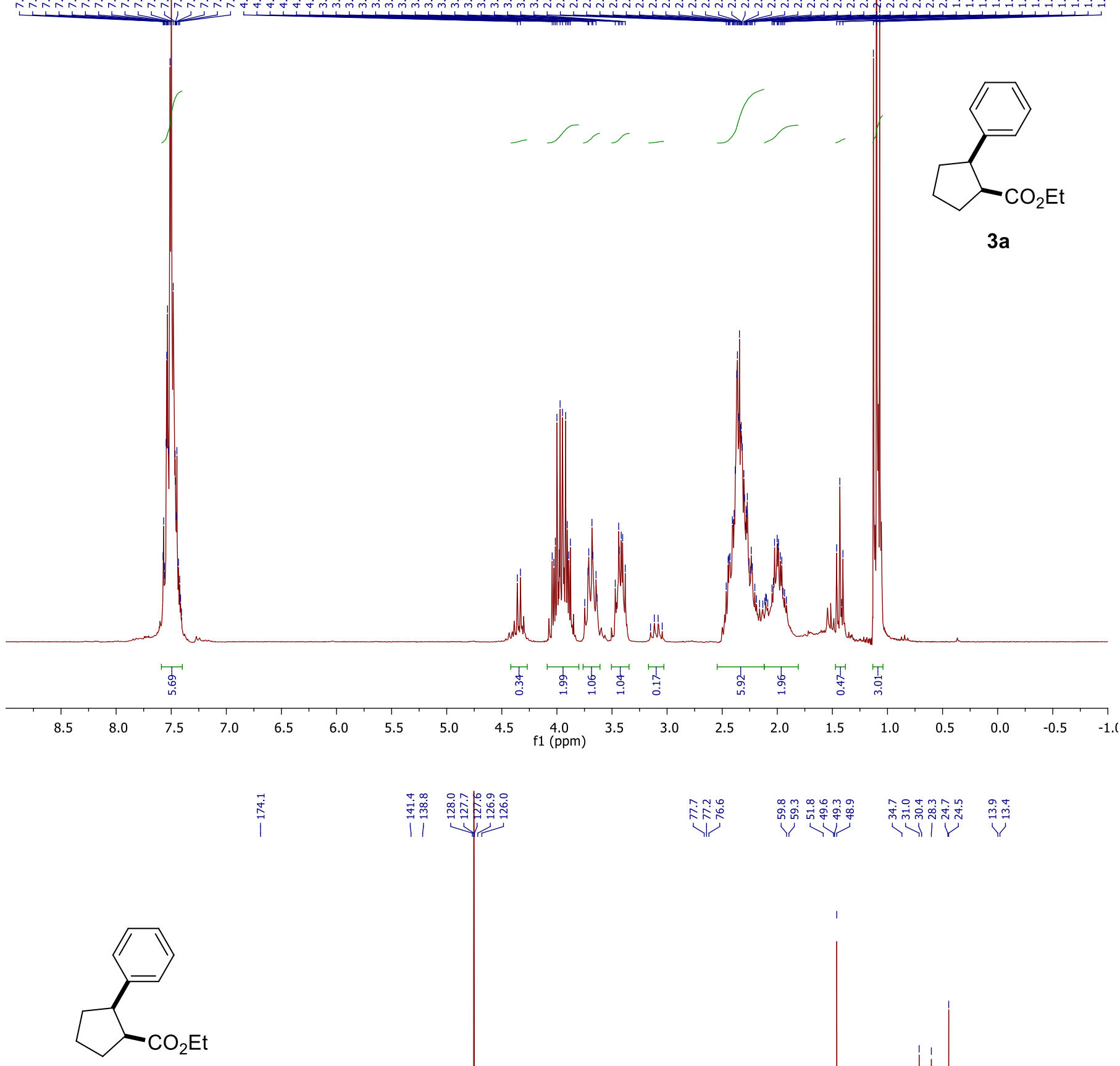

3a

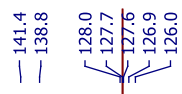

许

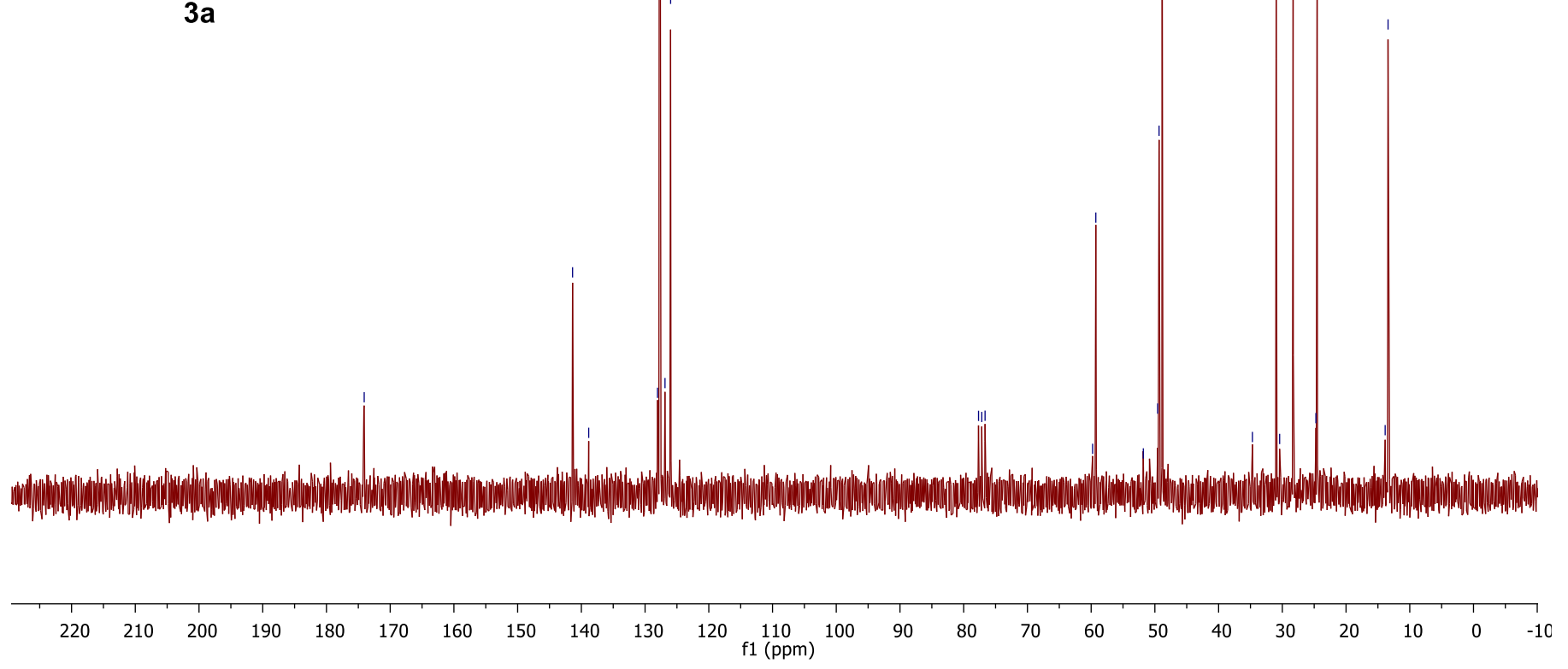




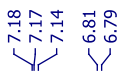

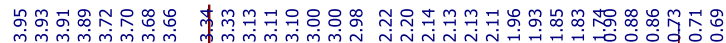

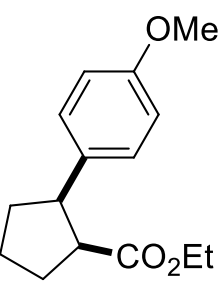

$3 b$
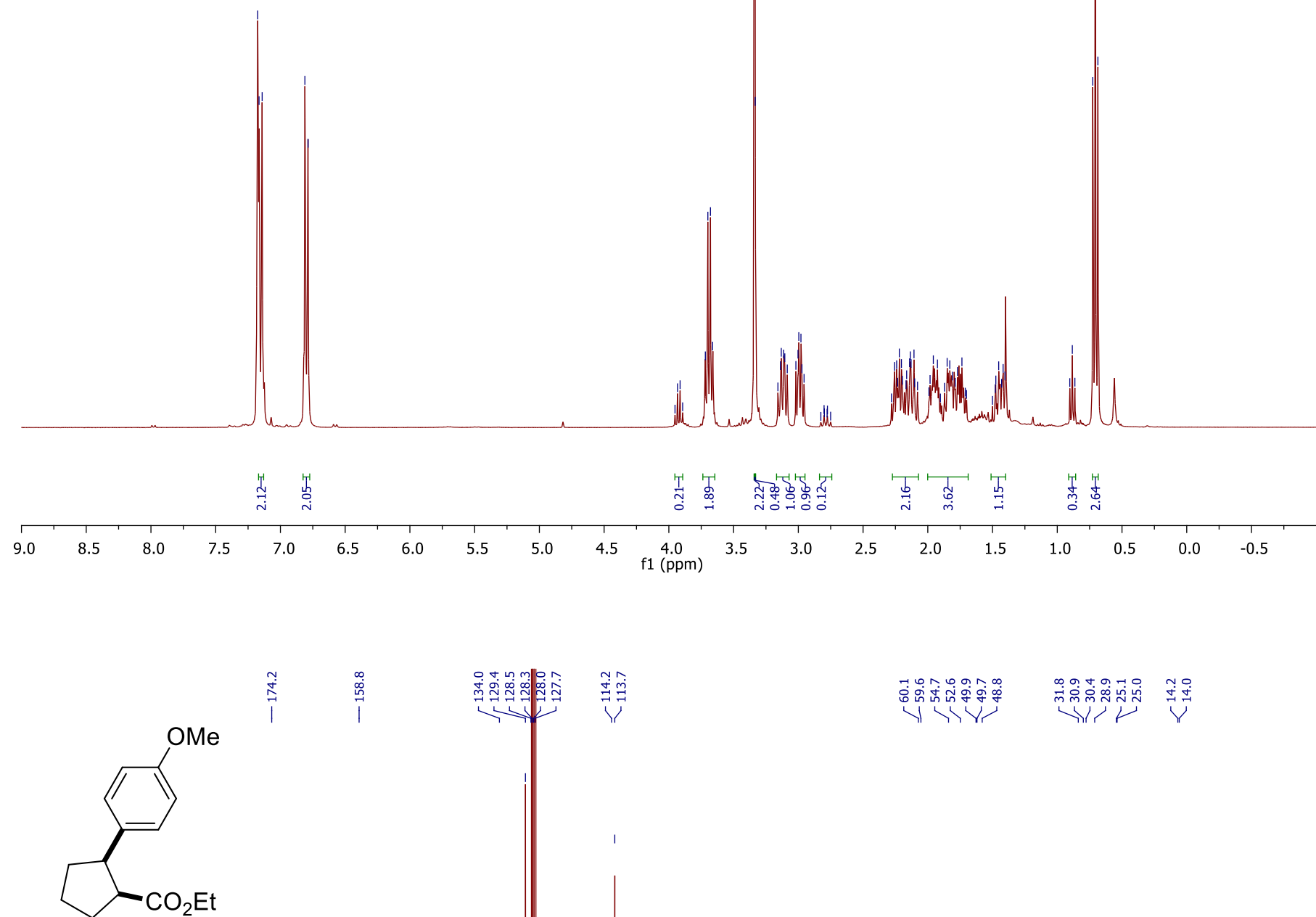

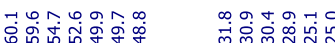

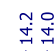

3b

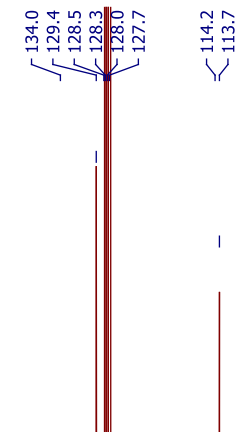

।

$\begin{array}{llllllllllll}210 & 200 & 190 & 180 & 170 & 160 & 150 & 140 & 130 & 120 & 110 & 100\end{array}$
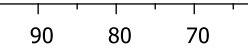

$60 \quad 50$

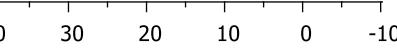




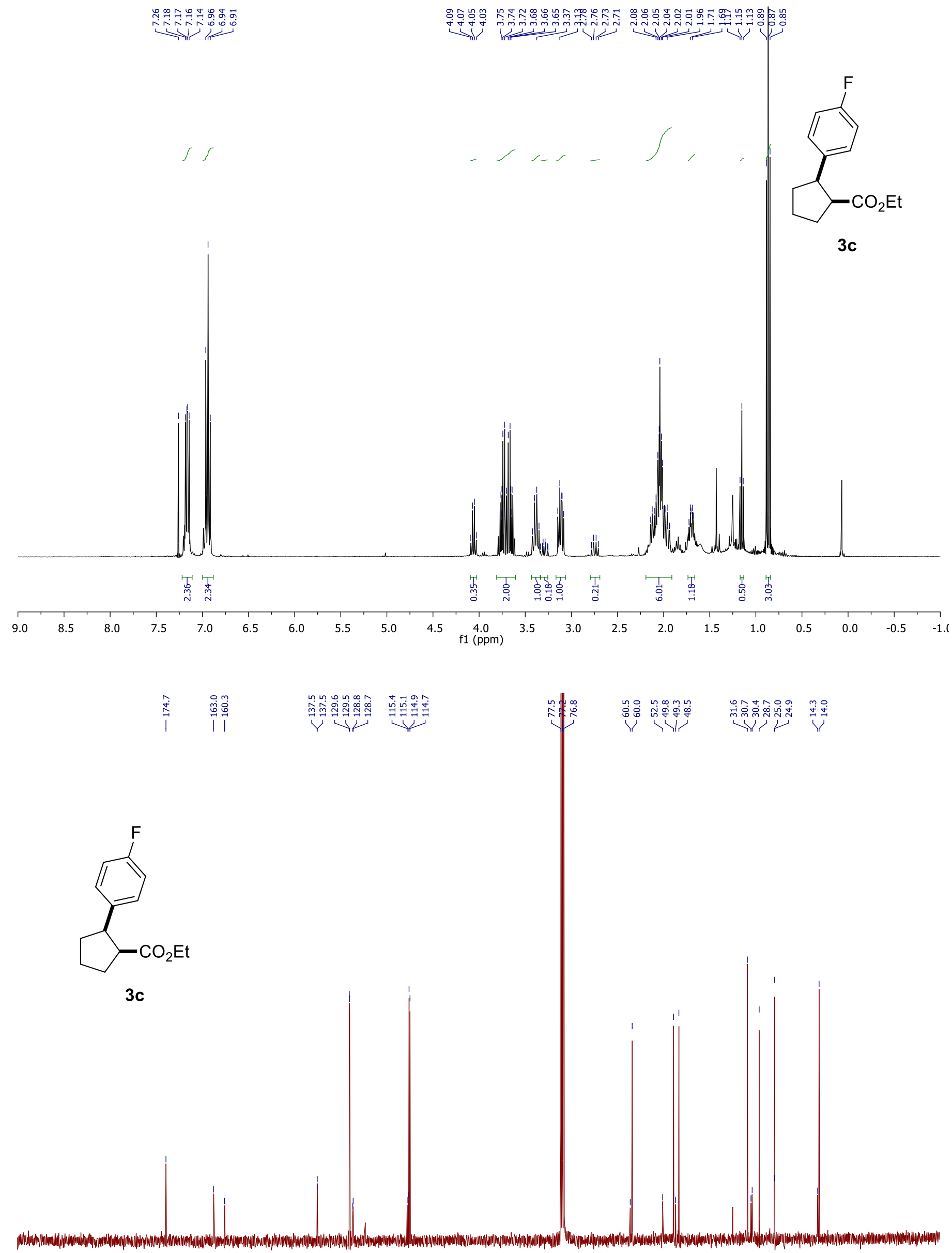

\begin{tabular}{rlllllllllllllllllllllll}
\hline & 210 & 200 & 190 & 180 & 170 & 160 & 150 & 140 & 130 & 120 & 110 & $\underset{\mathrm{f} 1(\mathrm{ppm})}{100}$ & 80 & 70 & 60 & 50 & 40 & 30 & 20 & 10 & 0 & -10
\end{tabular} 


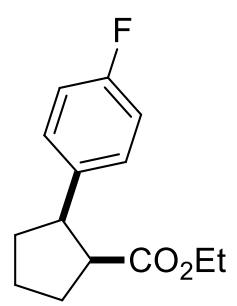

$3 c$

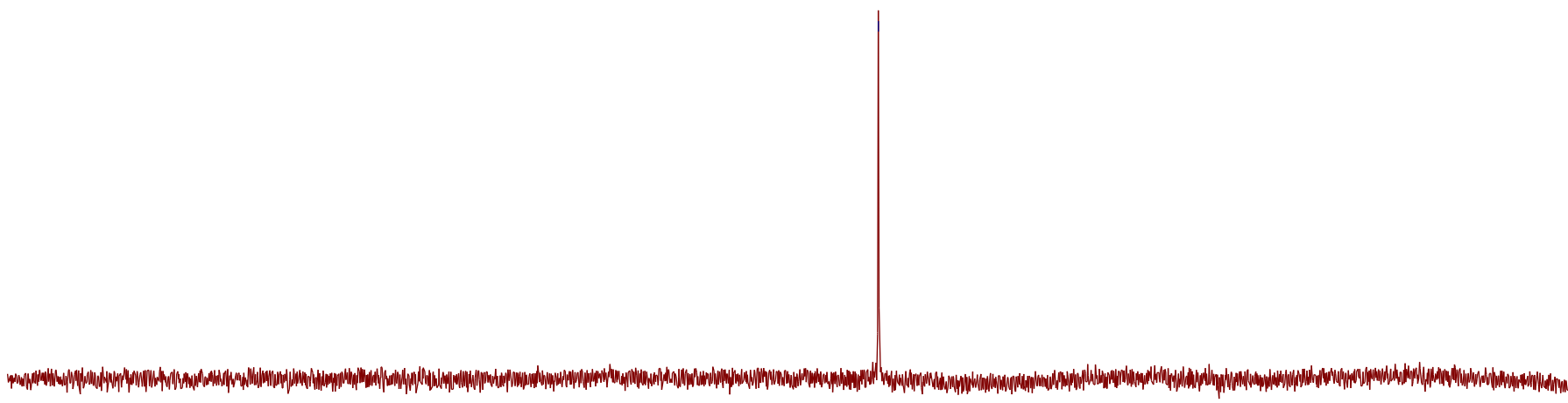

$\begin{array}{llllllllllllll}40 & 30 & 20 & 10 & 0 & -10 & -20 & -30 & -40 & -50 & -60 & -70 & -80 & -90 \\ \mathrm{f} 1(\mathrm{ppm}) & -110\end{array}$

$\begin{array}{lllllll}-130 & -150 & -170 & -190 & -210 & -230\end{array}$



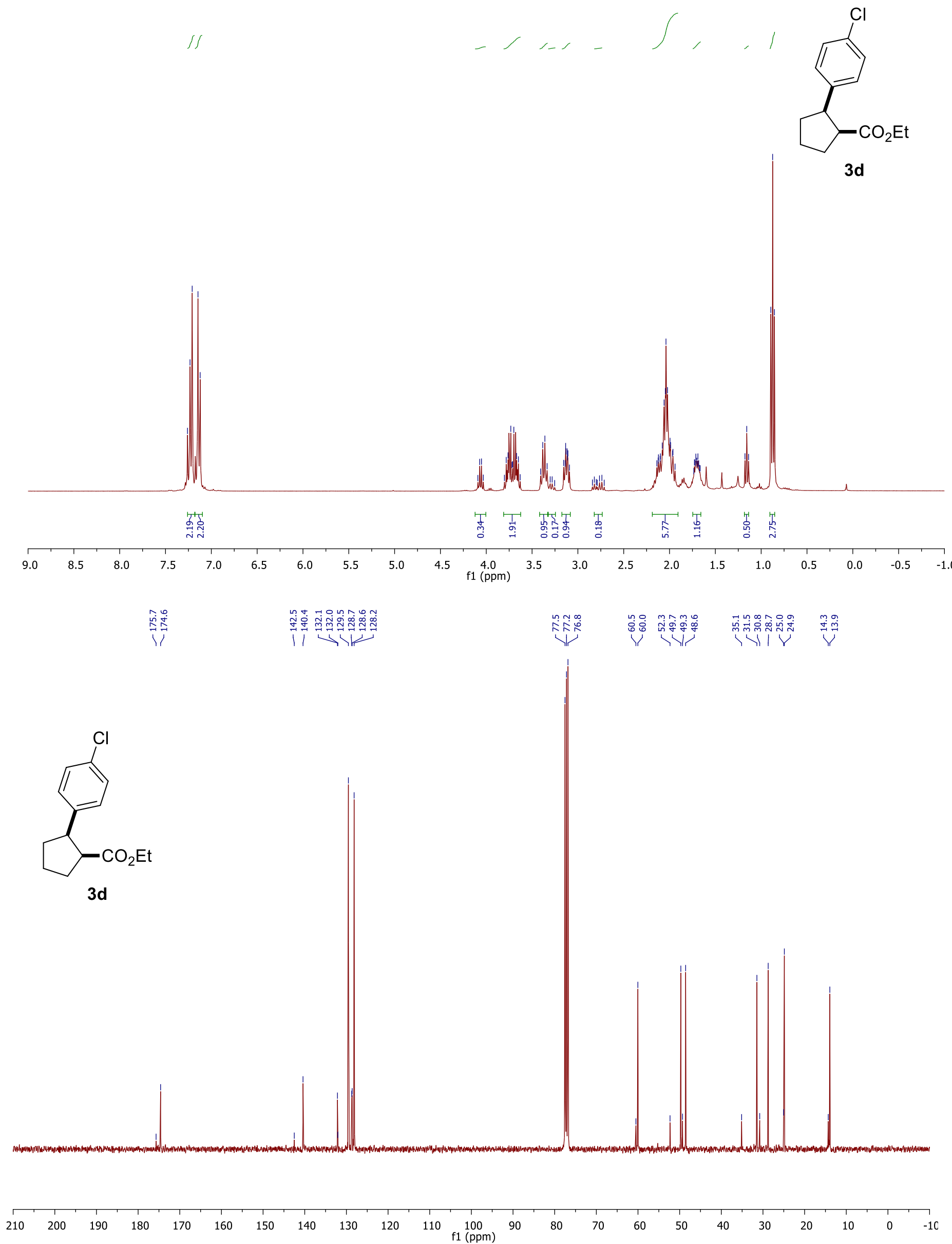


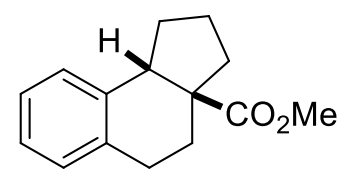

$3 \mathbf{f}$

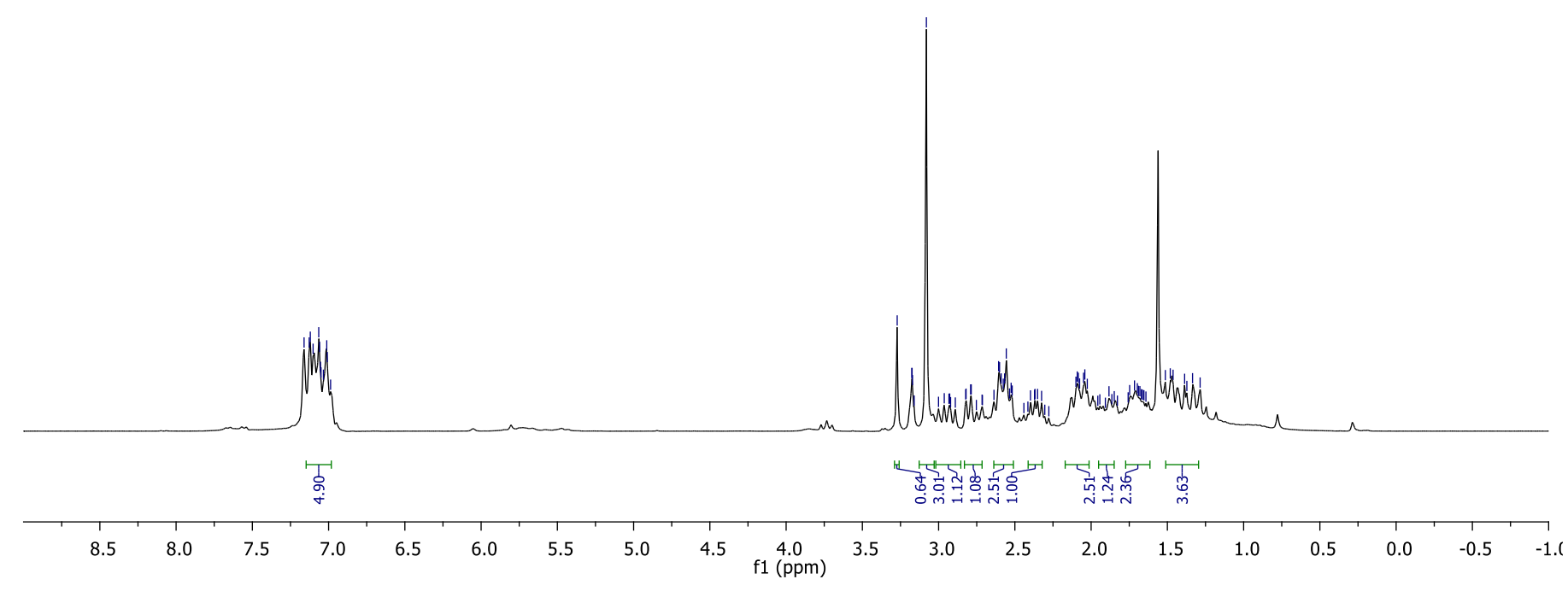

|

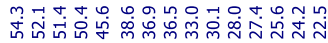

II, सा।<smiles>CCCC1c2ccccc2CCC1OC</smiles>

3f
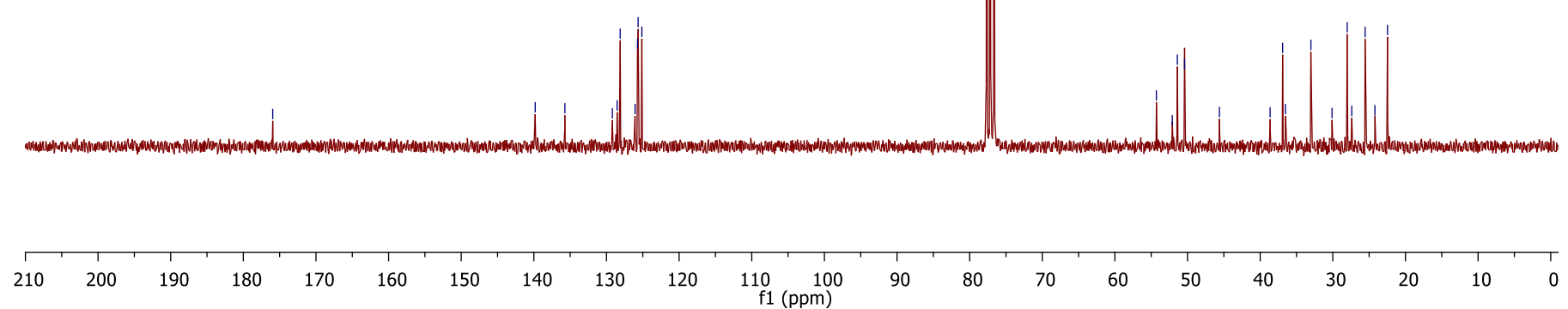

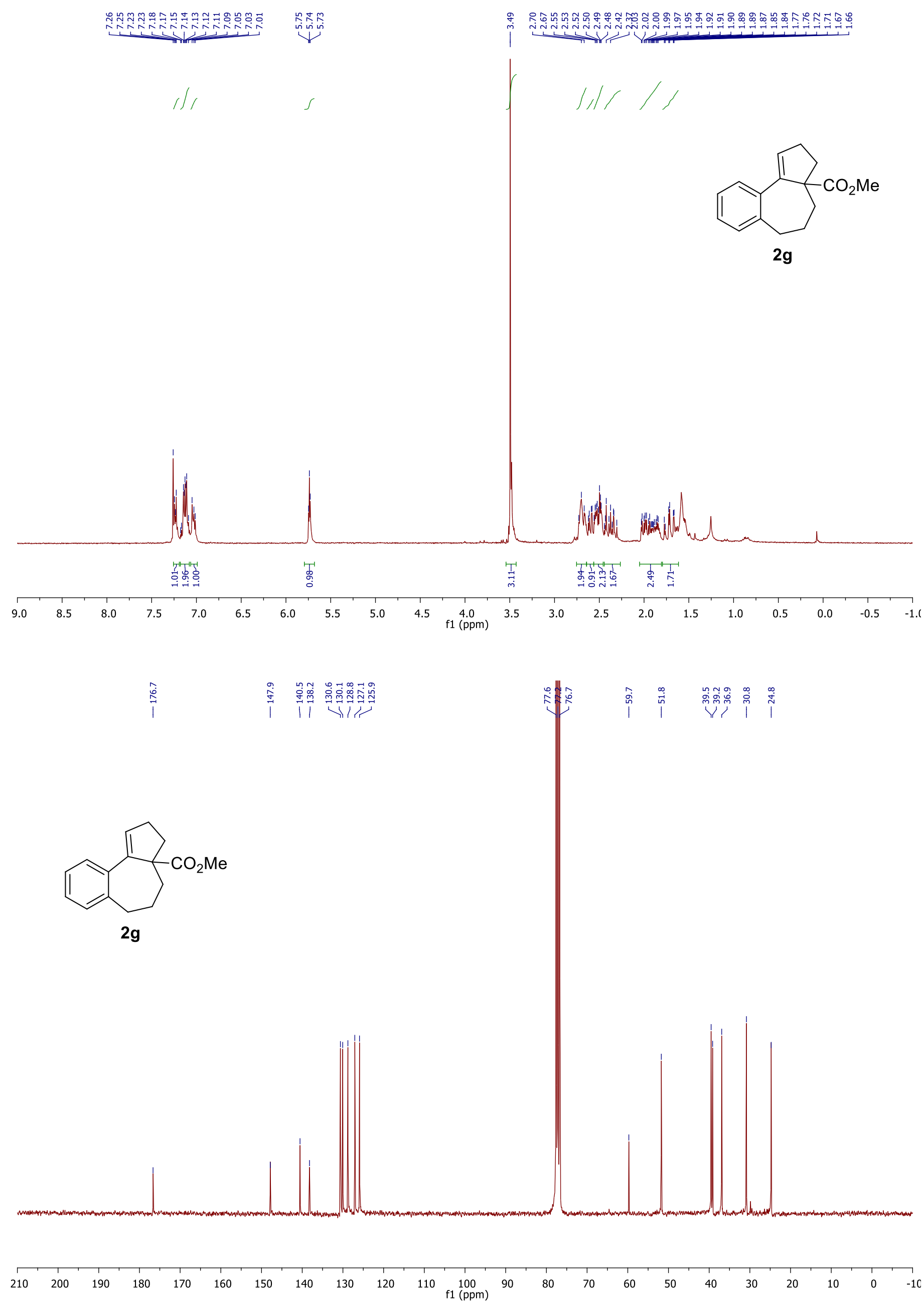


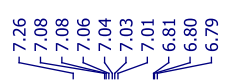

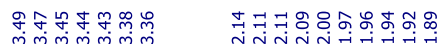

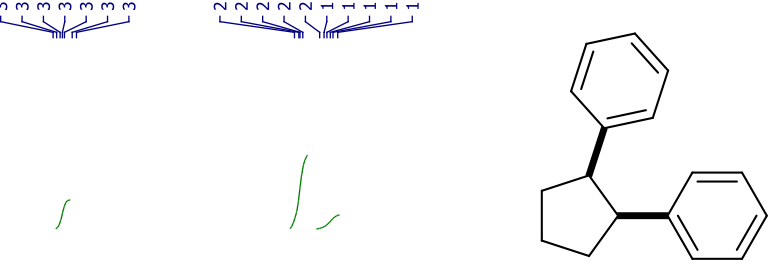

$3 h$

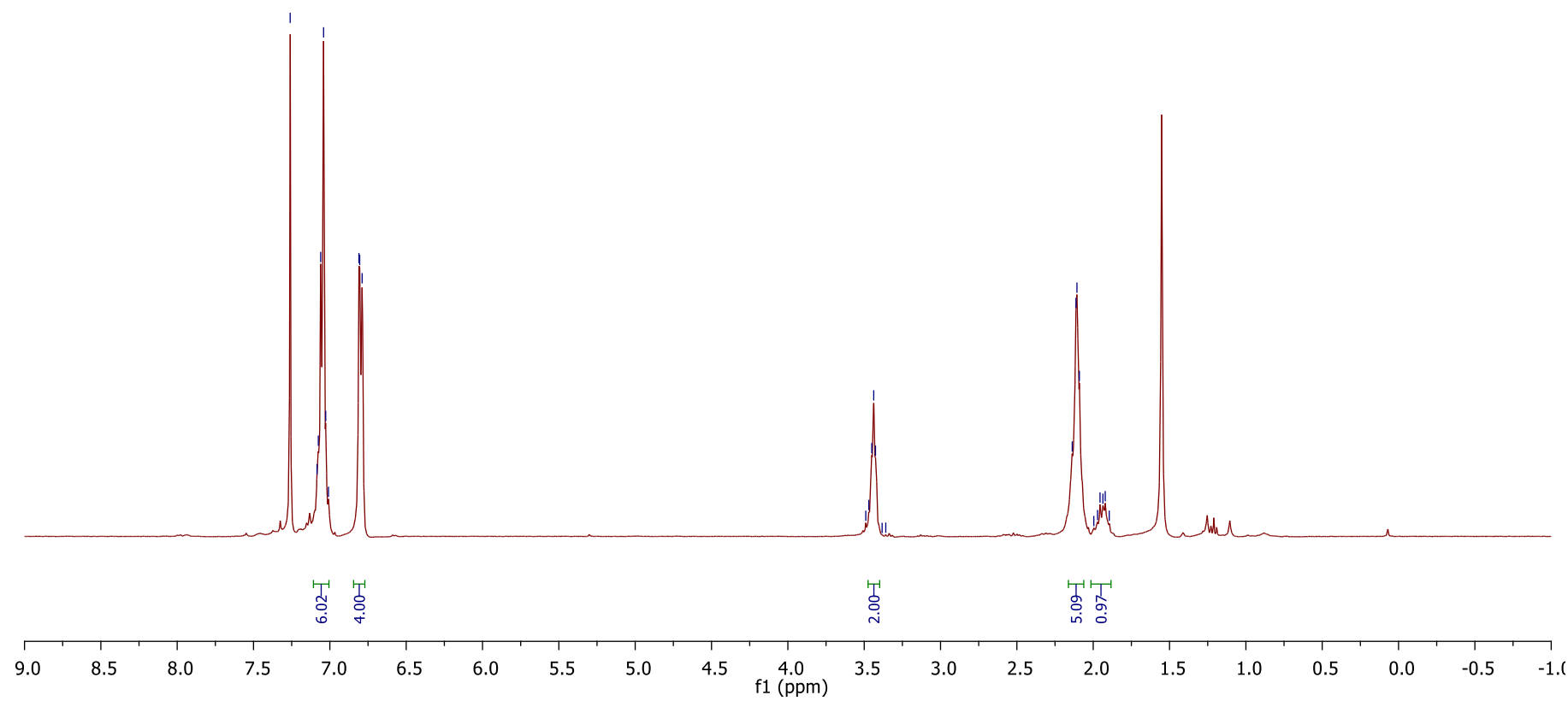

إن

证

i.j.

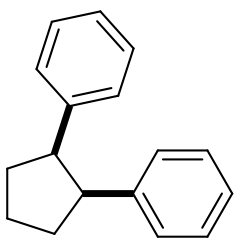

$3 h$

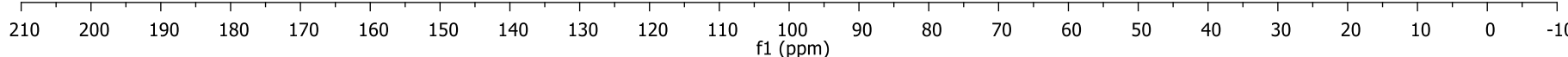



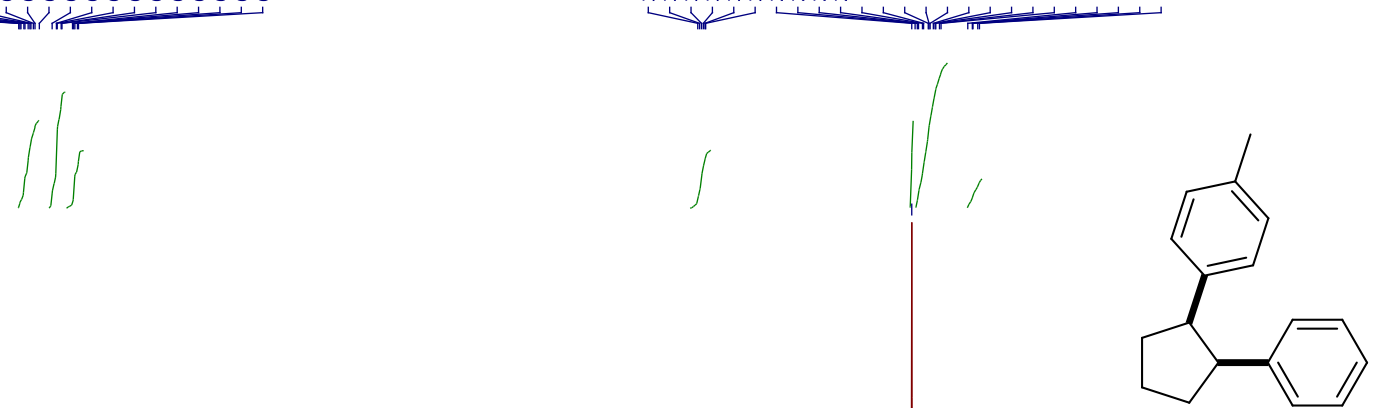

$3 \mathbf{i}$

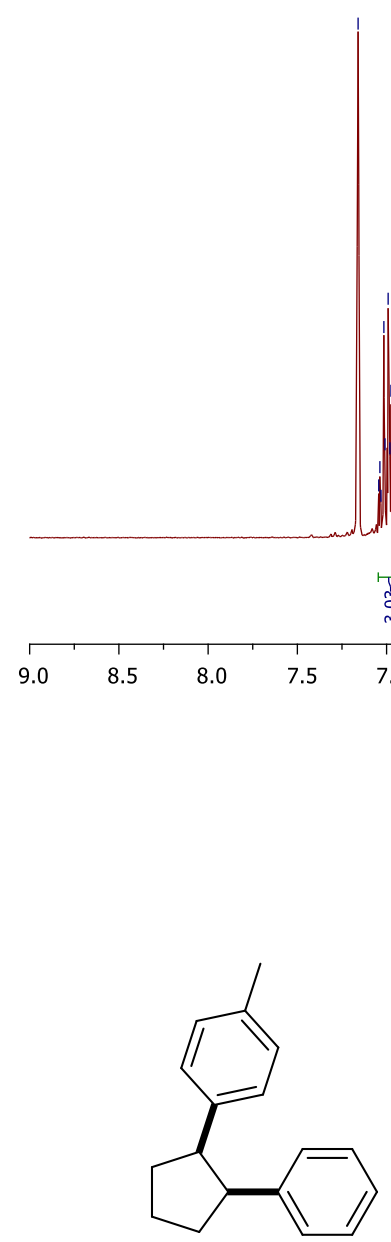

3i

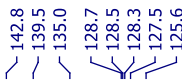
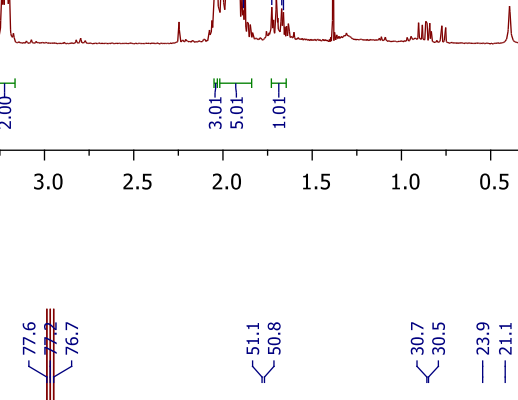

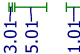

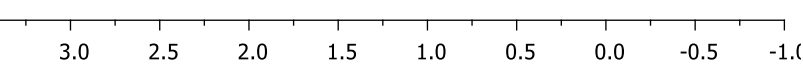



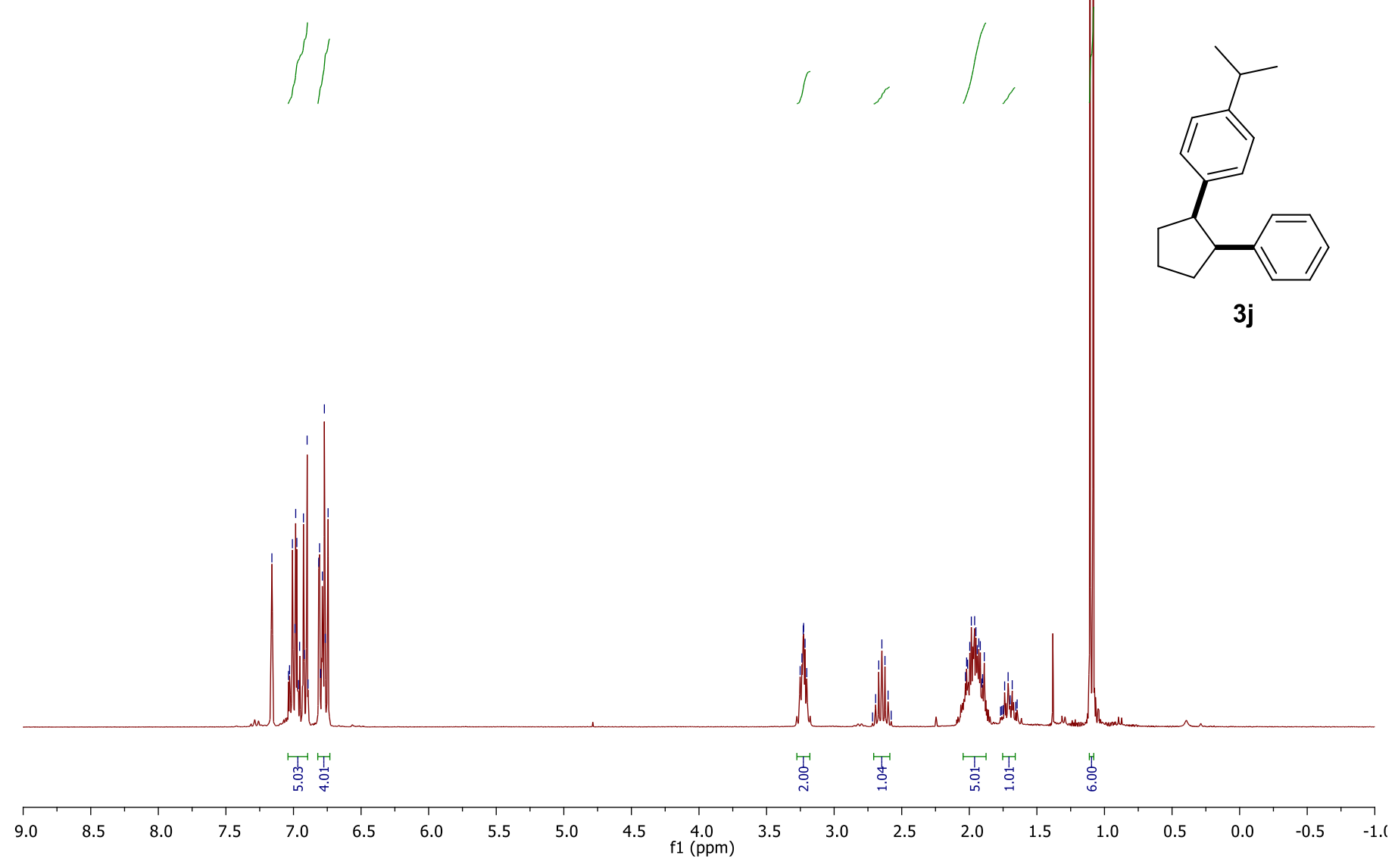

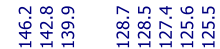

1114

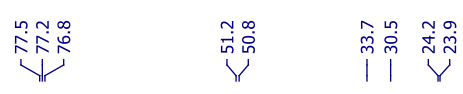

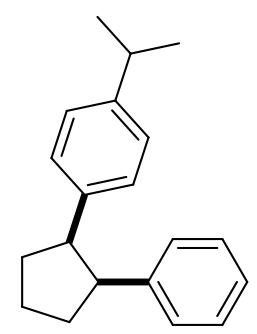

3j

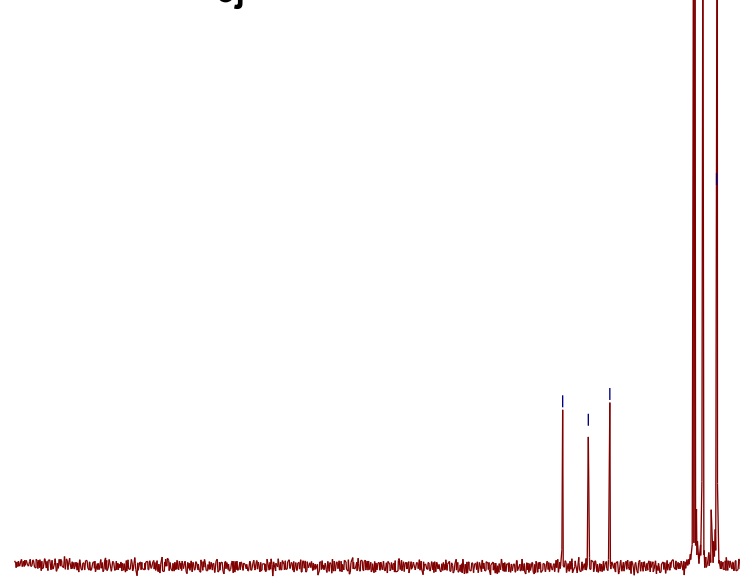

$\begin{array}{llllllllllllllllllllllll}210 & 200 & 190 & 180 & 170 & 160 & 150 & 140 & 130 & 120 & 110 & \begin{array}{c}100 \\ \mathrm{f} 1(\mathrm{ppm})\end{array} & 90 & 80 & 70 & 60 & 50 & 40 & 30 & 20 & 10 & 0 & -10 & \end{array}$ 

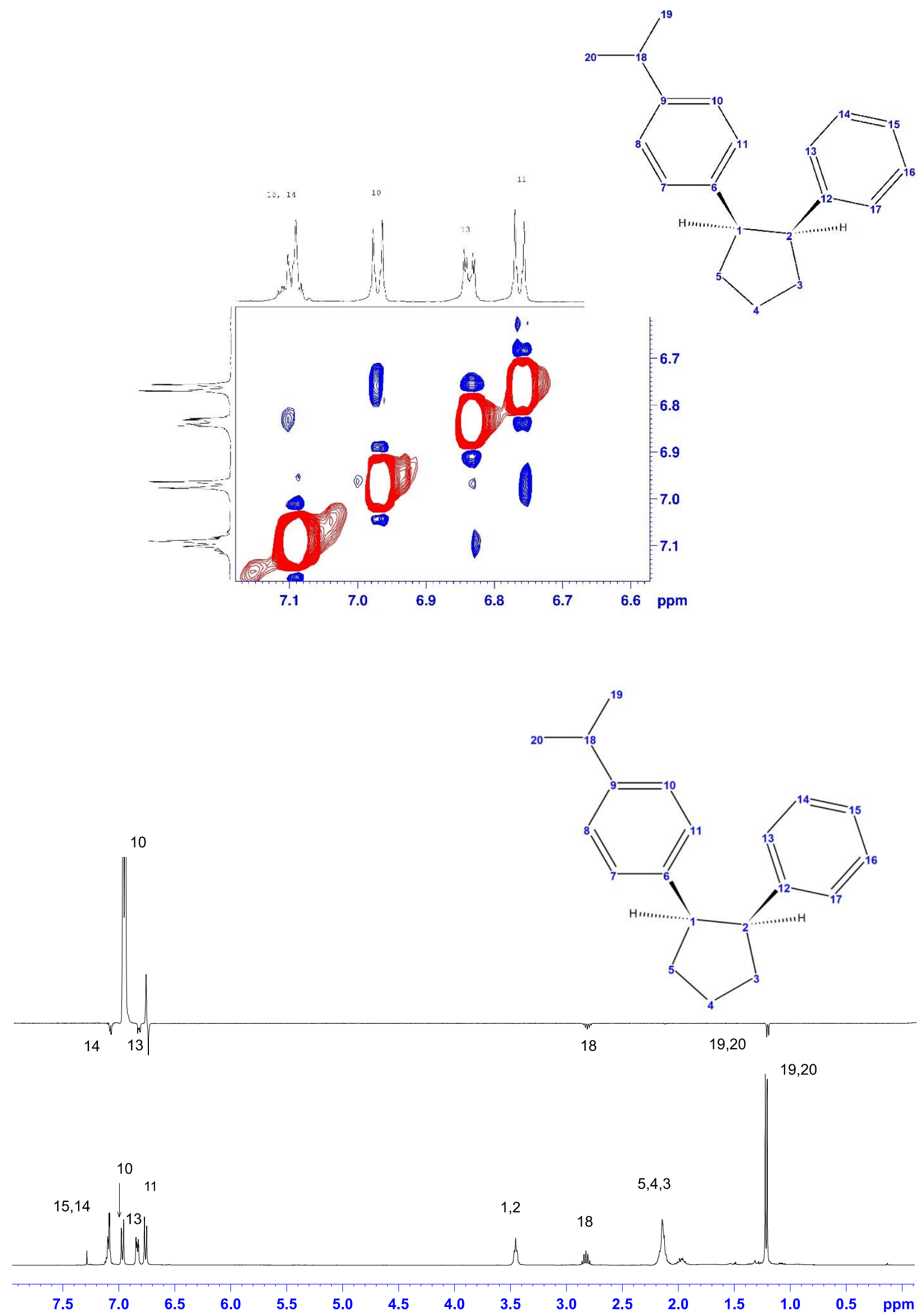

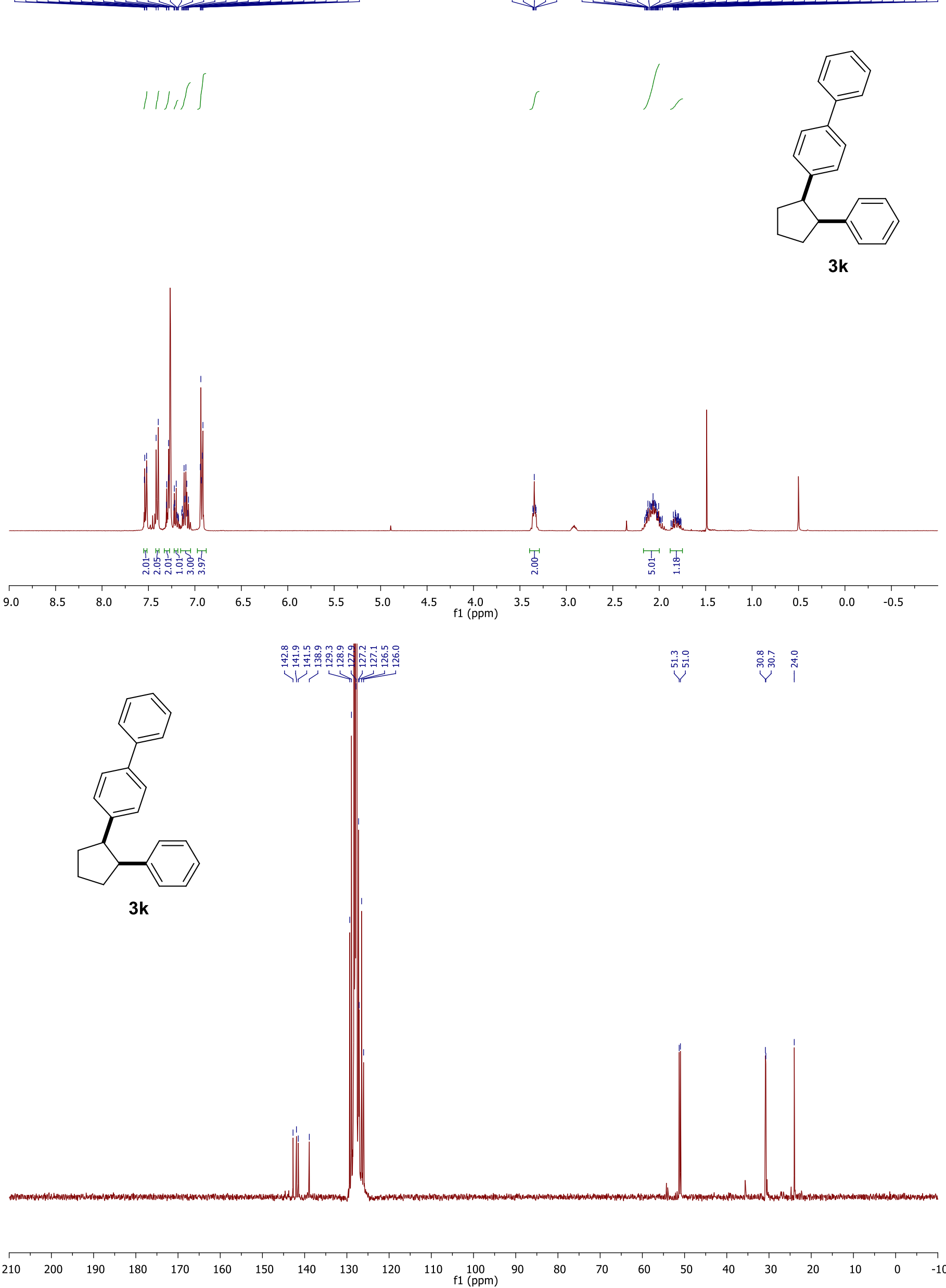

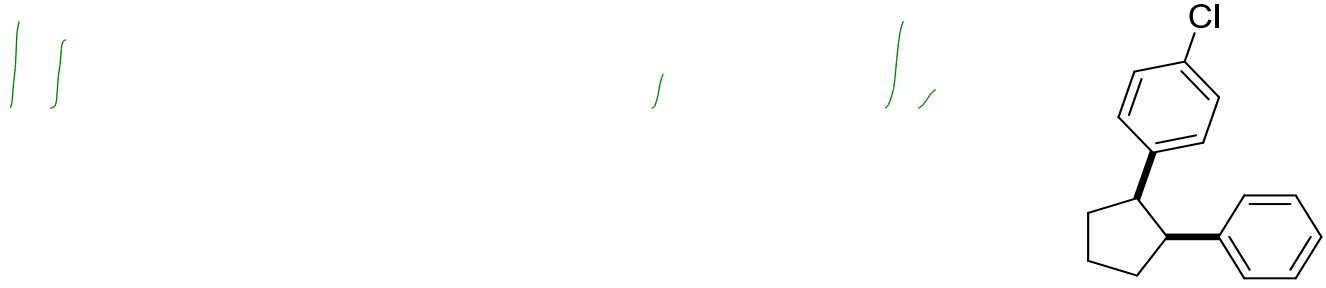

31
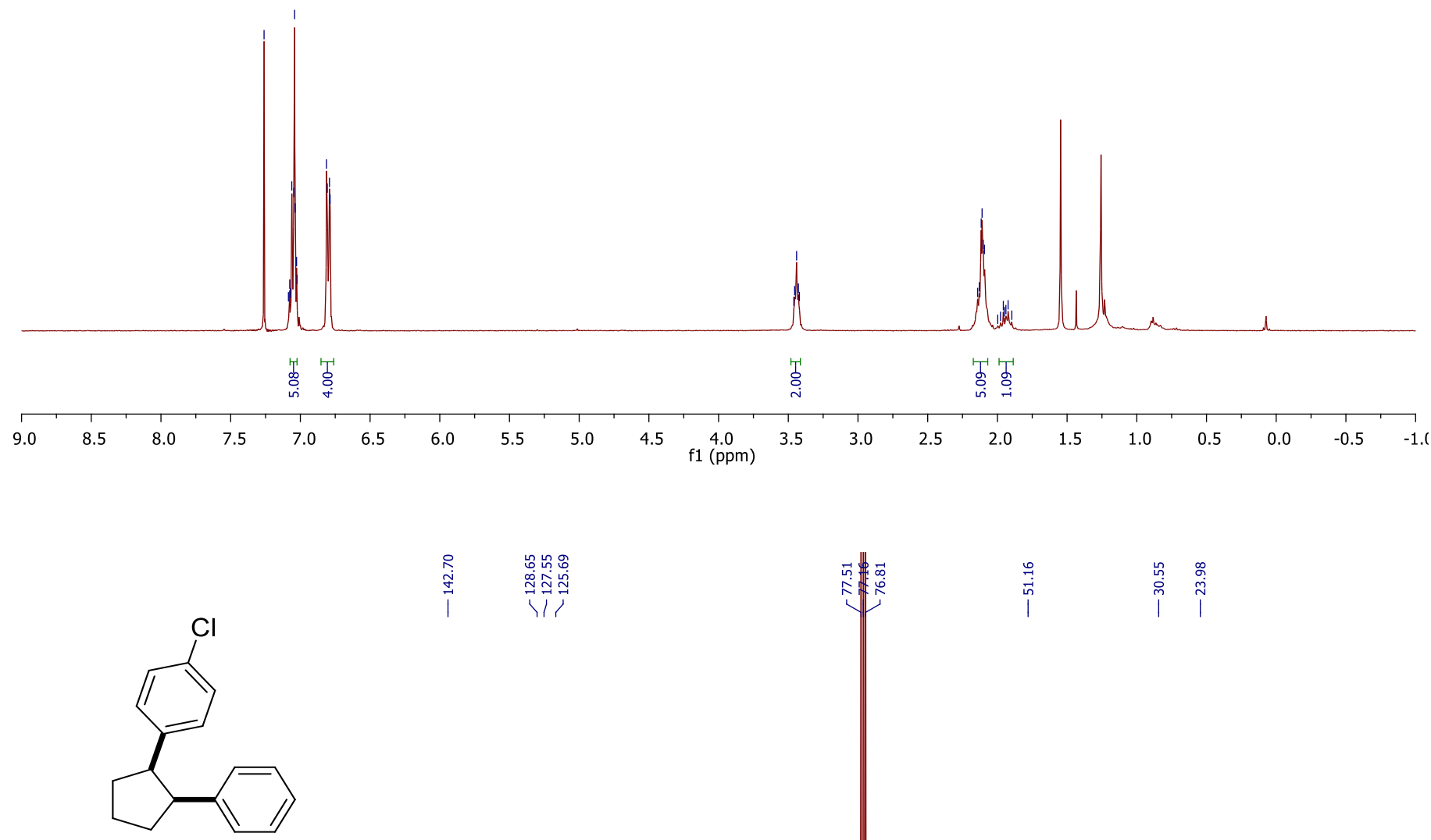

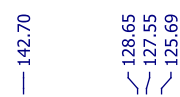

3I

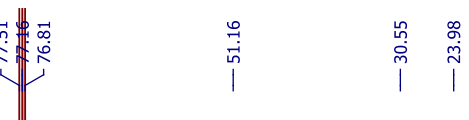



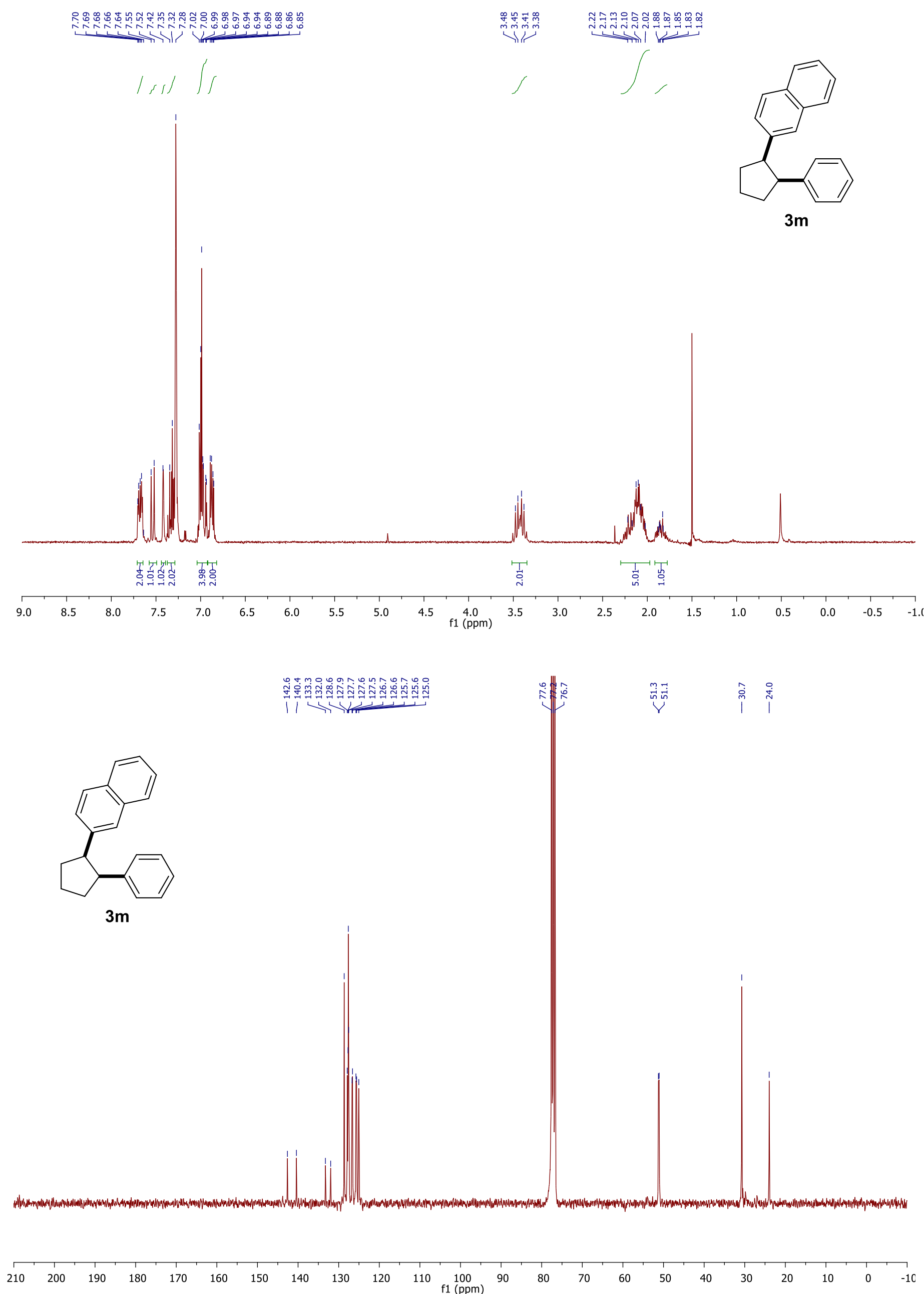


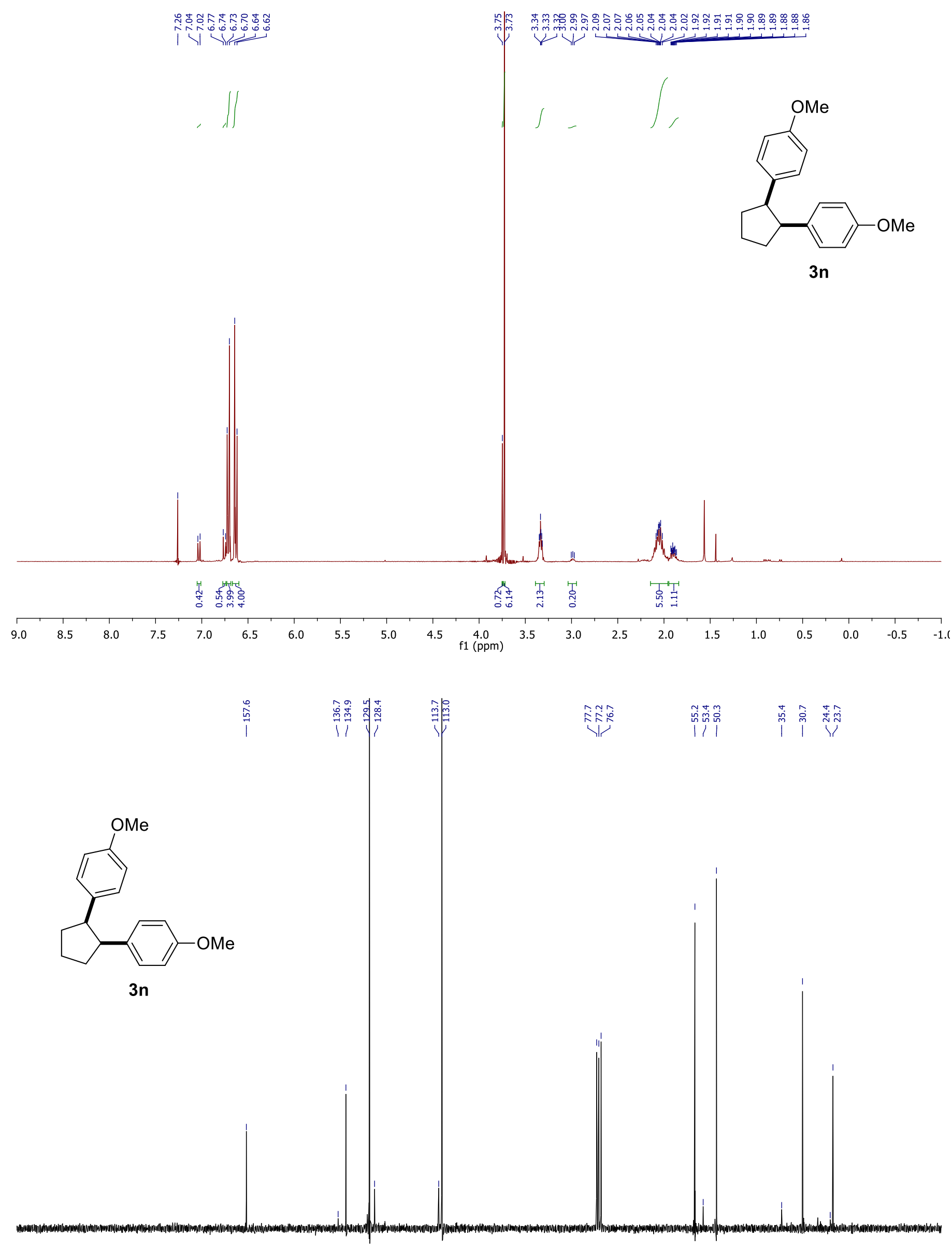

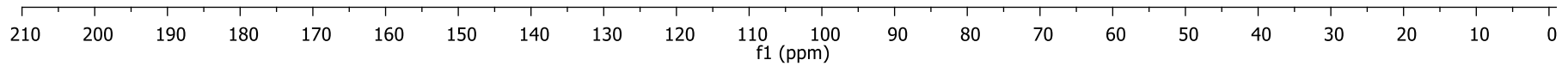




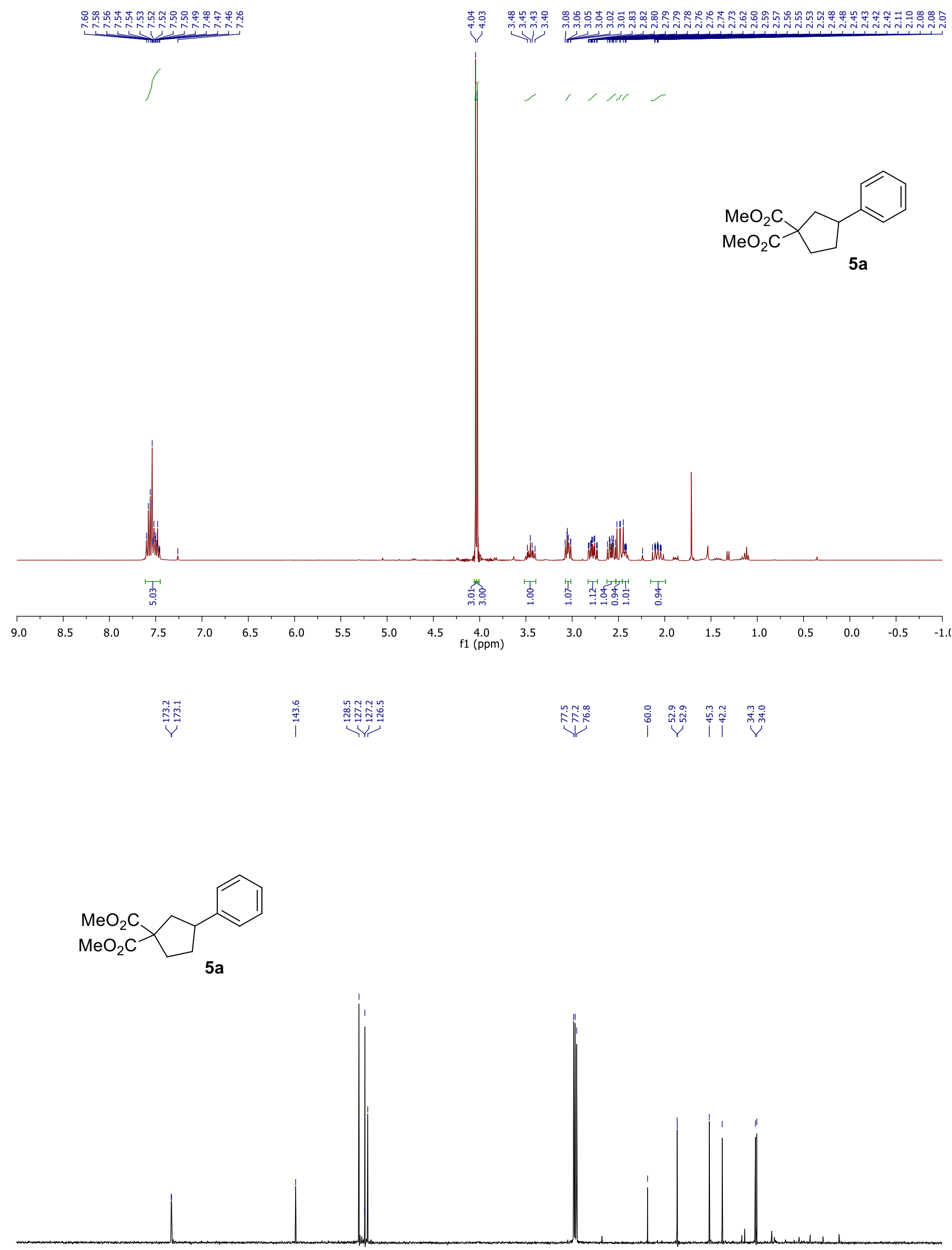

$\begin{array}{llllllllllllllllllllllll}200 & 190 & 180 & 170 & 160 & 150 & 140 & 130 & 120 & 110 & \begin{array}{l}100 \\ \mathrm{f} 1(\mathrm{ppm})\end{array} & 90 & 80 & 70 & 60 & 50 & 40 & 30 & 20 & 10 & 0 & -10\end{array}$ 

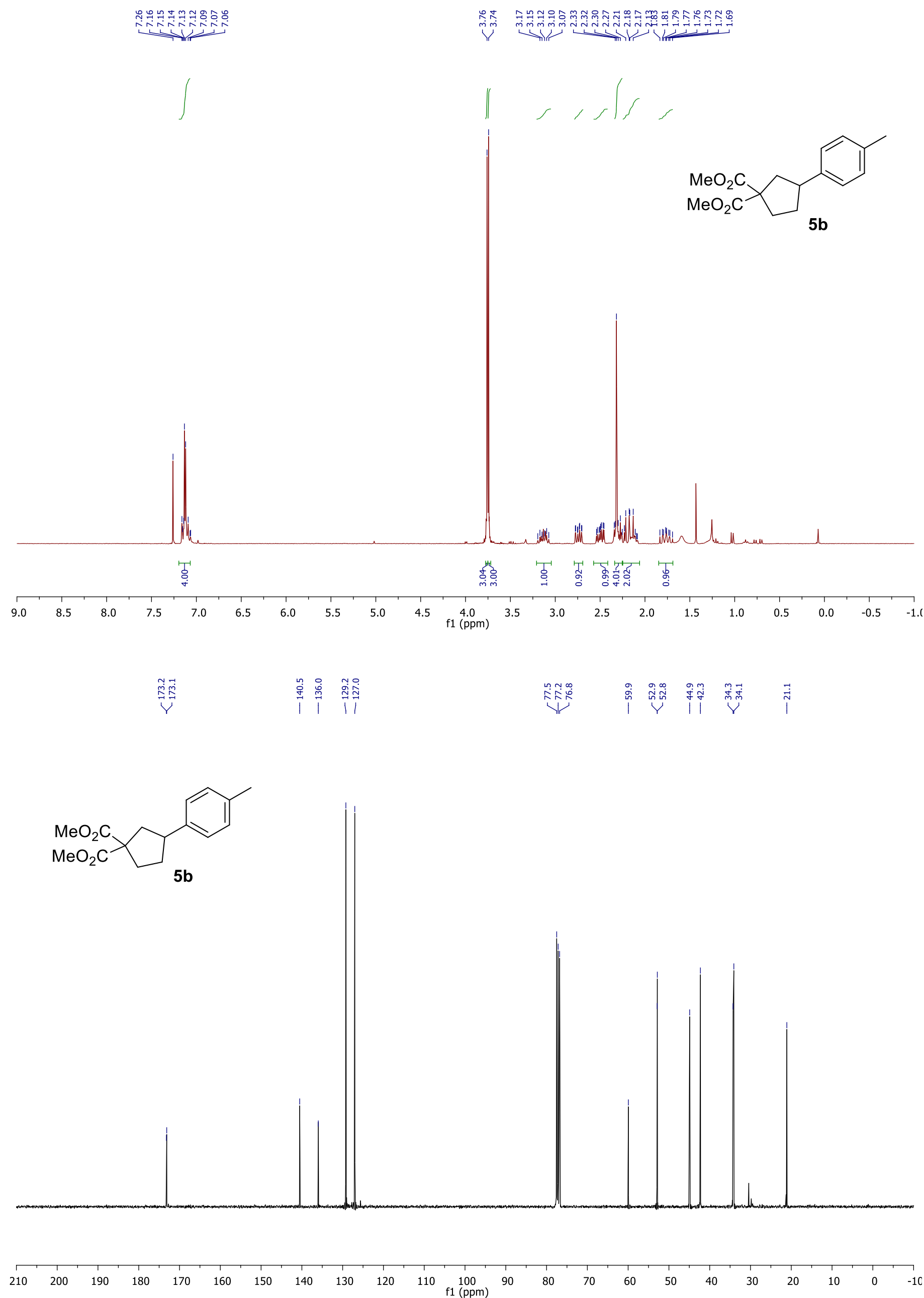


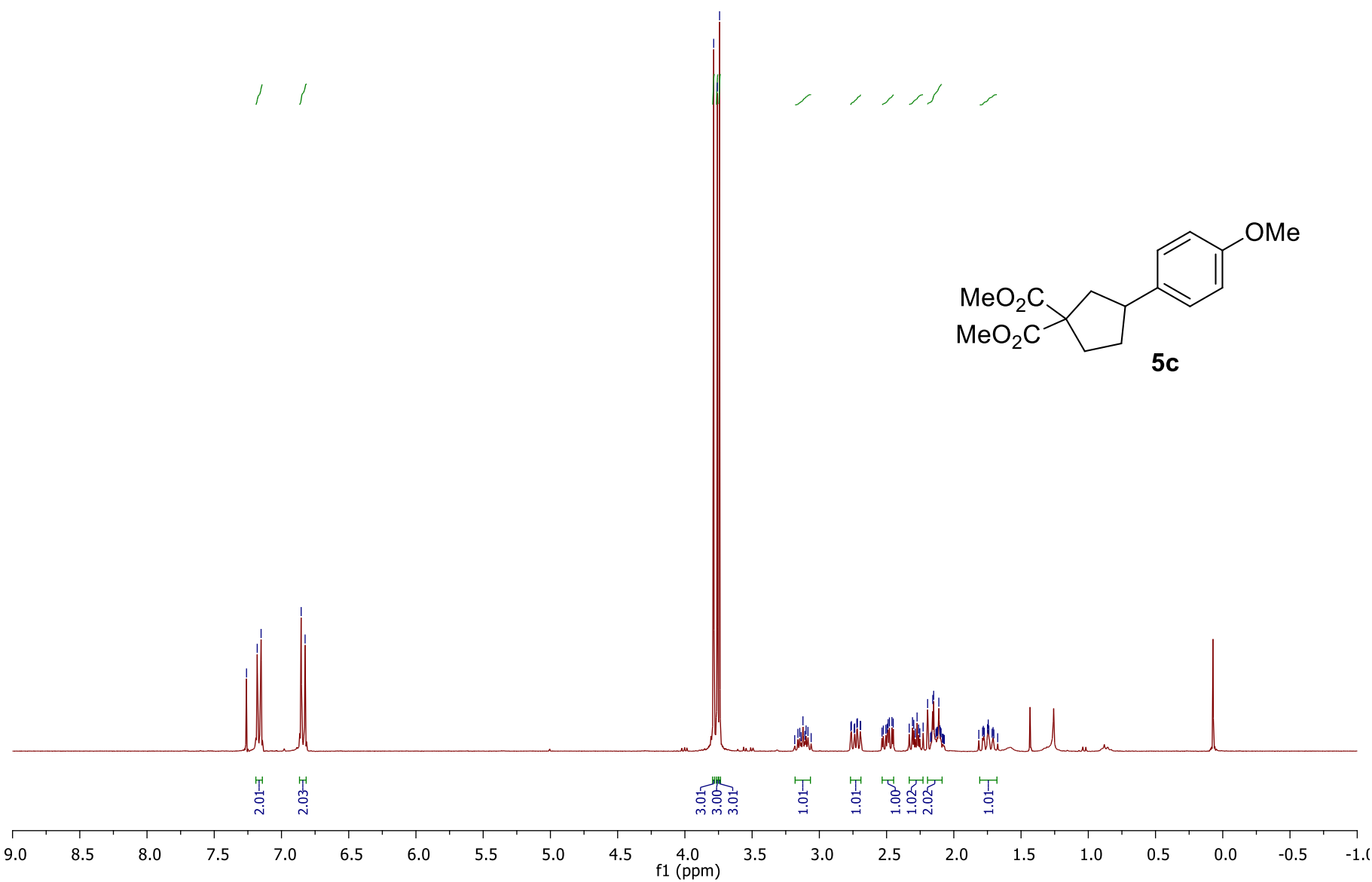<smiles>COC(=O)C1(C(OC)OC)CCC(c2ccc(OC)cc2)C1</smiles>

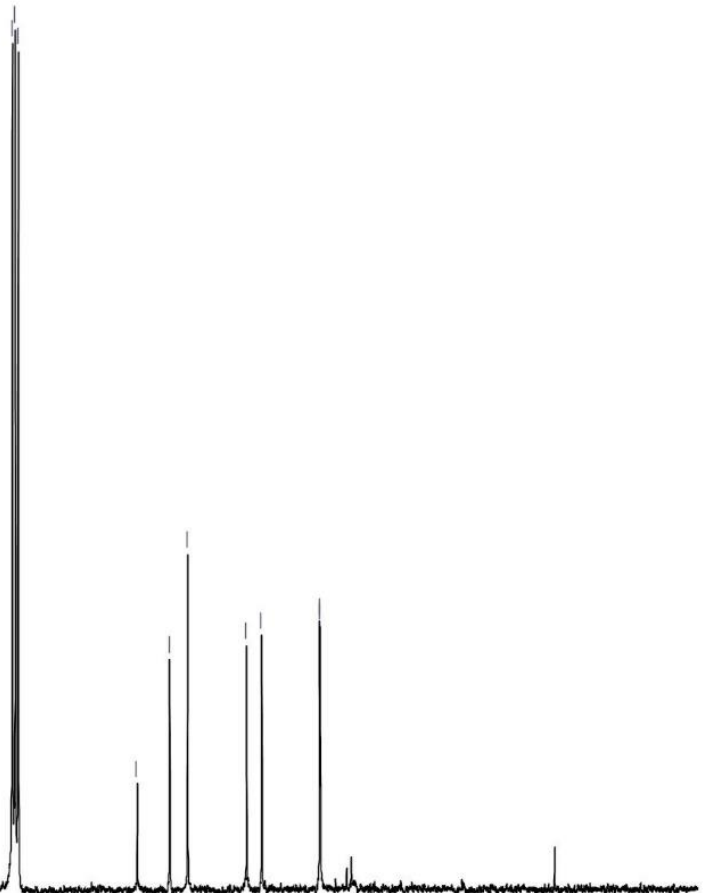



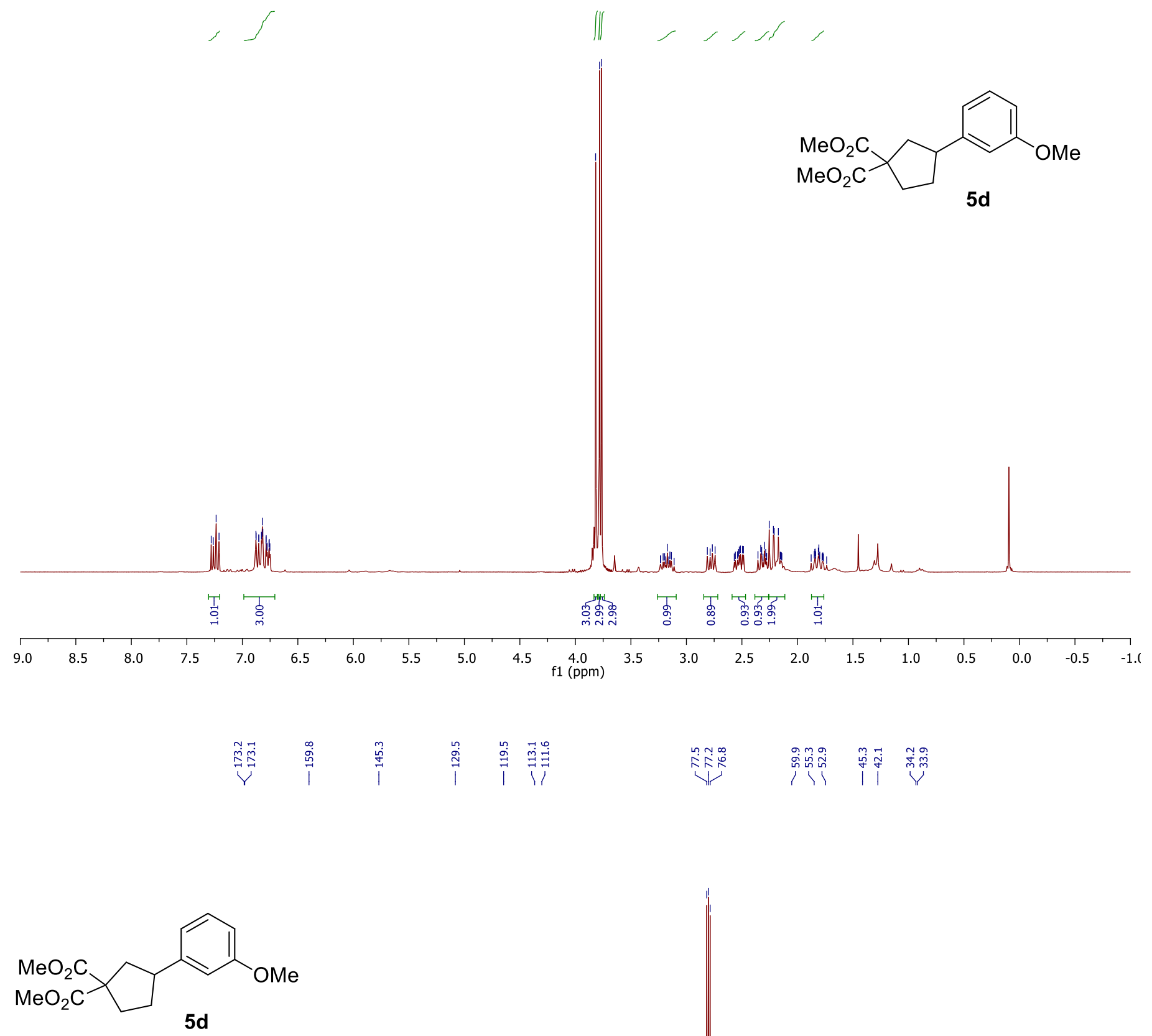

\section{5d}



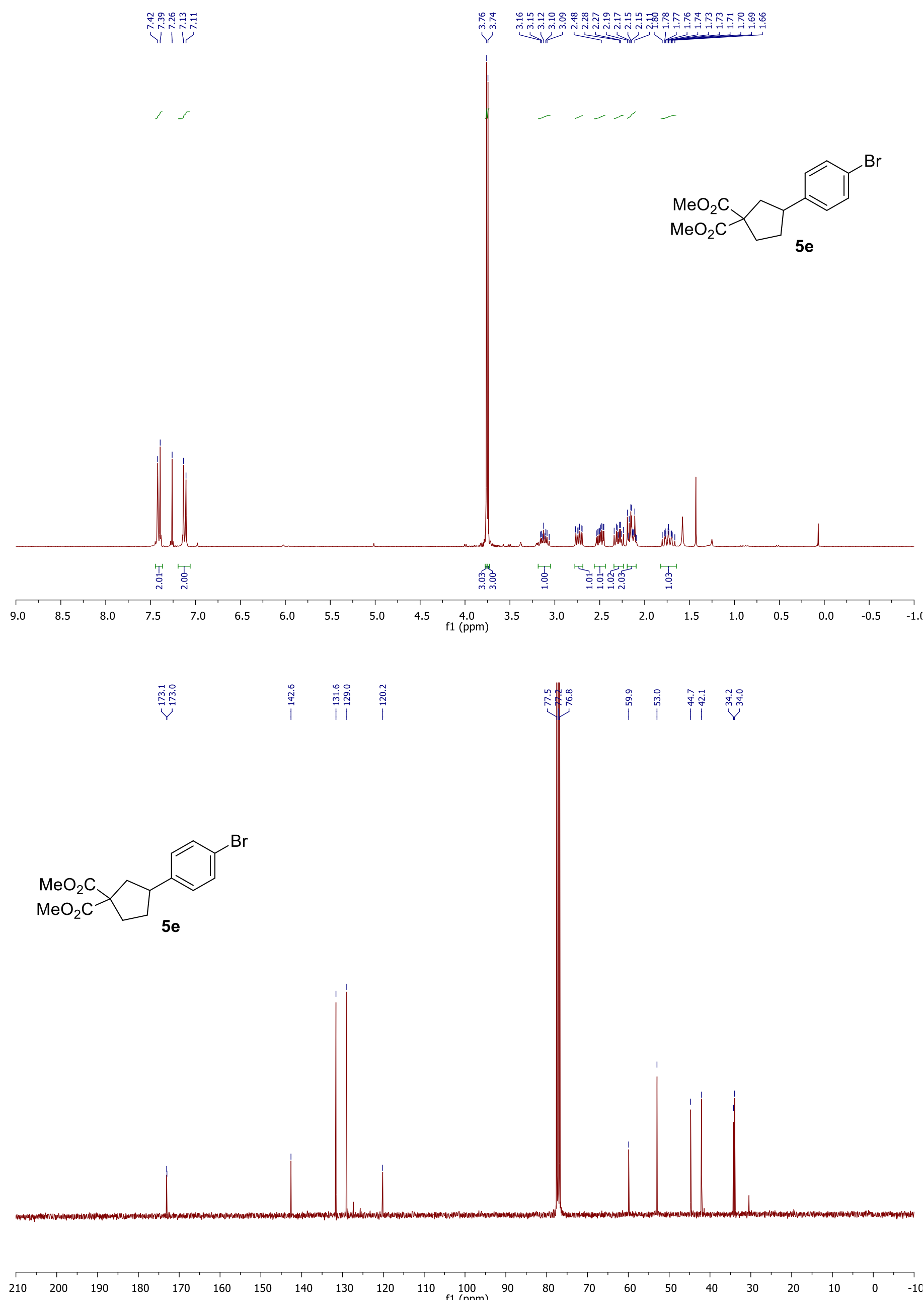

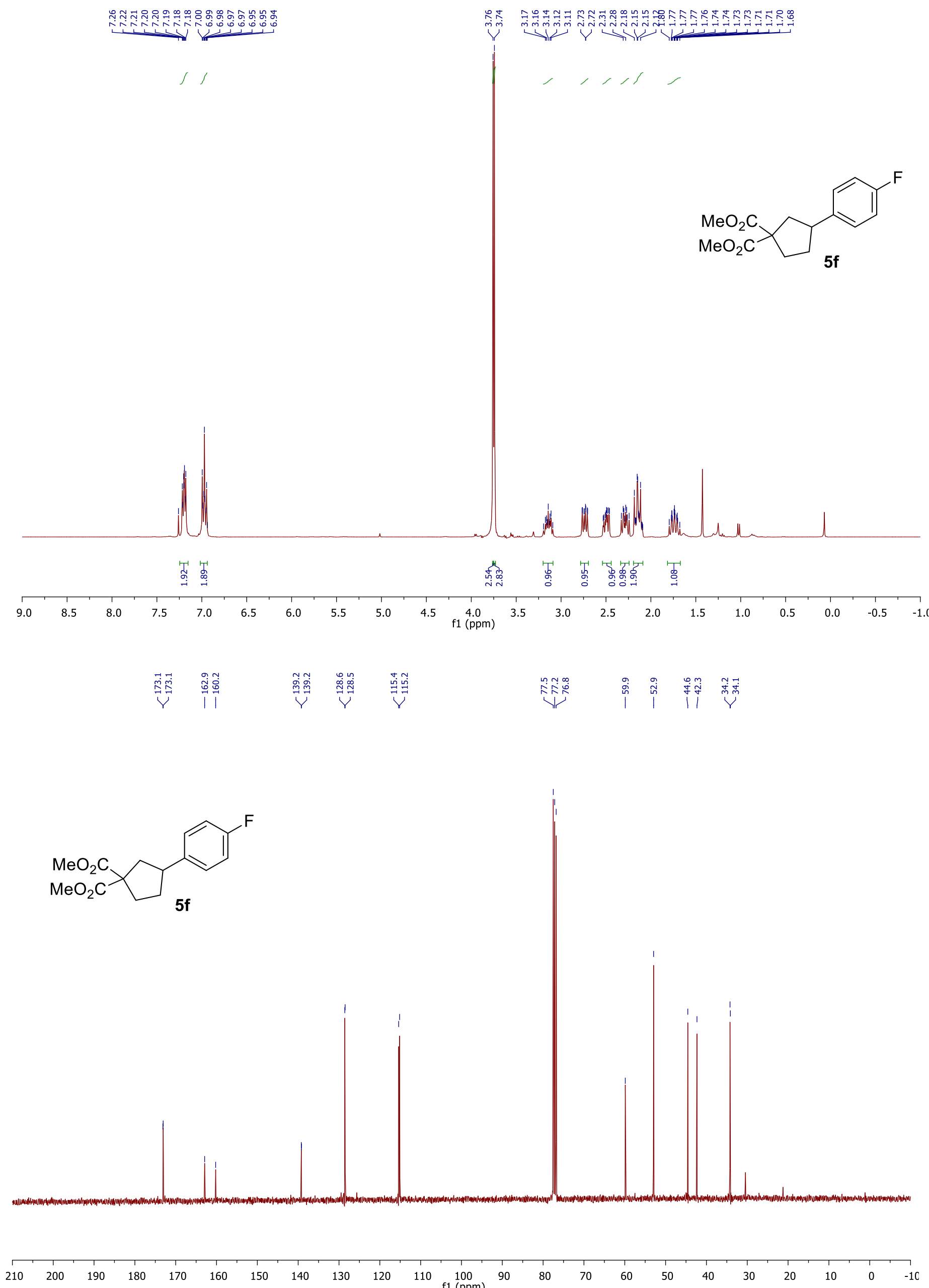
$\mathrm{MeO}_{2} \mathrm{C} \times \mathrm{Fif}^{\mathrm{F}}$

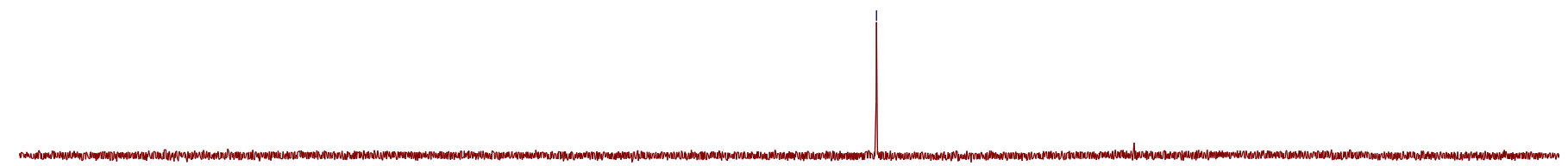

$\begin{array}{llllllllllllll}40 & 30 & 20 & 10 & 0 & -10 & -20 & -30 & -40 & -50 & -60 & -70 & -80 & -90 \\ \mathrm{f1}(\mathrm{ppm})\end{array}$ 


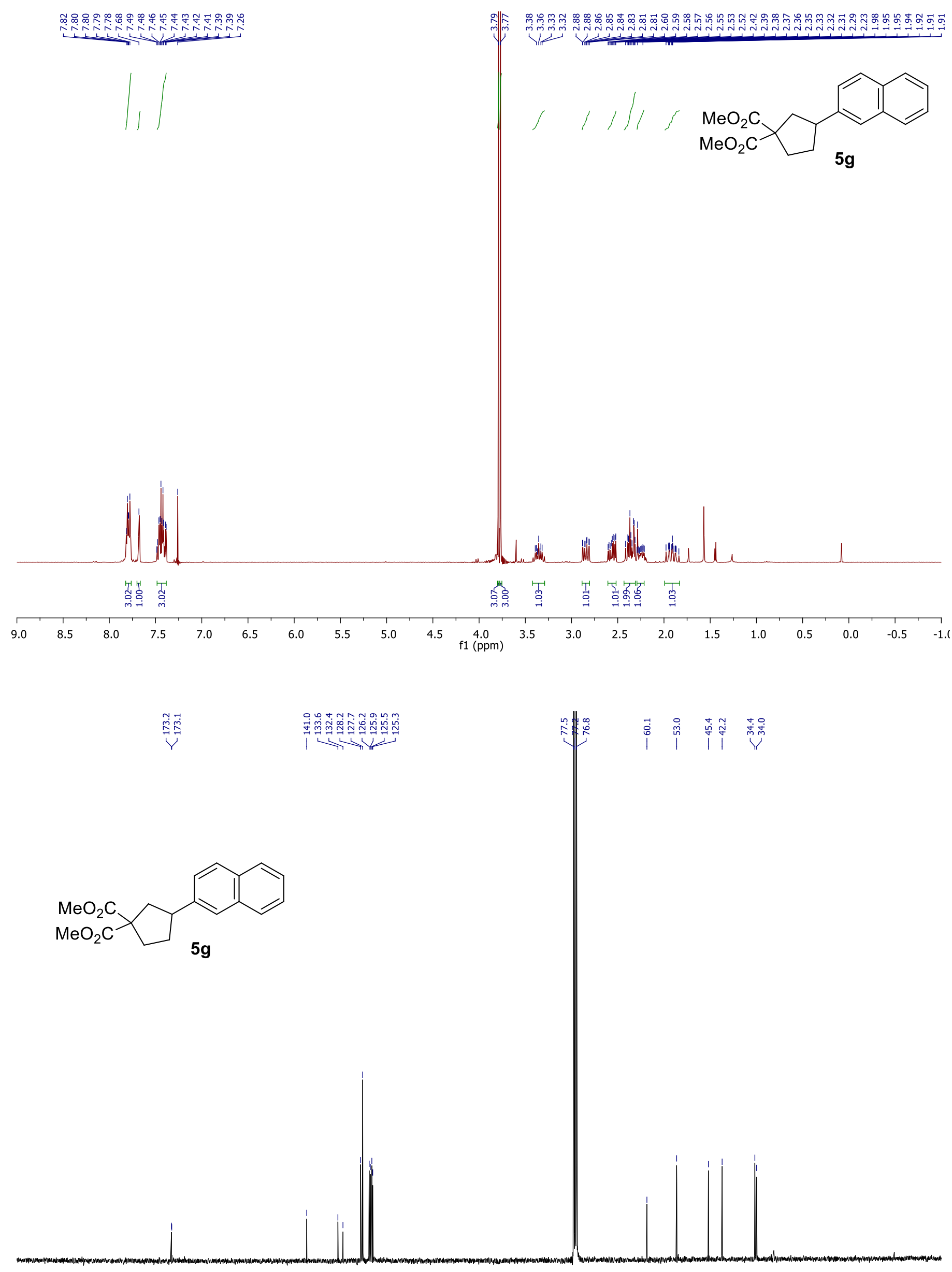

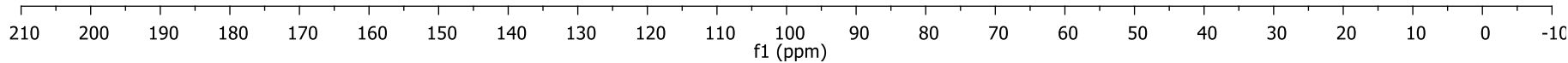




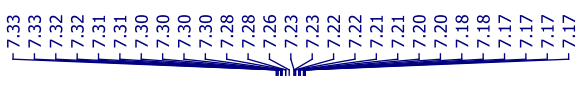

II
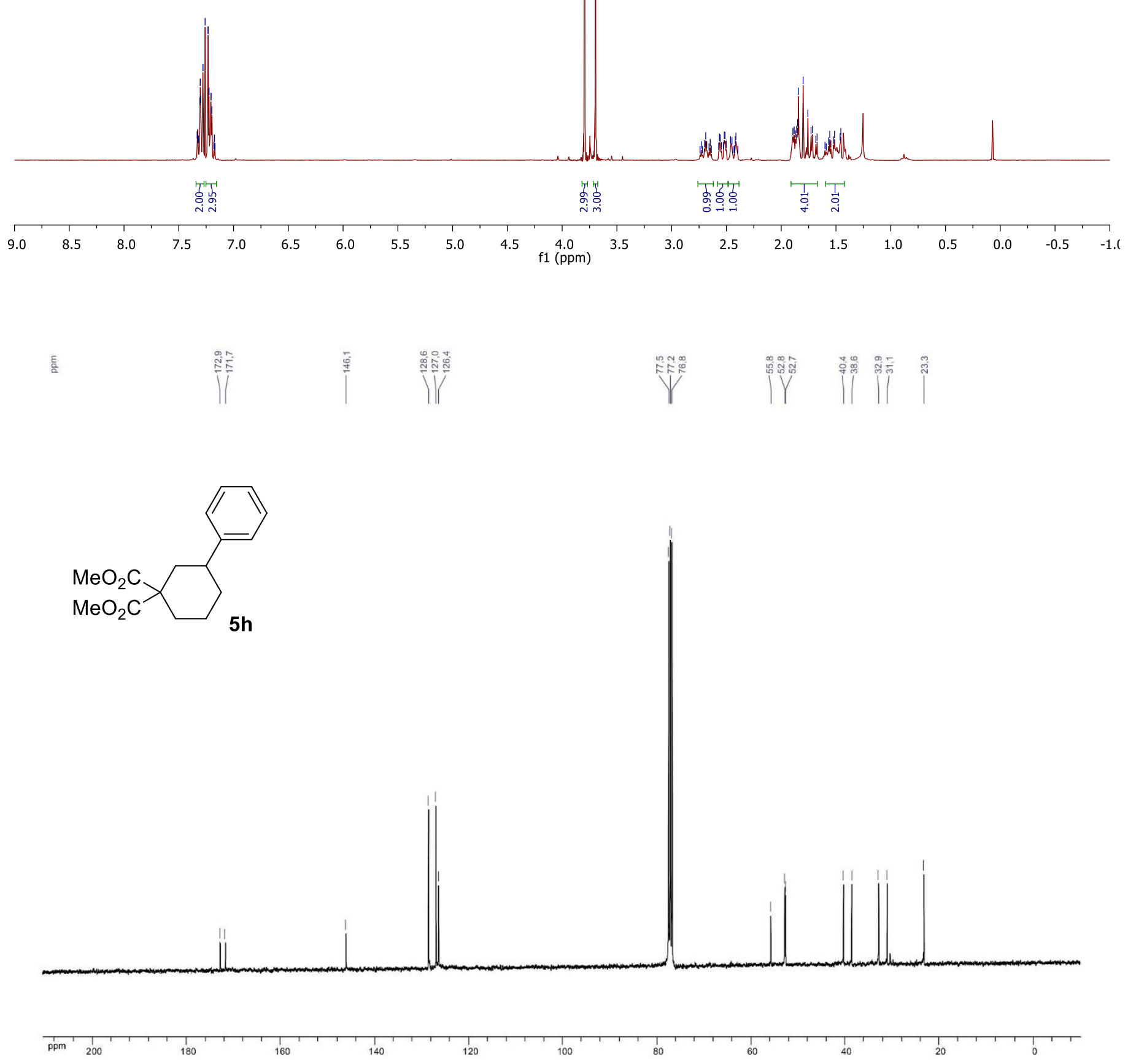

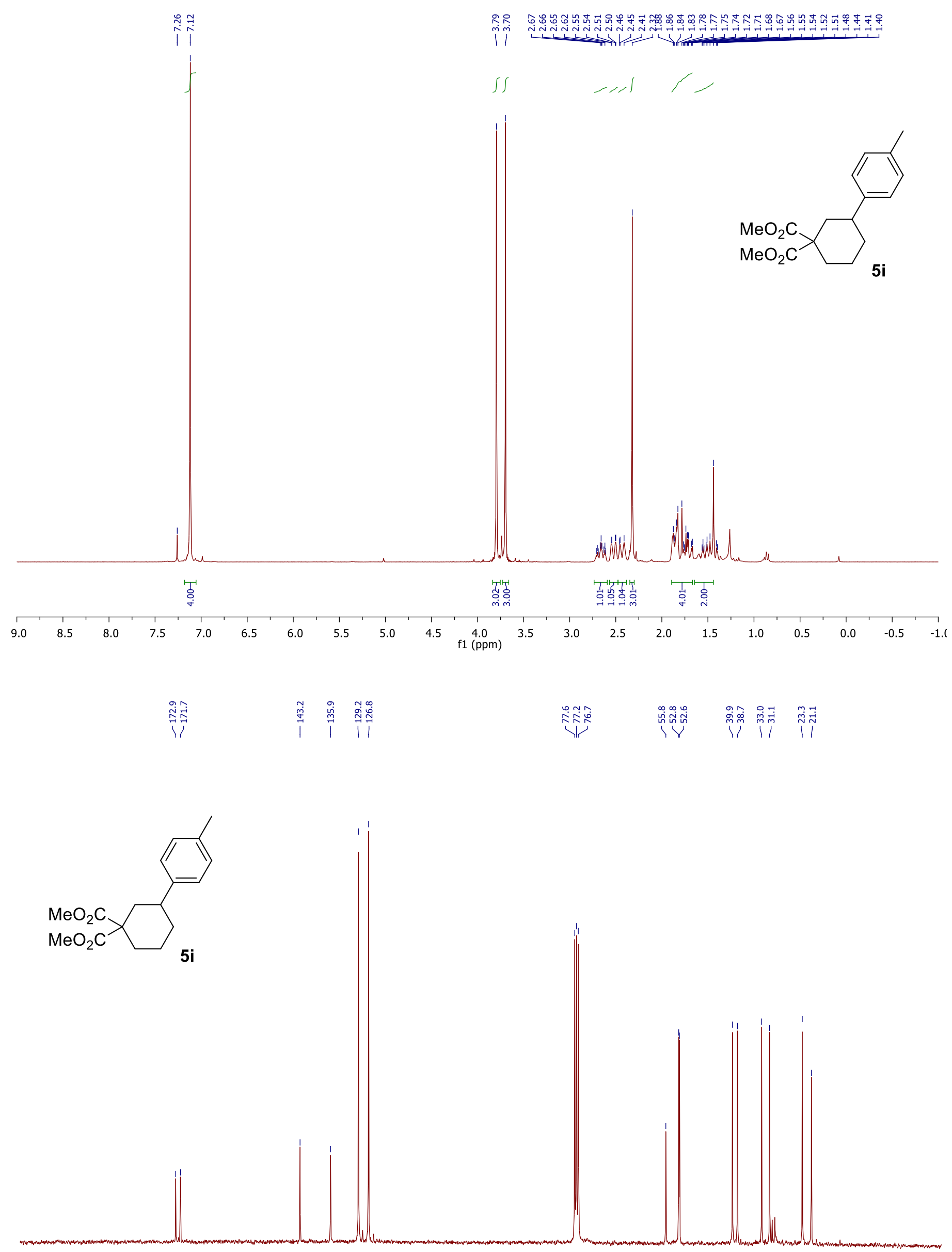

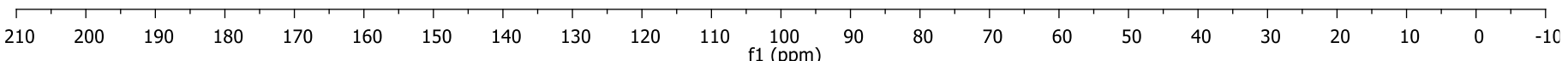



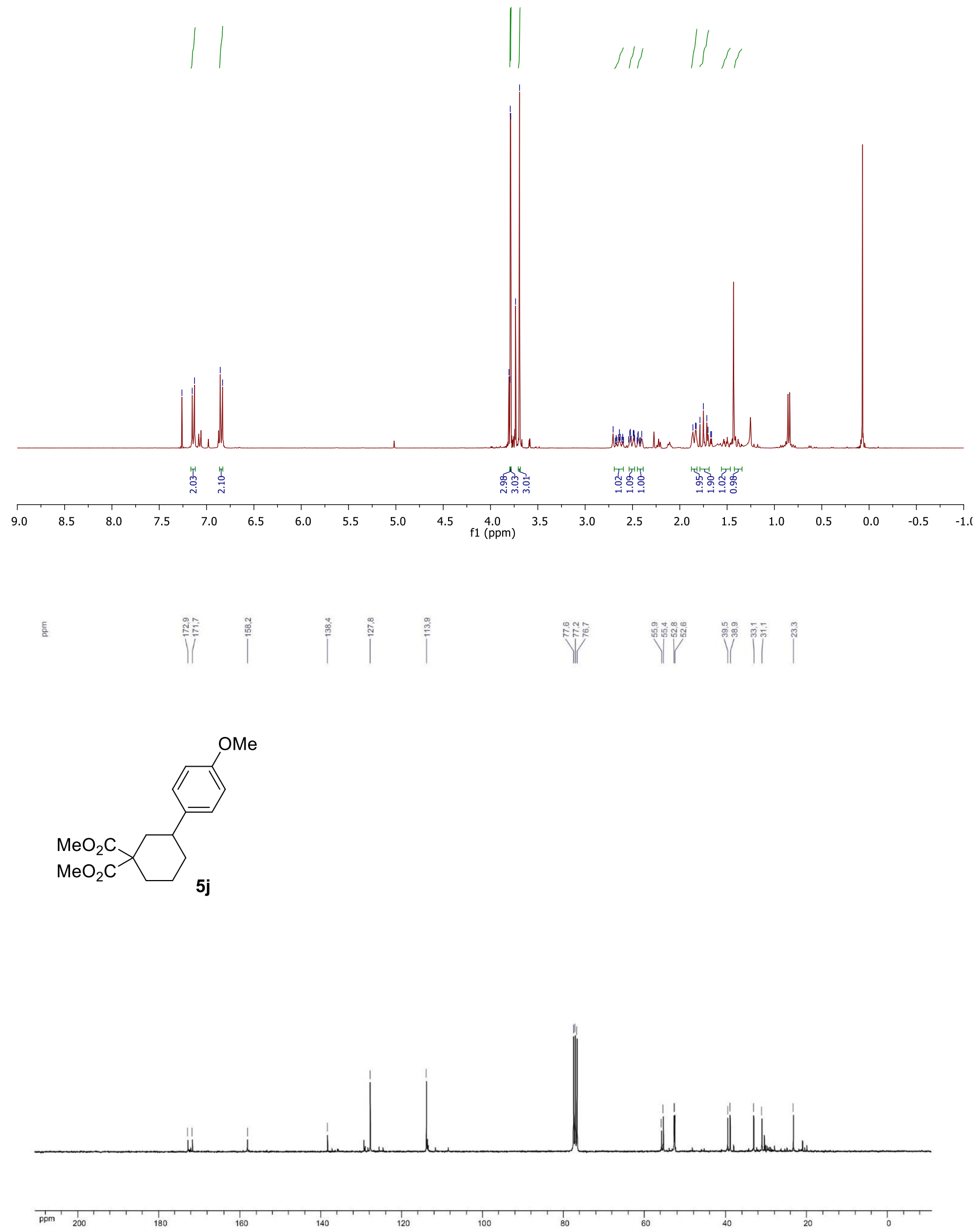

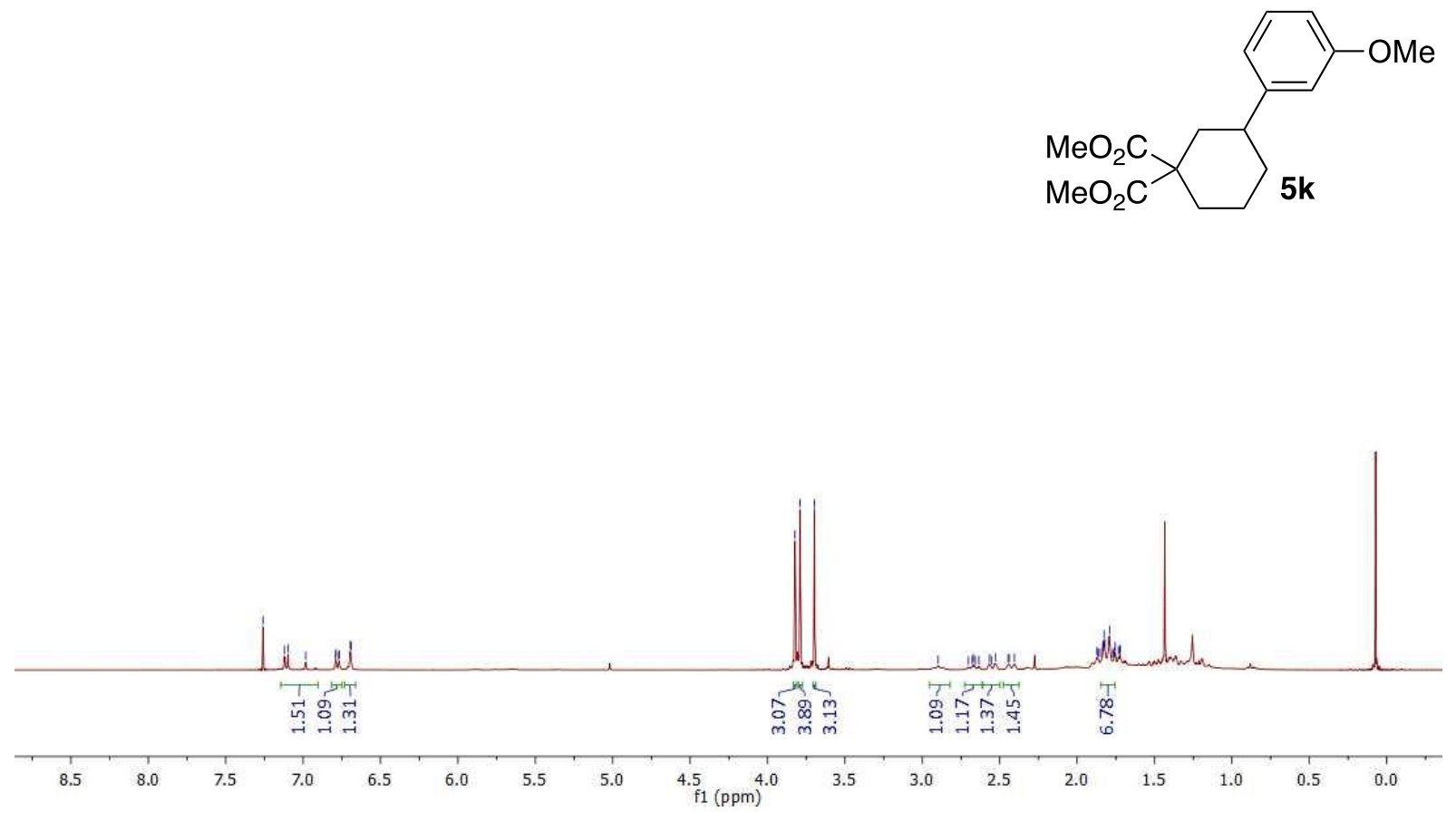

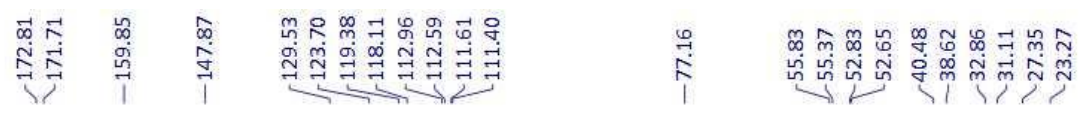

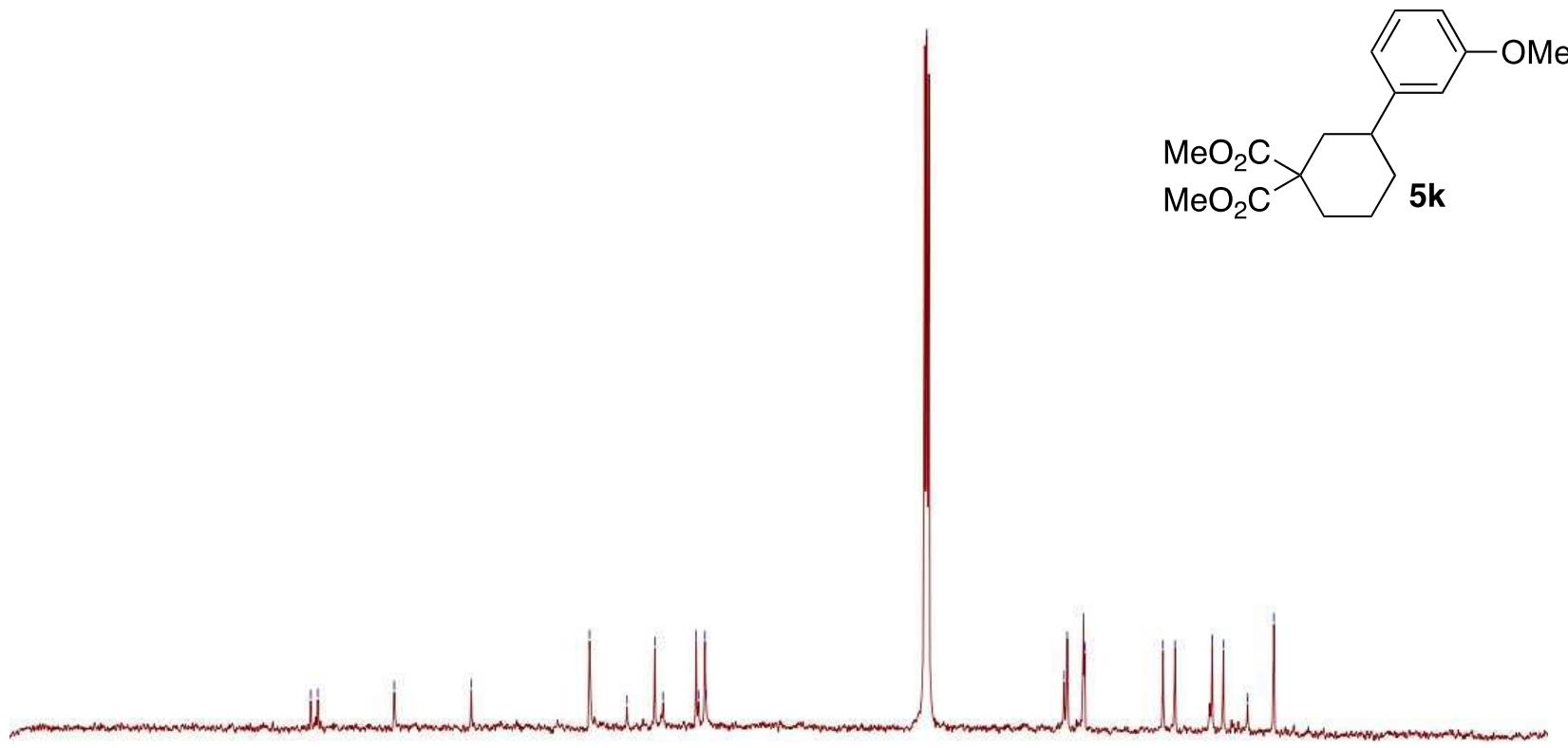

$\begin{array}{llllllllllllllllllllllll}210 & 200 & 190 & 180 & 170 & 160 & 150 & 140 & 130 & 120 & 110 & \begin{array}{l}100 \\ \mathrm{f} 1(\mathrm{ppm})\end{array} & 90 & 80 & 70 & 60 & 50 & 40 & 30 & 20 & 10 & 0 & -10 & \end{array}$ 

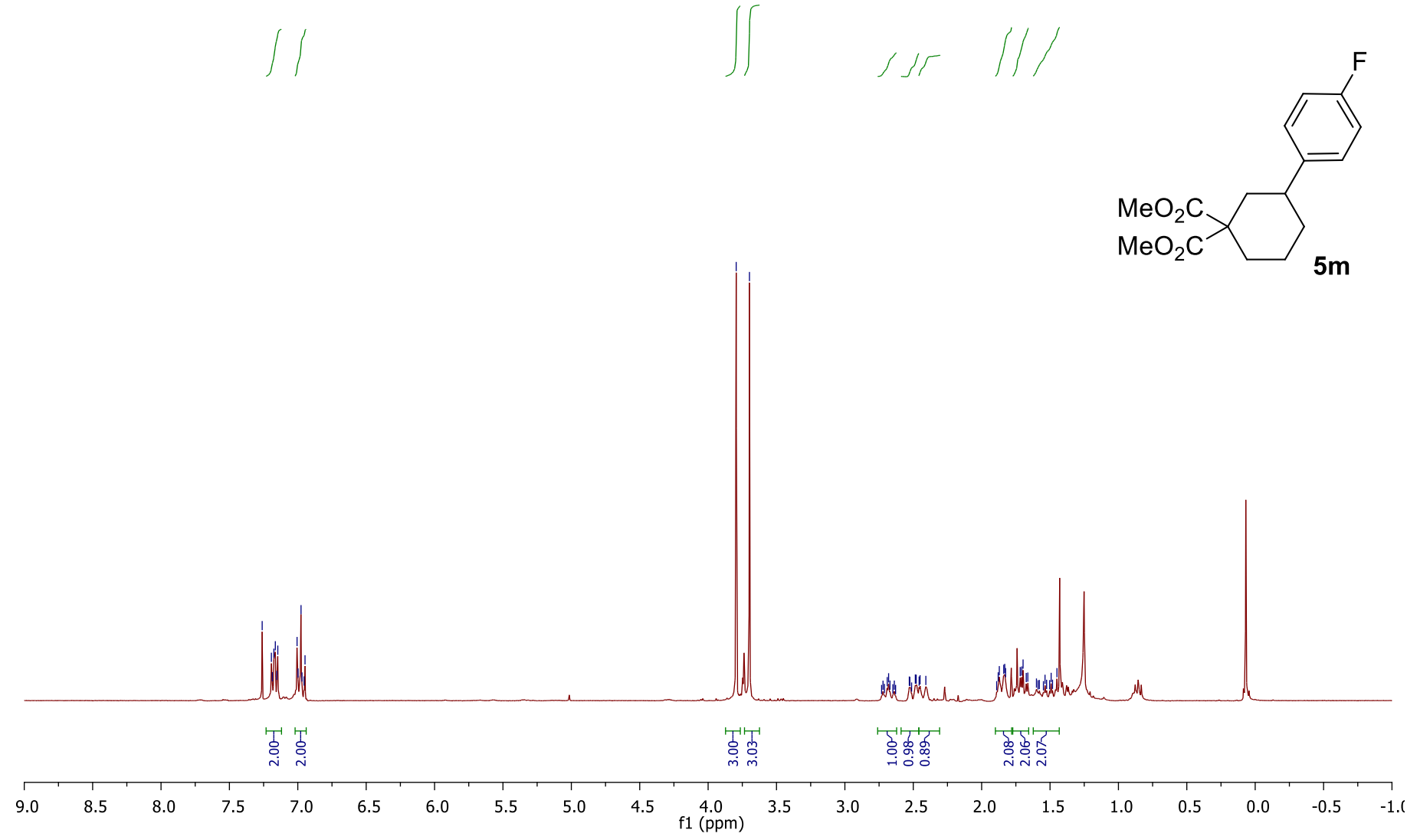

V.

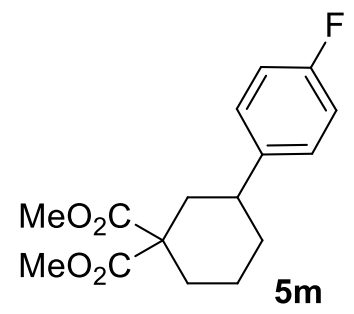



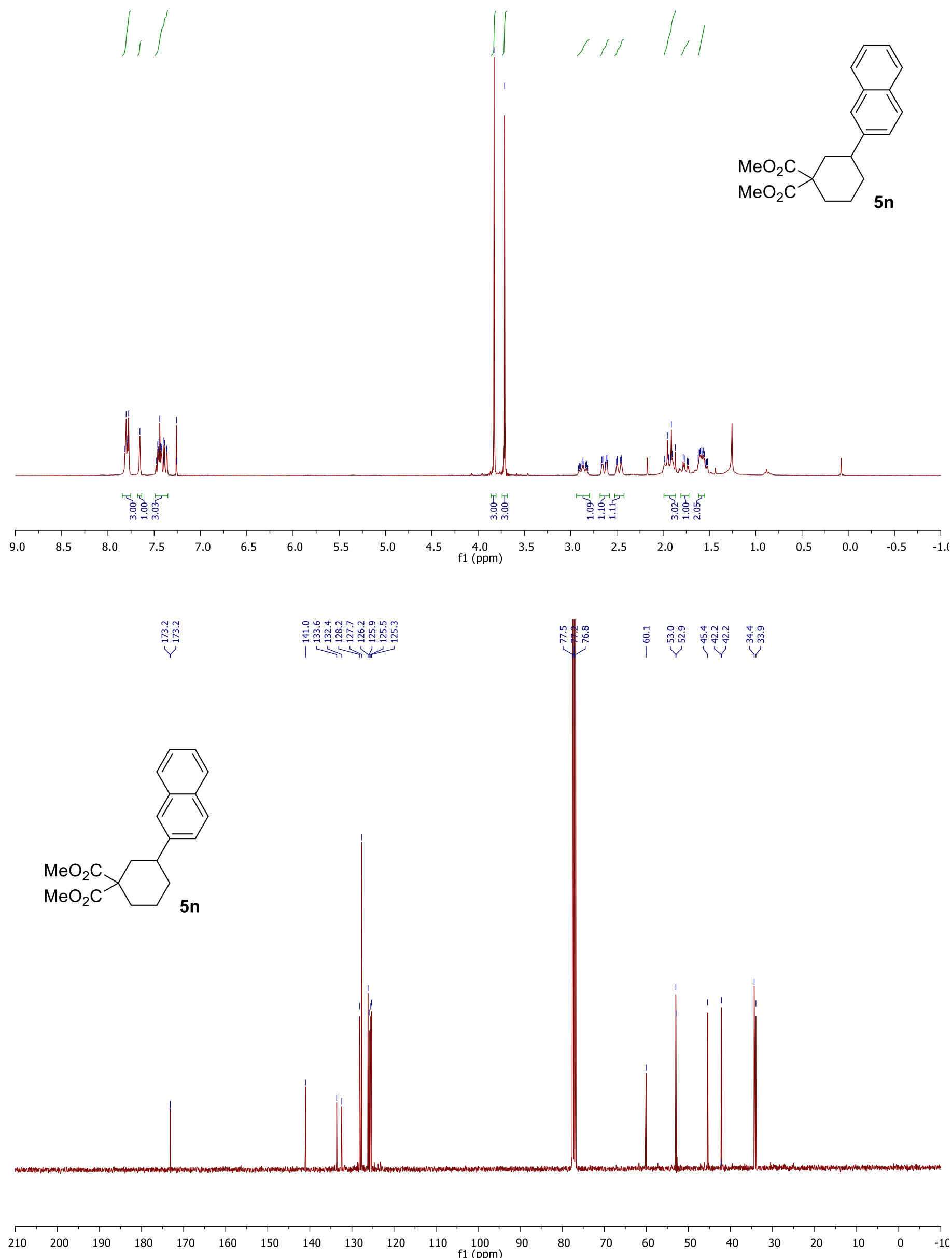